\title{
USO DE ÓLEOS SEM SURFACTANTES NA APLICAÇÃO DE CLORPIRIFÓS VIA INSETIGAÇÃO NA CULTURA DE MILHO
}

\section{WULF SCHMIDT}

\author{
Dissertação apresentada a Escola Superior de \\ Agricultura "Luiz de Queiroz", Universidade de São \\ Paulo, para obtenção do título de Mestre em \\ Agronomia, Área de Concentração: Irrigação e \\ Drenagem.
}

P I R A C I C A B A

Estado de São Paulo - Brasil

Abril - 2003 


\title{
USO DE ÓLEOS SEM SURFACTANTES NA APLICAÇÃO DE CLORPIRIFÓS VIA INSETIGAÇÃO NA CULTURA DE MILHO
}

\section{WULF SCHMIDT}

Engenheiro Agrônomo

\section{Orientador: Prof. Dr. DURVAL DOURADO NETO}

\author{
Dissertação apresentada a Escola Superior de \\ Agricultura "Luiz de Queiroz", Universidade de São \\ Paulo, para obtenção do título de Mestre em \\ Agronomia, Área de Concentração: Irrigação e \\ Drenagem.
}

P I R A C I C A B A

Estado de São Paulo - Brasil

Abril - 2003 


\title{
Dados Internacionais de Catalogação na Publicação (CIP)
} DIVISÃO DE BIBLIOTECA E DOCUMENTAÇÃO - ESALQ/USP

\author{
Schmidt, Wulf \\ Uso de óleos sem surfactantes na a plic ação de c lorpirifós via \\ insetigação na cultura de milho / Wulf Schmidt. - - Piracicaba, 2003. \\ 83 p. : il. \\ Dissertação (mestrado) - - Escola Superior de Agricultura Luiz de \\ Queiroz, 2003. \\ Bibliografia. \\ 1. Controle fitossanitário 2. Imiga ção 3. Manejo integrado 4. Milho 5. \\ Pesticidas 6. Quimigação 7. Surfactantes I. Título
}

CDD 633.15

"Permitida a cópia total ou parcial deste documento, desde que citada a fonte - $\mathrm{O}$ autor" 
Aos meus pais,

\section{OFEREÇO.}

Para minha esposa Ana Lana, e a nossos filhos: Talita, Danilo e Veronica,

DEDICO. 


\section{AGRADECIMENTOS}

A Deus pela vida e pelas graças alcançadas;

Ao Departamento de Engenharia Rural, Escola Superior de Agricultura "Luiz de Queiroz", Universidade de São Paulo, pela oportunidade oferecida, e a seus funcionários pelo apoio e amizade;

Ao Departamento de Produção Vegetal, Escola Superior de Agricultura "Luiz de Queiroz", Universidade de São Paulo, pelo suporte e apoio oferecidos;

Ao cnpq, Ministério de Ciência e Tecnologia, pela concessão da bolsa de estudos;

A Silvia, Eliana, Kátia a aos amigos da biblioteca central pela ajuda e amizade em diversos momentos do processo;

Ao professor, orientador e amigo, Durval Dourado Neto, pelo estímulo, encorajamento e amizade;

Ao Sr. Walter Stroebel, proprietário das fazendas Canadá e São Francisco e a seus funcionários pela viabilização a campo dos ensaios;

Ao amigo Engenheiro Agrônomo, M.Sc., Antônio Cesar dos Santos, pela ajuda na análise estatística dos dados;

A Dow AgroSciences por permitir a utilização dos dados gerados por mim, enquanto funcionário, para a realização deste trabalho;

A todos os colegas pela amizade, apoio e paciência. 


\section{SUMÁRIO}

Página

LISTA DE FIGURAS ........................................................................... viii

LISTA DE TABELAS.........................................................................

LISTA DE SÍMBOLOS........................................................................... xii

CURRICULUM VITAE ......................................................................... xiv

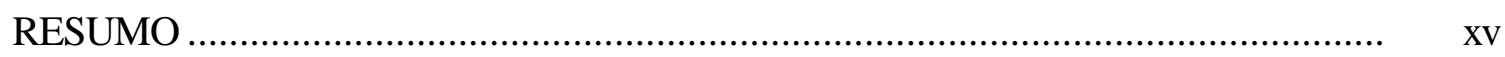

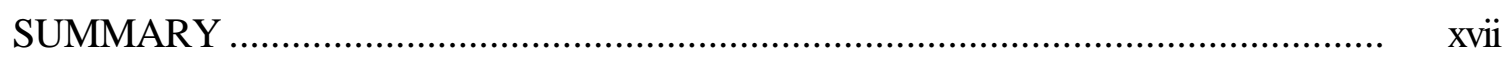

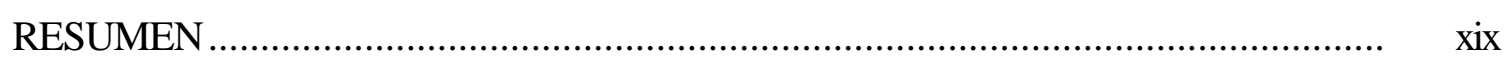

ZUSAMMENFASSUNG.........................................................................

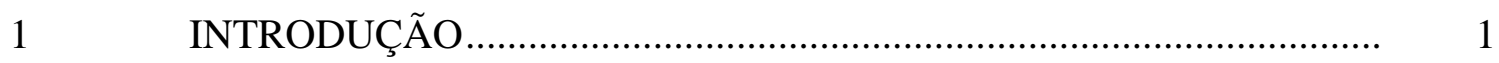

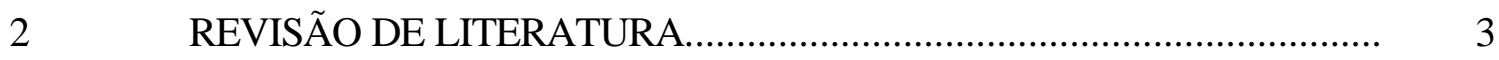

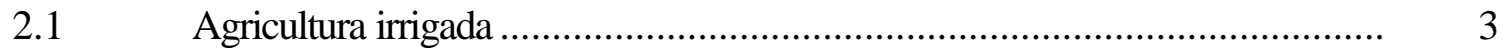

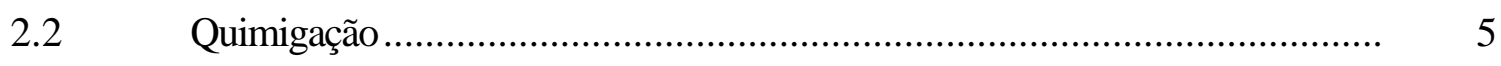

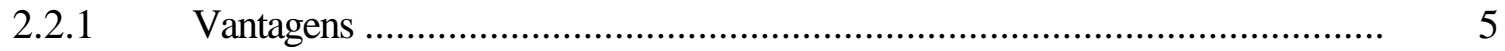

2.2.1.1 Uniformidade de aplicação......................................................................... 6

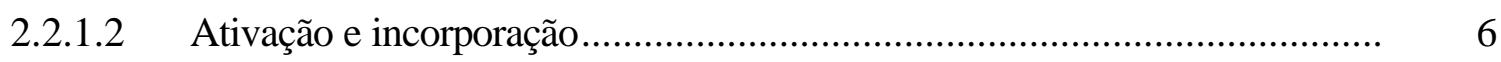

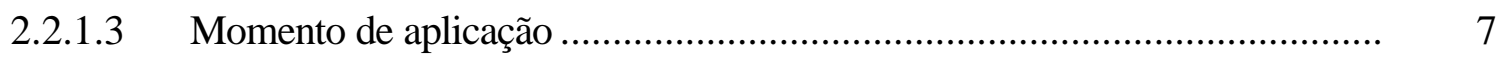

2.2.1.4 Possível redução das doses aplicadas ...................................................... 7

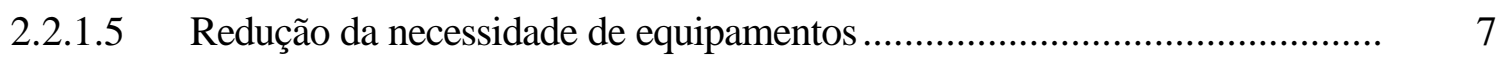

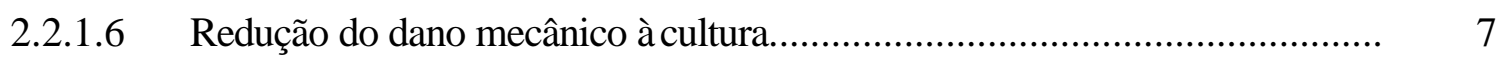

2.2.1.7 Redução do custo de aplicação.................................................................. 8

2.2.1.8 Redução na compactação de solo ........................................................ 9

2.2.1.9 Redução no risco de exposição do operador........................................... 9

2.2.1.10 Co-quimigação................................................................................ 11 
2.2.1.11 Segurança ambiental............................................................................ 11

2.2.2 Limitações......................................................................................... 12

2.2.2.1 Operador e investimento adicional......................................................... 12

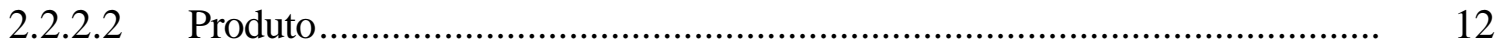

2.2.2.3 Tempo de aplicação .......................................................................... 12

2.2.2.4 Irrigação desnecessária ............................................................................ 13

2.3 Eficácia versus volume de calda .............................................................. 13

2.3.1 Uso de óleos não emulsionáveis .................................................................. 18

2.3.1.1 Formação de emulsões ................................................................................ 19

2.3.1.2 Uso de emulsões na agricultura ............................................................... 22

2.3.1.3 Propriedades dos óleos ....................................................................... 24

2.3.2 Uniformidade da distribuição dos produtos em quimigação ........................... 26

2.3.2.1 Velocidade da água no ponto de injeção ...................................................... 29

2.3.2.2 Direção do ponto de injeção....................................................................... 30

2.3.2.3 Características dos emissores ............................................................... 32

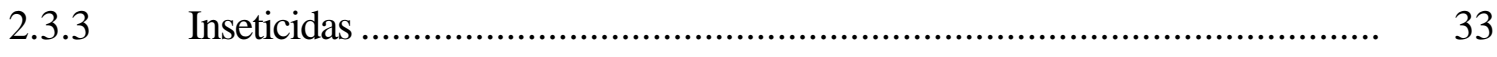

2.3.4 Herbicidas .............................................................................. 35

2.3.5 Fungicidas e nematicidas ...................................................................... 37

3 MATERIAL E MÉTODOS ……………….................................... 39

3.1 Metodologia para instalação de ensaios de quimigação via pivô central........ 39

3.1.1 Sinalização das parcelas............................................................................. 40

3.1.2 Cálculo da vazão injetada no sistema............................................................ 40

3.1.3 Calibração do equipamento ..................................................................... 40

3.2 Metodologia dos ensaios de inseticidas para o controle de lagarta do cartucho em milho................................................................................... 41

3.2.1 Aplicação dos tratamentos........................................................................ 41

3.2.2 Metodologia de avaliação ……………………………………………...... 42

3.2.3 Análise estatística ............................................................................. 43

3.3 Descrição do produto utilizado................................................................. 45

3.4 Ensaio I.................................................................................. 45 


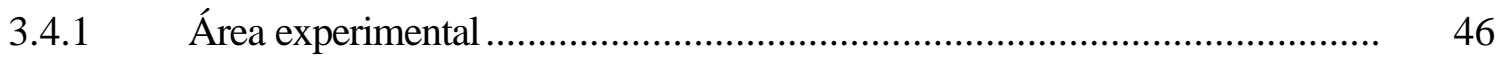

3.4.2 Do delineamento do ensaio ................................................................... 46

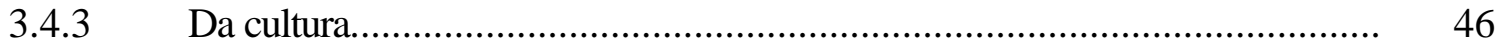

3.4.4 Da aplicação ................................................................................ 47

3.4.5 Dos tratamentos ........................................................................ 47

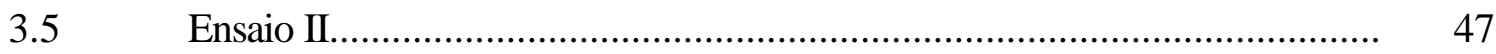

3.5.1 Área experimental .................................................................. 48

3.5.2 Do delineamento do ensaio ..................................................................... 48

3.5.3 Da cultura......................................................................................... 48

3.5.4 Dos tratamentos ....................................................................... 49

3.5.5 Da aplicação ....................................................................................... 49

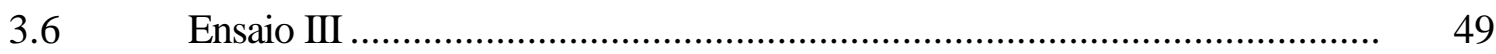

3.6.1 Área experimental ............................................................................ 50

3.6.2 Do delineamento do ensaio ................................................................... 50

3.6.3 Da cultura...................................................................................... 51

3.6.4 Da aplicação ................................................................................. 51

3.6.5 Dos tratamentos ............................................................................ 51

$4 \quad$ RESULTADOS E DISCUSSÃO.......................................................... 53

4.1 Sobre a metodologia utilizada................................................................. 53

4.2 Análise individual dos ensaios............................................................. 54

4.2.1 Ensaio I.................................................................................. 54

4.2.2 Ensaio II.................................................................................. 56

4.2.3 Ensaio III .................................................................................. 59

4.3 Análise consolidada ............................................................................. 63

$4.4 \quad$ Considerações finais ................................................................................ 69

$5 \quad$ CONCLUSÕES ...................................................................... 70

REFERÊNCIAS BIBLIOGRÁFICAS .................................................................

BIBLIOGRAFIA RECOMENDADA …………………................................ 82 


\section{LISTA DE FIGURAS}

Página

1 Representação esquemática do índice de eficiência de aplicação (IEA\%) da calda utilizada (adaptado de Fancelli \& Dourado Neto, 2000). Calda crítica inferior (CCI) e calda crítica superior (CCS).

2 Disposição dos coletores para amostragem de calda e distribuição do produto quimigado (Stone et al., 1994)

3 Concentração média de clorpirifós ( $\mu$ g clorpirifós.g material ${ }^{-1}$ ) nas folhas de milho e na superfície do solo (adaptado de Hills \& Waller, 1989).......................... 16

4 Processo de ruptura e formação de gotas (Hinze, 1955)...................................... 20

5 Processo de ruptura da interface da gota (Walstra, 1983). Do início do processo na parte superior até a ruptura em baixo

6 Influência da temperatura na viscosidade de diferentes tipos de óleos (Cochran et al., 1987).

7 Influência da temperatura na tensão superficial de diferentes tipos de óleos (Cochran et al., 1987).

8 Influência da concentração do inseticida e da temperatura na viscosidade de diferentes tipos de óleos (Cochran et al., 1987).

9 Distribuição e tamanho de gotas em uma emulsão óleo em água (Groselle et al., 1986).

10 Esquema do movimento ascendente das gotas grandes de óleo dentro da tubulação (Waller \& Hills, 1995).

11 Simulação do movimento de cada gota pela turbulência do fluxo (Waller \& Hills, 1995). 
12 Posição do ponto de injeção no interior da tubulação........................................... 30

13 Efeito do tipo de emissor e concentração da emulsão na distribuição relativa do espectro de gotas. (C004, C016, C064 e C128 indicam emulsificação química para a relação óleo/CE de 25,7, 132,3, 655,7, e 1999,0 respectivamente; e Mec indica emulsificação mecânica. Os prefixos, ' $\mathrm{F}$ ' e 'S' indicam a descarga de bicos planos (Unijet ${ }^{\circledR}$ TP11010) e bico com câmara de turbilhonamento (Whirljet $\left.{ }^{\circledR} 1 / 4 \mathrm{~B} 5-5 \mathrm{~W}\right)$, respectivamente) ................................ 33

14 Bomba injetora-dosadora de diafragma, marca Hidroflo. ….............................. 42

15 Esquema do posicionamento das áreas de bordadura e dos pontos de amostragem para quatro e seis pontos, utilizado para todos os ensaios.

16 Localização do ensaio I a partir de imagem do satélite Landsat, escala 1:25.000 (Miranda, 2001)

17 Localização do ensaio II a partir de imagem do satélite Landsat escala 1:25.000 (Miranda, 2001).

18 Localização do ensaio III a partir de imagem do satélite Landsat escala 1:25.000 (Miranda, 2001)

19 Análise consolidada dos três ensaios quanto à contagem de lagartas vivas aos 2 dias após aplicação.

20 Análise consolidada dos três ensaios quanto à percentagem de dano visual aos 6 dias após aplicação. (NDE: Nível de Dano Econômico).

21 Análise consolidada dos três ensaios quanto à percentagem de dano visual aos 10 dias após aplicação. (NDE: Nível de Dano Econômico). 


\section{LISTA DE TABELAS}

Página

1 Áreas irrigadas, distribuição por método, por estado e por regiões (Mil ha) Christofidis (2002)..................................................................................... 4

2 Número aferido de pivôs na região sudeste através de imagens de satélite................... 5

3 Principais termos associados à quimigação e a que se referem. ................................... 6

4 Percentagem estimada de perdas de produtividade causada pelo tráfego de máquinas na área plantada. ........................................................................ 8

5 Custos comparativos da quimigação versus aplicação convencional por hectare para um pivô de 101 ha $\left(\mathrm{R} \$ . \mathrm{ha}^{-1}\right)$ com altura manométrica de recalque de $60 \mathrm{~m} \mathrm{e}$ eficiência de $65 \%$.

6 Economia obtida por meio da quimigação em um ciclo anual de culturas quanto ao custo de aplicação.

7 Número de (re)cargas necessárias para aplicação de produtos fitossanitários numa área de 70 ha.

8 Volume de calda necessário (se ingerido) para se atingir a $\mathrm{DL}_{50}$ oral aguda de uma pessoa de $68 \mathrm{~kg}$ para diversos métodos de aplicação.

9 Concentração média do inseticida $\left(\mathrm{mg} \cdot \mathrm{L}^{-1}\right)$ e volume de água $(\mathrm{mL})$ para a distribuição nos quatro níveis na cultura (Stone et al., 1994).

10 Critérios de projeto referentes às técnicas de irrigação e quimigação (alvo folha).

11 Tipos de formulações de uso agrícola (Becher, 1985)

12 Variação no tamanho das gotas em função da frequiência de pulsos da bomba injetora-dosadora.

13 Tamanho médio de gotas em função da posição do ponto de injeção no interior da tubulação.

14 Caracterização resumida dos três ensaios 
15 Caracterização sumarizada do produto clorpirifós (Ware, 1993).............................. 45

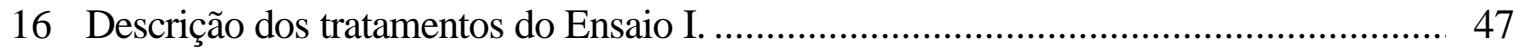

17 Descrição dos tratamentos do Ensaio II............................................................ 49

18 Descrição dos tratamentos do Ensaio III........................................................... 52

19 Eficiência dos tratamentos no controle da lagarta do cartucho em milho. Florestópolis/PR, safrinha de 1996 (Ensaio I)...................................................... 55

20 Eficiência dos tratamentos no controle da lagarta do cartucho em milho. Florestópolis/PR, safrinha de 1996 (Ensaio I). Dados transformados......................... 56

21 Eficiência dos tratamentos no controle da lagarta do cartucho em milho, Nova Fátima/PR, safrinha de 1997 (Ensaio II).

22 Eficiência dos tratamentos no controle da lagarta do cartucho em milho. Nova Fátima/PR, safrinha de 1997 (Ensaio II). Dados transformados.

23 Eficiência dos tratamentos no controle da lagarta do cartucho em milho, Nova Fátima/PR, safra de 1997 (Ensaio III)......

24 Eficiência dos tratamentos no controle da lagarta do cartucho em milho, Nova Fátima/PR, safra de 1997 (Ensaio III). Dados transformados..

25 Significância da análise fatorial do teste de probabilidade $(\mathrm{F})$ para o controle de

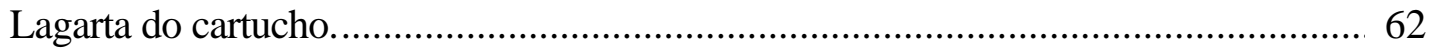

26 Análise Fatorial para contagem de lagartas aos 2 dias após aplicação......................... 62

27 Análise Fatorial para contagem de lagartas aos 6 dias após aplicação.......................... 62

28 Análise fatorial para percentagem calculada de dano visual aos 2 dias após aplicação.

29 Análise Fatorial para percentagem calculada de dano visual aos 6 dias após aplicação.

30 Análise Fatorial para percentagem calculada de dano visual aos 10 dias após aplicação.

31 Eficiência dos tratamentos no controle da lagarta do cartucho em milho. Dados originais consolidados dos três ensaios.

32 Eficiência dos tratamentos no controle da lagarta do cartucho em milho. Dados transformados, consolidados dos três ensaios 


\section{LISTA DE SÍMBOLOS}
A Área $\left(\mathrm{m}^{2}\right)$
$\mathrm{Ai} \quad$ Área irrigada (ha)
ANOVA Análise de variância
BBCH Bayer, BASF, Ciba e Hoechst. Pesquisadores dessas empresas que desenvolveram o código de estádios fenológicos descrito por Bleiholder et al., 1991.
CCI Calda crítica inferior
CCS Calda crítica superior
CE Concentrado emulsionável
CHP Clorpirifós
CUC Coeficiente de uniformidade de Christiansen
CV Coeficiente de variância
D Diâmetro (m)
DAA Dias após aplicação
DL50 Dose letal para metade de uma população de referência
DVM Diâmetro volumétrico mediano $(\mu \mathrm{m})$
e.g. exempli gratia (por exemplo)
EC Emulsão concentrada
ETm Evapotranspiração (mm.dia $\left.{ }^{-1}\right)$
GD Grânulo dispersível
GL Graus de liberdade
GR Granulada
i.a. Ingrediente ativo 


\begin{tabular}{|c|c|}
\hline IAF & Índice de área foliar $\left(\mathrm{m}^{2} \cdot \mathrm{m}^{-2}\right)$ \\
\hline IEA & Índice de eficiência agronômica \\
\hline $\mathrm{Lm}$ & Lâmina (mm) \\
\hline $\mathrm{NDE}$ & Nível de dano econômico \\
\hline p.c. & Produto comercial \\
\hline $\mathrm{PC}$ & Percentual de controle \\
\hline $\mathrm{PM}$ & Pó molhável \\
\hline Q & Vazão $\left(\mathrm{m}^{3} \cdot \mathrm{h}^{-1}\right)$ \\
\hline QM & Quadrados médios \\
\hline $\mathrm{Q}_{\mathrm{si}}$ & Vazão de um sistema de irrigação $\left(\mathrm{m}^{3} \cdot \mathrm{h}^{-1}\right)$ \\
\hline $\mathrm{Q}_{\mathrm{sq}}$ & Vazão de um suposto sistema de quimigação $\left(\mathrm{m}^{3} \cdot \mathrm{h}^{-1}\right)$ \\
\hline SAq & Solução aquosa \\
\hline $\mathrm{SC}$ & Suspensão ou solução concentrada \\
\hline SQ & Soma de quadrados \\
\hline $\mathrm{T}_{\mathrm{f}}$ & Tempo de funcionamento (h) \\
\hline $\mathrm{T}_{\mathrm{fd}}$ & Tempo de funcionamento diário (h.dia ${ }^{-1}$ ) \\
\hline $\mathrm{TS}$ & Tratamento de semente \\
\hline $\mathrm{V}$ & Velocidade $\left(\mathrm{m} \cdot \mathrm{s}^{-1}\right)$ \\
\hline $\mathrm{Vm}$ & Volume máximo (L.ha $\left.{ }^{-1}\right)$ \\
\hline
\end{tabular}




\section{CURRICULUM VITAE}

Wulf Schmidt é filho de Heinrich Schmidt e Elfriede Schmidt. Nasceu no dia 19 de agosto de 1962, em São Paulo/SP. Graduou-se engenheiro agrônomo em janeiro de 1985 pela Escola Superior de Agricultura "Luiz de Queiroz", Universidade de São Paulo. É casado com Ana Lana de Souza com quem teve três filhos. De 1985 a 2001 sempre trabalhou na empresa privada, em diversas empresas, atuando em áreas como análise financeira e de commodities, extensão rural e projeto, vendas, pesquisa e desenvolvimento e marketing. Atuou em várias geografias brasileiras tendo residido em Piracicaba/SP, Estância/SE, Barreiras/BA, Ribeirão Preto/SP e Londrina/PR. Atualmente reside em Piracicaba/SP. Seu último emprego foi na Dow AgroSciences onde ingressou em abril de 1993 atuando na área de pesquisa e desenvolvimento, saiu da empresa em dezembro de 2001 na função de desenvolvimento de mercados para inseticidas, fungicidas e biotecnologia, função esta que exercia havia quatro anos. Desde outubro de 1993 que atuava também como ponto de referência para quimigação (Dow Brasil), atribuição que manteve até sua saída. Nessa função, realizou várias palestras em várias instituições, públicas e privadas, apresentando vários trabalhos em congressos de pesquisas realizadas ou lideradas pelo mesmo. Em 2001 decidiu deixar a empresa para iniciar o curso de mestrado em agronomia, área de concentração irrigação e drenagem, na Escola Superior de Agricultura "Luiz de Queiroz" (ESALQ/USP). 


\section{USO DE ÓLEOS SEM SURFACTANTES NA APLICAÇÃO DE CLORPIRIFÓS VIA INSETIGAÇÃO NA CULTURA DE MILHO}

AUTOR: WULF SCHMIDT

Orientador: Prof. Dr. DURVAL DOURADO NETO

\section{RESUMO}

A irrigação é uma das tecnologias cujo retorno econômico é mais facilmente percebido pelo usuário, apesar do seu alto custo de investimento inicial. Nos últimos anos, com o fim dos financiamentos subsidiados, o agricultor irrigante tem buscado alternativas tecnológicas que lhe permitam o retorno do investimento em prazos cada vez menores. As soluções encontradas vão desde o uso da agricultura intensiva com a semeadura de culturas em sucessão (cultivos anuais), ou de várias safras (perenes), como também a maximização do uso do equipamento de irrigação, que tem sido usado cada vez com maior freqüência para a aplicação de produtos químicos por meio da quimigação. Esse panorama tem gerado, em algumas situações, desequilíbrio no agroecossistema com várias conseqüências, entre as quais destacam-se a explosão de pragas e doenças e a compactação de solos. A quimigação, apresenta uma série de vantagens e desvantagens. Dentre as vantagens, destacam-se o seu baixo custo quando comparado a outros métodos, e o menor tráfego de máquina na área cultivada, o que também favorece o menor dano mecânico às culturas. Entre as limitações, destaca-se o fato de que nem todos os produtos podem ser utilizados, pois esses precisam apresentar determinadas características físico-químicas como baixa solubilidade em água e alta em solventes orgânicos. O presente trabalho visa gerar informações sobre o uso de óleos sem surfactantes para a dissolução de formulações comerciais de clorpirifós (concentrado emulsionável), e sua efetividade no controle da lagarta do cartucho 
(Spodoptera frugiperda) no milho quando comparado à formulação comercial sem mistura, aplicado por insetigação. Desse modo, espera-se viabilizar a quimigação foliar com possibilidade da redução de dose ou do número de aplicações além de propor uma metodologia para instalação de ensaios de quimigação a campo. Foram instalados durante os anos de 1996 e 1997, três ensaios em três safras distintas, todos com elevada pressão de infestação, em áreas comerciais, onde os tratamentos foram injetados diretamente na base do pivô por meio de uma bomba injetora-dosadora. As parcelas, em forma de cunha, tinham no mínimo $50 \mathrm{~m}$ no perímetro de modo a evitar contaminação entre os tratamentos, e uma área mínima de um hectare. Foram amostrados de quatro a seis pontos para cada parcela. Os resultados obtidos mostraram a viabilidade da técnica, uma vez que a metade da dose comercial dissolvida no óleo mostrou a mesma efetividade de controle que a dose comercial, o que sinaliza a possibilidade da redução da dose ou do número de aplicações minimizando os custos para o produtor com menor impacto ambiental, o que favorece o manejo integrado e a sustentabilidade da agricultura. As informações geradas viabilizam a quimigação como método de aplicação de baixo custo, e a metodologia sugerida comprovou-se eficiente para a instalação de ensaios a campo. 


\section{USE OF OILS WITHOUT EMULSIFIERS TO APPLY CHLORPIRIFOS THROUGH INSECTIGATION ON CORN}

Author: WULF SCHMIDT

Advisor: Prof. Dr. DURVAL DOURADO NETO

\section{SUMMARY}

Irrigation is perceived by the farmers as the best payback technology, beside its initial investment cost. With the end of subsidized interests for agriculture in the last years, irrigated farmers are more and more looking for shorter paybacks of their investments. The alternatives presented are successive cropping (annual crops) or more that one harvest (perennial crops) per year, and to maximize the use of the irrigation equipment which is more frequently being used to apply chemical which is known as chemigation. This scenario generates in some situations an unbalance at the environment with several consequences like pest and diseases flare and soil compaction. Chemigation has advantages and limitations. Among the advantages is to be highlighted the lower application cost when compared to other methods, and less tracking in the area which reduce soil compaction and also crop losses due to crop damage. The main limitation is that not all products can be used in chemigation. They must attend some physical chemical properties like low water solubility and high solubility in organic solvents. The present work has the intention to generate information about the feasibility of mixing commercial formulations (emulsifiable concentrate-EC) with oils and no addition of any surfactant and the effectiveness of this mixture in comparison to standard when insectigated to control fall armyworm (Spodoptera frugiperda) in corn. This way, it is expected to viabilize foliar chemigation, with the possibility of rate or applications number reduction, and also to propose a standardized methodology to install field trials. 
Three trials were installed during 1996 and 1997 in three different seasons, all of them with high infestation level, in commercial areas, where treatments were injected in the center of the pivots using an injection pump. The plots, in a wedge form, had a minimal lenght at the perimeter to avoid treatments contamination, which provided a minimal area of one hectare each plot. Sampling was done at four to six points for each plot. Data showed the viability of the techniques, since the half of commercial rate diluted in oil without surfactants had shown the same effectiveness that standard (full rate without oil). This sign up the possibility of a rate reduction or perhaps less applications, which will minimizes farmers' costs with less environmental impact, being favorable to integrated pest management and agriculture sustainability. Generated information shows the workability of chemigation as a low cost application method, as well as the proposed methodology to install field trials had shown to be effective. 


\section{USO DE ACEITES SIN SURFACTANTES EN LA APLICACIÓN DE CLORPIRIFÓS VÍA INSECTIGACIÓN EN EL CULTIVO DE MAÍZ}

AUTOR: WULF SCHMIDT

Orientador: Prof. Dr. DURVAL DOURADO NETO

\section{RESUMEN}

El riego es una de las tecnologías que más rápidamente retorna al agricultor la inversión inicial. Actualmente en Brasil, con el fin de los créditos agrícolas subsidiados, el agricultor regante ha buscado alternativas tecnológicas que le posibiliten el retorno de la inversión en el menor tiempo posible. Entre las soluciones encontradas se pueden mencionar la agricultura intensiva con la siembra de varios cultivos anuales sucesivamente en un mismo año, varias cosechas por año en cultivos perennes y la maximización del uso del equipamiento de riego, el cual, cada vez con mayor intensidad, está siendo sido utilizado para aplicar los químicos, práctica conocida como quimigación. Este panorama ha causado, en algunas situaciones, un desequilibrio en los agroecosistemas con variadas consecuencias, entre las cuales se destacan la proliferación de plagas y enfermedades y la compactación del suelo. La quimigación presenta una serie de ventajas y limitaciones. Entre las ventajas se destaca el bajo costo de aplicación en comparación a los otros métodos, y el menor tráfico de maquinarias, lo que también disminuye el daño mecánico a los cultivos. Entre las limitaciones, hay que mencionar el hecho de que no todos los productos pueden ser aplicados, ya que estos deben tener determinadas características físico-químicas como solubilidad baja en agua y alta en solventes orgánicos. El objetivo del presente trabajo fue obtener informaciones sobre el uso de aceites sin surfactantes mezclados con formulaciones comerciales de clorpirifós 
(concentrados emulsionables), y su efectividad en el control del gusano cogollero u oruga militar tardía (Spodoptera frugiperda) en maíz en comparación a la formulación comercial sin mezcla, aplicados vía insectigación. Con esto se espera viabilizar la quimigación foliar, con posibilidad de reducción de la dosis o del número de aplicaciones. También fue propuesta una metodología para la instalación a campo de ensayos de quimigación. En 1996 y 1997 fueron instalados en áreas comerciales tres ensayos en tres zafras distintas, todos con elevado nivel de infestación. Las distintas mezclas del insecticida (tratamientos) fueron inyectadas directamente en el centro del tubo principal de los pivotes centrales por medio de una bomba inyectora-dosificadora. Las parcelas, con el formato de una cuña, tenían un perímetro mínimo de $50 \mathrm{~m}$ para evitar la contaminación entre los tratamientos, lo que generó un área mínima de una hectárea. Las mediciones fueron realizadas en cuatro a seis puntos en cada parcela. Los resultados obtenidos muestran la viabilidad de la técnica ya que la mitad de la dosis comercial mezclada con aceite tuvo la misma efectividad en el control que la dosis comercial (sin aceite), lo que posibilitaría la reducción de la dosis o del número de aplicaciones, disminuyendo los costos para el productor y el impacto ambiental y favoreciendo así el manejo integrado en el marco de una agricultura sostenible. Los resultados obtenidos muestran la viabilidad de la práctica de quimigación para la aplicación de los productos, y la adecuación de la metodología propuesta para la instalación de los ensayos. 


\title{
DIE ANWENDUNG EMULGATORLOSER ÖLE BEI DER VERWENDUNG VON CHLORPYRIFOS MITTELS INSEKTIGATION BEIM MAISANBAU
}

AUTOR: WULF SCHMIDT

\author{
Berater: Prof. Dr. DURVAL DOURADO NETO
}

\section{ZUSAMMENFASSUNG}

Die Bewässerung ist eine der Technologien, deren wirtschaftlicher Rückfluss, trotz seiner anfänglichen hohen Investitionskosten, vom Verbraucher am leichtesten bemerkt wird. In den letzten Jahren, mit dem Ende der subventionierten Finanzierungen in Brasilien, hat der bewässernde Landwirt Alternativtechnologien gesucht, die ihm den Investmentrückfluss in immer kleineren Zeitabständen erlaubt. Die gefundenen Lösungen gehen ab der intensiven Landwirtschaft mit der Aussaat von Erfolgskulturen (Jahresanbau), oder verschiedenen Ernten (perennierenden), sowie auch ab der Maximierung der Anwendung von Bewässerungsanlagen, die von Mal zu Mal mit größerer Häufigkeit bei der Verwendung chemischer Mittel durch Chemigation angewendet wurden. Dieses Panorama hat in einigen Situationen das Ungleichgewicht im Agroökosystem mit verschiedenen Folgen verursacht, unter denen sich die Explosion der Plagen und Krankheiten und die Kompaktierung des Bodens hervorheben. Die Chemigation zeigt eine Reihe von Vor und Nachteilen. Zwischen den Vorteilen heben sich die niedrigen Kosten hervor, verglichen mit denen anderer Methoden, und der geringere Maschinenverkehr innerhalb der bebauten Fläche, was auch den kleineren mechanischen Schaden an den Kulturen begünstigt. Zwischen den Begrenzungen hebt sich auch die Tatsache hervor, dass nicht alle Mittel benutzt werden können, denn diese müssen gewisse physikochemische Eigenschaften, wie niedrige Löslichkeit in Wasser 
und hohe in organischen Lösungsmitteln, aufweisen. Die vorliegende Arbeit beabsichtigt Informationen hervorzubringen über emulgatorlose Öle zur Auflösung von kommerziellen Formulierungen der Chlorpyrifos (emulgierbares Konzentrat) und über seine Wirksamkeit in der Kontrolle der Spodoptera frugiperda im Mais, verglichen mit der kommerziellen Formulierung ohne Beimischung, die mittels Insektigation verwendet wird. Somit erwartet man die Blatt-Chemigation mit einer möglichen Reduzierung der Dosierung oder der Anzahl der Anwendungen zu ermöglichen und ausserdem eine Methodologie zur Installation von Versuchen der Chemigation auf dem Feld vorzuschlagen. Während der Jahre 1996 und 1997 wurden drei Versuche in drei verschiedenen Ernten installiert, alle mit erhöhtem Befallungsdruck, in kommerziellen Flächen, wo die Behandlungen direkt in die Pivotbasis durch eine Dosierungseinspritzpumpe eingespritzt wurden. Um eine Ansteckung zwischen den Behandlungen zu vermeiden, hatten die Parzellen, in Keilform, mindestens $50 \mathrm{~m}$ im Umfang und eine Mindestfläche von einem Hektar. Es wurden an vier bis sechs Stellen je Behandlung Versuche vorgenommen. Die gewonnenen Ergebnisse zeigten die Realisierbarkeit der Technik auf, da die Hälfte der kommerziellen Dosierung in emulgatorloser Öl aufgelöst, die gleiche Wirksamkeit vorzeigte wie die kommerzielle Dosierung, was die Möglichkeit der Dosierungsverminderung oder Anwendungsanzahl ankündigt, und somit die Kosten für den Produzenten mit einem geringeren Umwelteinfluss minimisiert, was wiederum die integrierte Handhabung und die Unterhaltung der Landwirtschaft begünstigt. Die vorgebrachten Informationen ermöglichen die Chemigation als eine Verwendungsmethode mit geringem Kostenaufwand, und die vorgeschlagene Methodologie hat sich als effizient für die Installation von Versuchen auf dem Feld erwiesen. 


\section{INTRODUÇÃO}

Em 2001, o Brasil possuía cerca de 3,15 milhões de hectares irrigados representando 5,9\% dos 53,5 milhões de hectares da área cultivada. Desse total, 1,65 milhão de hectares são de irrigação por superfície, 615 mil hectares por aspersão convencional, 652 mil hectares por pivô central, e, 248 mil hectares por irrigação localizada. Temos porém um potencial sustentável para o desenvolvimento da irrigação próximo a 30 milhões de hectares (Christofidis, 2002).

Com o fim dos subsídios à agricultura irrigada proporcionada por programas governamentais como o PROFIR, o PROINE e o PRONI, a sua viabilidade econômica passa necessariamente por alguns aspectos como: a maximização do uso da área irrigada e do equipamento e a obtenção de altas produtividades com o menor custo de produção possível, uma vez que raramente é possível o controle sobre o preço do produto final. A maximização do uso da área, implica em cultivos sucessivos (para lavouras anuais), ou várias safras para culturas perenes, observando-se hoje, em média, entre duas a três safras por hectare por ano em média.

Essa agricultura intensiva implica em um maior nível de uso de insumos e maior tráfego de máquinas, causando desequilíbrio no agroecossistema. A busca de novas tecnologias de manejo da área, entre as quais a quimigação, é uma alternativa aos produtores para maximizar o rendimento minimizando os custos. Segundo Johnson et al. (1986), "quimigação é a prática de se aplicar agro-químicos através da água de irrigação". Desse termo derivam outros como insetigação para a aplicação de inseticidas, fungigação para aplicação de fungicidas, herbigação para herbicidas e assim por diante. De maneira geral, guardadas as características de cada sistema de irrigação, todos podem ser utilizados para essa prática. 
Vários autores mencionam os benefícios advindos da quimigação, mas sem dúvida o mais atrativo para o agricultor é o menor custo da aplicação, quando comparada a outros métodos.

Este trabalho tem como objetivo validar a tecnologia da dissolução da formulação comercial (concentrado emulsionável) de clorpirifós em óleos sem surfactantes, para aplicação no dossel da cultura de milho por insetigação, de modo a possibilitar (i) melhorar a eficácia (índice de mortalidade acima de 80\%) e a consistência (eficaz em diferentes locais e épocas) no controle da lagarta do cartucho (Spodoptera frugiperda), (ii) gerar informações para a viabilização da quimigação foliar, (iii) reduzir a dose ou o número de aplicações visando diminuir a quantidade de defensivos na área irrigada, favorecendo a sustentabilidade agrícola e um menor impacto ambiental, e (iv) sugerir uma metodologia padronizada para a instalação de ensaios a campo via quimigação, no intuito de facilitar a condução de novos experimentos. 


\section{REVISÃO DE LITERATURA}

\subsection{Agricultura irrigada}

A área irrigada do mundo corresponde a apenas $18 \%$ do total cultivado, mas é responsável por 42\% da produção colhida (Christofidis, 2001 e 2002). Por isso, pela demanda crescente de alimentos, e pela perspectiva eminente de escassez de água potável, fica evidente a necessidade de se pesquisar alternativas que possibilitem uma maior eficiência à agricultura irrigada.

Christofidis (2002) comenta que, em 2001, o Brasil possuía cerca de 3.150 .000 ha irrigados representando 5,9\% dos 53,5 milhões de ha cultivados. Desse total, 1.650.000 ha são de irrigação por superfície, 615.000 ha por aspersão convencional, 652.000 ha por pivô central, e 248.000 ha através de irrigação localizada. Outro dado relevante levantado pelo autor é que o Brasil teria um potencial de uso para desenvolvimento sustentável da irrigação de 29,5 milhões ha.

A Tabela 1 mostra a distribuição dessas áreas por regiões e por estado. Schmidt et al. (2003) em levantamento feito a partir de imagens de satélite, comentam que há distorções nesses números, como a do estado do Rio de Janeiro que apresenta 6.620 ha irrigados por pivôs no levantamento feito por Christofidis (2002), mas onde apenas 15 equipamentos foram identificados nas imagens de satélite (Tabela 2), perfazendo uma área por equipamento de 441,3 ha o que não é possível. Essas distorções, presumem os autores, devem estar associadas à fonte dos dados.

No trabalho de Christofidis (2002), a fonte mais provável seria a documentação

fiscal de aquisição dos equipamentos, que é enviado geralmente para o endereço comercial da empresa, freqüentemente divergente do local de instalação. Outra fonte 
provável de erro é a mudança de localização do equipamento entre a data de aquisição e a data das imagens.

Tabela 1. Áreas irrigadas, distribuição por método, por estado e por regiões (Mil ha) Christofidis (2002).

\begin{tabular}{|c|c|c|c|c|c|}
\hline & Superfície & $\begin{array}{c}\text { Aspersão } \\
\text { convencional }\end{array}$ & Pivô central & Localizada & TOTAL \\
\hline BRASIL & 1.634 & 615 & 652 & 248 & 3.149 \\
\hline NORTE & 82,0 & 6,1 & 1,4 & 1,7 & 91,0 \\
\hline RO & 0,0 & 4,1 & --- & 0,5 & 4,6 \\
\hline $\mathrm{AC}$ & 0,5 & 0,1 & -- & 0,0 & 0,6 \\
\hline $\mathrm{AM}$ & 1,0 & 0,7 & --- & 0,1 & 1,8 \\
\hline $\mathrm{RR}$ & 8,4 & 0,3 & 0,1 & 0,2 & 9,0 \\
\hline PA & 6,6 & 0,2 & --- & 0,3 & 7,1 \\
\hline AP & 1,4 & 0,3 & --- & 0,2 & 1,9 \\
\hline TO & 64,0 & 0,3 & 1,3 & 0,4 & 66,0 \\
\hline NORDESTE & 190,7 & 242,5 & 122,0 & 138,4 & 663,7 \\
\hline MA & 23,8 & 11,5 & 2,9 & 6,0 & 44,2 \\
\hline PI & 10,3 & 7,0 & ,7 & 6,1 & 27,2 \\
\hline $\mathrm{CE}$ & 19,5 & 30,2 & 17,5 & 5,3 & 72,6 \\
\hline RN & --- & 2,7 & 1,1 & 14,0 & 17,8 \\
\hline PB & 30,0 & 8,3 & 2,0 & 7,3 & 47,6 \\
\hline PE & 31,6 & 42,2 & 9,4 & 8,7 & 92,0 \\
\hline $\mathrm{AL}$ & 7,1 & 56,5 & 5,9 & 6 & 70,1 \\
\hline SE & 30,4 & 8,4 & ,3 & 6,2 & 45,3 \\
\hline BA & 37,9 & 75,7 & 82,1 & 84,1 & 279,9 \\
\hline SUDESTE & 217,9 & 245,8 & 362,6 & 83,4 & 909,6 \\
\hline MG & 107,9 & 73,5 & 87,9 & 44,6 & 314,0 \\
\hline ES & 17,3 & 53,8 & 13,7 & 6,4 & 91,3 \\
\hline $\mathrm{RJ}$ & 14,8 & 14,2 & 6,6 & ,4 & 36,0 \\
\hline SP & 77,8 & 104,2 & 254,4 & 32,0 & 468,4 \\
\hline SUL & $1.095,5$ & 82,1 & 0,5 & 18,8 & $1.196,8$ \\
\hline PR & 14,4 & 35,8 & 0,5 & 1,1 & 51,8 \\
\hline $\mathrm{SC}$ & 115,5 & 20,6 & -- & 1,2 & 137,3 \\
\hline RS & 965,6 & 25,7 & --- & 16,5 & $1.007,8$ \\
\hline CENTRO-OESTE & 47,8 & 39,0 & 165,0 & 6,2 & 258,1 \\
\hline MS & 41,3 & 3,2 & 36,7 &, 3 & 81,5 \\
\hline MT & 4,1 & 2,8 & 3,8 & 4,0 & 14,7 \\
\hline $\mathrm{GO}$ & 2,3 & 29,3 & 118,1 & 1,3 & 150,9 \\
\hline DF & 0,2 & 3,7 & 6,4 & 0,7 & 11,0 \\
\hline
\end{tabular}


Tabela 2. Número aferido de pivôs na região sudeste através de imagens de satélite.

\begin{tabular}{cccc}
\hline & Total pivôs & Área (ha) ${ }^{1}$ & $\begin{array}{c}\text { Área média por } \\
\text { equipamento (ha) }\end{array}$ \\
\hline REGIÃO SUDESTE & 4.134 & 362.618 & 87,72 \\
Espírito Santo & 329 & 13.688 & 41,60 \\
Minas Gerais & 2.485 & 87.950 & 35,39 \\
Rio de Janeiro & 15 & 6.620 & 441,33 \\
São Paulo & 1.305 & 254.360 & 194,91 \\
\hline
\end{tabular}

${ }^{1}$ Christofidis (2002)

\subsection{Quimigação}

Johnson et al. (1986) definem quimigação como a "prática de se aplicar agro químicos através da água de irrigação". Costa et al. (1994) incluem o termo 'biológico' na definição, pela possibilidade da aplicação de bioinseticidas, por exemplo, ficando então a definição como sendo: "prática de se aplicar produtos agro químicos e biológicos através da água de irrigação". A Tabela 3 mostra outros termos, e os produtos químicos derivados aos quais se referem.

Para o caso de produtos fitossanitários, os mesmo têm que apresentar as seguintes propriedades físico-químicas para serem quimigáveis: (i) baixa solubilidade em água com alta estabilidade; (ii) alta solubilidade em solventes orgânicos; e (iii) não serem corrosivos ao equipamento (Junqueira Neto, 1994; Viana, 1994; Vieira, 1994; Young, 1984). As propriedades nencionadas são obrigatórias, enquanto que as demais que caracterizam as moléculas, embora importantes, não diferenciam os produtos quanto a sua aplicabilidade em quimigação.

\subsubsection{Vantagens}

A quimigação, segundo vários autores (Johnson et al., 1986; Junqueira Neto, 1994; Threadgill, 1985; Vieira, 1994; Viana, 1994; Young, 1980), apresenta uma série de vantagens ao produtor quando comparada a outros métodos de aplicação. As principais e mais freqüentemente mencionadas são discutidas a seguir. 
Tabela 3. Principais termos associados à quimigação e a que se referem.

\begin{tabular}{cc}
\hline Técnica & Produto \\
\hline Herbigação & Herbicidas \\
Insetigação & Inseticidas \\
Fungigação & Fungicidas \\
Nematigação & Nematicidas \\
Fertigação ou fertirrigação & Fertilizantes \\
Carbonigação & Gás carbônico \\
\hline
\end{tabular}

\subsubsection{Uniformidade de aplicação}

Pelo movimento contínuo de um pivô, ou sistema linear, a possibilidade de que uma faixa da cultura não seja aplicada ou de sobreposição (risco de fitotoxicidade), ocorrerá apenas se houver alguma falha durante a injeção do produto, e se o equipamento não for desligado ao se completar a volta. Pair $(1983)^{1}$, citado por Threadgill (1985), comenta que a uniformidade de aplicação de químicos para pivô e movimento lateral é maior ou igual a 90\%, para aspersão convencional ou rolão de 70 a $75 \%$, menor que $80 \%$ para os auto-propelidos (diretamente relacionados com a condição climática no momento da aplicação). A uniformidade de distribuição de produto pela água de irrigação está diretamente relacionada com a uniformidade de distribuição da água. Yates (1962) atribui 70\% de uniformidade para aplicação aérea, enquanto Bode et al. (1968) atribuem de 50 a $92 \%$ de uniformidade para a aplicação tratorizada.

\subsubsection{Ativação e incorporação}

A própria lâmina de irrigação já provê o meio de incorporação, bem como a umidade necessária para a ativação dos produtos que a necessitem, o que é fundamental, por exemplo, no caso de alguns herbicidas de solo como aqueles do grupo das dinitroanilinas (trifluralina, pendimentalin, orizalin, e.g.), e do grupo das acetanilidas (metolaclor, alaclor, acetoclor, e.g.), ou então para o controle de pragas e doenças de solo. Em algumas situações, pode ser o único meio de se utilizar herbicidas que

\footnotetext{
${ }^{1}$ PAIR, C.H.(Ed.) Irrigation. 4 ed. The Irrigation Association, Silver Spring/MD, 1983, 686 p.
} 
necessitam de incorporação como a trifluralina e EPTC, ou mesmo para arrastar herbicidas pré-emergentes até o solo em áreas com cobertura morta, como no sistema de semeadura direta.

\subsubsection{Momento de aplicação}

Pelo fato de poder ser aplicada à noite, com uma chuva leve, logo após uma chuva, e com ventos de 16 a $19 \mathrm{~km} \cdot \mathrm{h}^{-1}$ (Costa et al., 1994), situações estas onde uma aplicação aérea ou tratorizada seria inviável, a quimigação permite que se aplique no momento exato do estádio da cultura e da planta daninha, do estágio ou do momento de maior suscetibilidade da praga ou doença, enfim, nas condições em que, certamente, obter-se-á maior eficácia dos produtos aplicados (Chalfant \& Young, 1982).

\subsubsection{Possível redução das doses aplicadas}

A redução da dose aplicada pode ser obtida devido a: (i) uniformidade da aplicação, (ii) da capacidade de ativação e incorporação, e (iii) da maior flexibilidade no momento de aplicação. Devido a maior eficácia de aplicação, poderá ser possível a redução da dose aplicada, não por aplicação, mas no número total de aplicações no ciclo da cultura, significando uma menor quantidade de químicos por hectare por ano (Costa et al. 1994, Chalfant \& Young, 1982).

\subsubsection{Redução da necessidade de equipamentos}

O uso do pivô para aplicações pode diminuir a necessidade de equipamentos como: trator, pulverizador e, em alguns casos, equipamentos para incorporação, uma vez que maximiza a operacionalidade para o produtor (Ogg et al., 1983).

\subsubsection{Redução do dano mecânico à cultura}

O dano mecânico à cultura pela entrada de máquinas não se restringe apenas ao amassamento. A perda de produção causada por esse fator é relativamente simples de se calcular. Entretanto o uso de máquinas na área danifica tecidos vegetais favorecendo a entrada de patógenos, transporta sementes de plantas daninhas, insetos e esporos de fungos, contribuindo assim para a disseminação dos mesmos. Em função das inúmeras variáveis envolvidas, é bastante difícil a execução de trabalhos científicos mensurando esse tipo de dano. Os números e as informações disponíveis são geralmente fruto da 
vivência e experiência dos pesquisadores e produtores envolvidos e foram sumarizados na Tabela 4 (Schmidt, 1997).

Tabela 4. Percentagem estimada de perdas de produtividade causada pelo tráfego de máquinas na área plantada.

\begin{tabular}{cc}
\hline Cultura & Perdas estimadas (\%) \\
\hline Soja & 3 \\
Milho & 3 a 5 \\
Feijão & 5 a 8 (até 12 na florada) \\
Trigo & 5 a 8 \\
Tomate & 10 a 15 \\
Batata & 10 a 15 \\
\hline
\end{tabular}

\subsubsection{Redução do custo de aplicação}

Pela otimização do uso do equipamento, menor consumo de energia, pela maior eficácia na aplicação dos produtos, e o menor gasto com mão-de-obra (um homem pode supervisionar a aplicação de vários pivôs simultaneamente), pode-se chegar a uma economia de $\mathrm{R} \$ 15,84$ (cerca de US\$5,00) por aplicação por hectare em comparação a uma aplicação tratorizada ou aérea, conforme pode ser visualizado na

, corroborando os resultados obtidos por Johnson et al. (1986) e Threadgill et al. (1985) para as condições americanas. A Tabela 6 mostra a economia obtida em um ano de cultivo.

Tabela 5. Custos comparativos da quimigação versus aplicação convencional por hectare para um pivô de 101 ha $\left(\mathrm{R} \$ . \mathrm{ha}^{-1}\right)$ com altura manométrica de recalque de $60 \mathrm{~m}$ e eficiência de $65 \%$.

\begin{tabular}{llcc}
\hline \multirow{2}{*}{ Sistema } & Descriminação & Parcial & Custo \\
\hline Trator+ pulverizador & & & 20,19 \\
& Moto-bomba & 3,50 & \\
Pivô & Moto-redutores & 0,25 & \\
& Água & 0,60 & 4,35 \\
\hline
\end{tabular}


Tabela 6. Economia obtida por meio da quimigação em um ciclo anual de culturas quanto ao custo de aplicação.

\begin{tabular}{|c|c|c|c|c|}
\hline \multirow[t]{2}{*}{ Cultura } & \multirow{2}{*}{$\begin{array}{l}\text { Número de } \\
\text { aplicações }\end{array}$} & \multirow{2}{*}{$\begin{array}{l}\text { Ciclo da cultura } \\
\text { (dias) }\end{array}$} & \multicolumn{2}{|c|}{ Economia } \\
\hline & & & $\left(\mathrm{R} \$ \mathrm{ha}^{-1}\right)^{3}$ & $\left(\right.$ US\$.ha ${ }^{-1}$ ) \\
\hline Milho & 8 & 120 & 128,30 & 40,73 \\
\hline Feijão & 10 & 90 & 160,40 & 50,92 \\
\hline Batata & $32^{2}$ & 120 & 513,23 & 162,93 \\
\hline TOTAL & 50 & 330 & 801,93 & 254,58 \\
\hline
\end{tabular}

${ }^{1}$ Inclui fertilizantes, herbicidas, fungicidas e inseticidas.

2 Nazareno et al. (1995).

${ }^{3}$ Para referência em dólar usar a taxa cambial de R\$ 3,15/US\$.

\subsubsection{Redução na compactação de solo}

Principalmente em áreas irrigadas onde a agricultura se faz de forma intensiva e com o conseqüente aumento no tráfego de máquinas, a compactação é um sério problema nos solos brasileiros, agravado pela própria irrigação (Coelho, 1996). A consequiência imediata da compactação é a formação de uma camada de impedimento que dificulta o desenvolvimento do sistema radicular, diminui a velocidade de infiltração básica de água e diminui a aeração do solo. Esses fatores contribuem para, irrigações mais freqüentes, maior risco de erosão superficial, menor volume de solo explorado pelas raízes com menor eficiência na absorção de água e nutrientes, tendo como conseqüência menores produtividades.

A quimigação permite, com eficiência, a redução no tráfego de máquinas, diminuindo seu efeito compactador e, dessa forma, reduzem-se os custos com a descompactação dessas áreas (Coelho, 1996).

\subsubsection{Redução no risco de exposição do operador}

O fator de maior risco para o operador durante a aplicação é o preparo da calda, quando se está manipulando o produto concentrado. A quimigação proporciona um menor número de (re)cargas para cobrir a área por permitir caldas mais concentradas ou mesmo injetando o produto puro no sistema (Tabela 7). Na quimigação o operador permanece junto do ponto de injeção, no centro do pivô, enquanto que na aplicação 
convencional ele percorre a área toda com o trator correndo risco de exposição à deriva (Chalfant \& Young, 1982; Schmidt \& Dourado Neto, 2003).

Tabela 7. Número de (re)cargas necessárias para aplicação de produtos fitossanitários numa área de 70 ha.

\begin{tabular}{lccc}
\hline \multicolumn{1}{c}{ Item } & Trator & \multicolumn{2}{c}{ Quimigação } \\
\hline Volume de calda & $200{\mathrm{~L} \cdot \mathrm{ha}^{-1}}^{-1}$ & $220 \mathrm{~L}^{-1} \mathrm{~h}^{(1)}$ & $1,8 \mathrm{~L}^{-1} \mathrm{~h}^{(2)}$ \\
Tanque & $2.000 \mathrm{~L}$ & $2.000 \mathrm{~L}$ & $20 \mathrm{~L}$ \\
(Re)cargas & 7 & 2,5 & 2 \\
Volume & $14.000 \mathrm{~L}$ & $5.000 \mathrm{~L}$ & $42 \mathrm{~L}$ \\
Dose & $(3)$ & $(3)$ & $600 \mathrm{~mL} \cdot \mathrm{ha}^{-1}$ \\
Tempo & $9 \mathrm{~h}$ & $23 \mathrm{~h}$ & $23 \mathrm{~h}$ \\
\hline
\end{tabular}

${ }^{1}$ Bomba dosadora de duplo pistão

${ }^{2}$ Bomba dosadora de diafragma que possibilita injeção de produto puro no sistema (sem pré-diluição)

${ }^{3}$ Qualquer dose comercial

O grande volume de água utilizado na quimigação é outro ponto favorável. A diluição decorrente impacta diretamente no risco de se atingir as DL50 aguda, tanto oral quanto dermal (Jonhson et al., 1986). Como exemplo, a Tabela 8 mostra o volume necessário para atingir a $\mathrm{DL}_{50}$ oral aguda considerando-se a dose recomendada em rótulo dos inseticidas citados. Sendo a $\mathrm{DL}_{50}$ oral aguda a dose necessária para matar metade de uma população de ratos (macho e fêmea têm valores distintos) por ingestão, fica evidente que na quimigação, o indivíduo morreria afogado antes de atingir a mesma, pois teria que ingerir um volume de calda muito maior para atingir a mesma quantidade de ingrediente ativo.

Tabela 8. Volume de calda necessário (se ingerido) para se atingir a DL50 oral aguda de uma pessoa de $68 \mathrm{~kg}$ para diversos métodos de aplicação.

\begin{tabular}{|c|c|c|c|c|c|}
\hline \multirow{4}{*}{ Produto } & \multirow{4}{*}{$\begin{array}{c}\mathrm{DL}_{50} \text { oral aguda } \\
\left(\mathrm{mg} \cdot \mathrm{kg}^{-1}\right)\end{array}$} & \multirow{4}{*}{$\begin{array}{c}\text { Dose } \\
\text { g.ha- }{ }^{-1} \text { i.a. }\end{array}$} & \multicolumn{3}{|c|}{ Método de aplicação } \\
\hline & & & \multicolumn{3}{|c|}{ Volume de calda } \\
\hline & & & Avião & Trator & Pivô \\
\hline & & & 47 L.ha $^{-1}$ & 234 L.ha $^{-1}$ & 25.000 L.ha ${ }^{-1}$ \\
\hline Paration Metil & $4-13^{1}$ & 600 & $21-69 \mathrm{~mL}$ & $106-345 \mathrm{~mL}$ & $11,3-36,8 \mathrm{~L}$ \\
\hline Clorpirifós & $136-163$ & 288 & 724-868 mL & $3,6-4,3 \mathrm{~L}$ & $385,3-461,8 \mathrm{~L}$ \\
\hline
\end{tabular}

\footnotetext{
${ }^{1} \mathrm{O}$ menor valor refere-se às fêmeas e o maior aos machos.
} 


\subsubsection{Co-quimigação}

Aplicação simultânea de vários produtos. Há alguns produtos que não podem ser misturados num tanque de pulverização por apresentarem incompatibilidade física (floculam ou precipitam, e.g.). A aplicação concomitante na quimigação faz-se mediante a utilização de equipamento e ponto de injeção distintos. Desse modo, cada produto formará ao longo da tubulação sua própria emulsão (Young, 1984). Em outras palavras, ter-se-á a formação de duas ou mais fases dispersas (produtos) e uma fase contínua (água). Detalhes sobre emulsões serão abordados mais adiante.

\subsubsection{Segurança ambiental}

A quimigação é, sem dúvida, uma das formas de aplicação mais seguras existentes, desde que se utilizem os equipamentos de segurança necessários e imprescindíveis (American Society of Agricultural Engineers, 2000; Threadgill, 1985; Costa et al., 1994), e não se use, sob nenhum pretexto, a pressão negativa (sucção) para injeção de produtos no sistema.

A afirmação é possível pois a quimigação possibilita (i) a redução na dose de químicos por hectare por ano, (ii) a menor compactação de solo, diminuindo a erosão superficial e o conseqüente assoreamento dos mananciais, (iii) menor risco ao operador e, (iv) menor deriva dentre todos os métodos de aplicação (Byers et al., 2000; Kohl \& Deboer, 1984; Kohl et al., 1987; Spray Drift task Force, 1997; Villa Nova et al., 1997).

Nos Estados Unidos, é crescente a preocupação em relação a contaminação do lençol freático por nitratos e alguns produtos como as triazinas (herbicidas). No Brasil, não existem muitos estudos sobre o assunto, mas existem alguns aspectos fundamentais que diferem a nossa condição da americana.

A maioria dos equipamentos americanos capta água de mananciais subterrâneos em áreas onde predominam solos pouco argilosos e relativamente rasos, o que favorece a lixiviação, enquanto no Brasil, a principal fonte é superficial, os solos são profundos e geralmente com teor de argila elevado, o que favorece a fixação das moléculas aos colóides do solo. O maior risco é a contaminação de mananciais pela erosão superficial, causada na maioria dos casos por projetos mal dimensionados ou áreas mal manejadas. Faltam também estudos no Brasil de como proceder em caso de um acidente (refluxo 
e.g.) contaminar uma fonte superficial, informação essa disponível para águas subterrâneas (Warner et al., 1989).

\subsubsection{Limitações}

\subsubsection{Operador e investimento adicional}

O operador precisa ter necessariamente uma melhor qualificação técnica ou a propriedade uma boa assessoria. Esse investimento em recurso humano é fundamental para se garantir uma boa eficácia com o mínimo risco operacional.

Como a maioria dos equipamentos de irrigação não tem no seu projeto original incluídos os equipamentos de segurança necessários para a prática da quimigação, faz-se necessário esse investimento adicional, além da aquisição de uma bomba dosadorainjetora. Esse investimento, entretanto, é rapidamente amortizado pelo benefício que traz (Schmidt, 2000; Schmidt \& Dourado Neto, 2003).

\subsubsection{Produto}

Conforme já mencionado, os produtos para serem quimigáveis precisam necessariamente ter baixa solubilidade em água e alta em orgânicos, ou seja, serem lipofílicos. Essa exigência limita os produtos a serem utilizados. É preciso pois buscar a informação sobre solubilidade que muitas vezes é de difícil obtenção, mesmo junto às empresas fabricantes (Johnson et al. 1986; Schmidt, 1997; Threadgil, 1985).

\subsubsection{Tempo de aplicação}

O tempo de aplicação em quimigação é maior em relação a aplicação aérea, porém, em relação a tratorizada pode ser igual ou um pouco maior. Por exemplo, um pivô de 100 ha leva 20 horas para dar um giro completo. Um trator com pulverizador de $2.000 \mathrm{~L}$, barra de aplicação de $20 \mathrm{~m}$, aplicando $200 \mathrm{~L} . h a^{-1}$ de calda, andando a uma velocidade de $6 \mathrm{~km} \cdot \mathrm{h}^{-1}$, aplica $2.000 \mathrm{~m}^{2} \cdot \mathrm{min}^{-1}$. Isso significa que ele levaria $8 \mathrm{~h}$ e $20 \mathrm{~min}$ para aplicar os 100 ha. Adiciona-se ainda o tempo para reabastecimento (cerca de 20 minutos por parada) perfazendo um total de 180 min ou 3 horas, que somado ao tempo efetivo de aplicação totaliza 11 h 20 min, tempo não muito inferior que o do pivô. Há no entanto, equipamentos mais modernos que fazem o giro em tempos próximos a doze horas. $\mathrm{O}$ pivô permite aplicações noturnas com muito mais facilidade que o trator, o que 
otimiza os equipamentos na propriedade na medida em que aumenta a janela de aplicação (Schmidt \& Dourado Neto, 2003).

\subsubsection{Irrigação desnecessária}

Se, no momento da quimigação, o solo não necessitar de água, deve-se avaliar a relação custo e benefício da aplicação, principalmente no que diz respeito à demanda de energia elétrica. No entanto, na maioria das vezes, é compensadora face às demais formas de aplicação (Schmidt \& Dourado Neto, 2003).

\subsection{Eficácia versus volume de calda}

Desde o princípio da quimigação, o grande questionamento tem sido sobre o grande volume de água aplicado na quimigação e a possibilidade da "lavagem" dos produtos, principalmente aqueles aplicados sobre as folhas (Young, 1980).

Dourado Neto \& Fancelli (1999 e 2000), Fancelli \& Dourado Neto (2000) e Vilela (2002), afirmam que a eficiência do controle químico é diretamente proporcional à quantidade do ingrediente ativo que atinge o alvo, o que é inquestionável. Baseiam a afirmação na Figura 1 que mostra a variação do índice de eficácia de aplicação (IEA\%), diretamente relacionado à quantidade do ativo que atinge o alvo folha, em função da calda utilizada. Até o valor da calda crítica inferior (CCI), a quantidade de ingrediente ativo que atinge o alvo folha vai crescendo limitado pelo volume de calda aplicado e a solubilidade. Acima do valor de calda crítica superior (CCS) há a limitação de área foliar para retenção do ativo (ou índice de área foliar, se expresso por unidade de área explorada pela planta), com a consequente lavagem do produto das folhas pelo grande volume de água aplicado. $\mathrm{O}$ índice de área foliar (IAF) é função da arquitetura da planta, do tipo da folha (pilosa, cerosa, glabra, e.g.), e do estádio de desenvolvimento da planta. Segundo eses autores, a planta não teria capacidade de reter volumes de calda acima de 2000 L.ha $^{-1}$.

Com o mesmo pensamento, Basanta (1999) propôs um modelo que estimasse a capacidade de retenção foliar na cultura do milho, no intuito de prover suporte a decisão do uso ou não da quimigação foliar. 


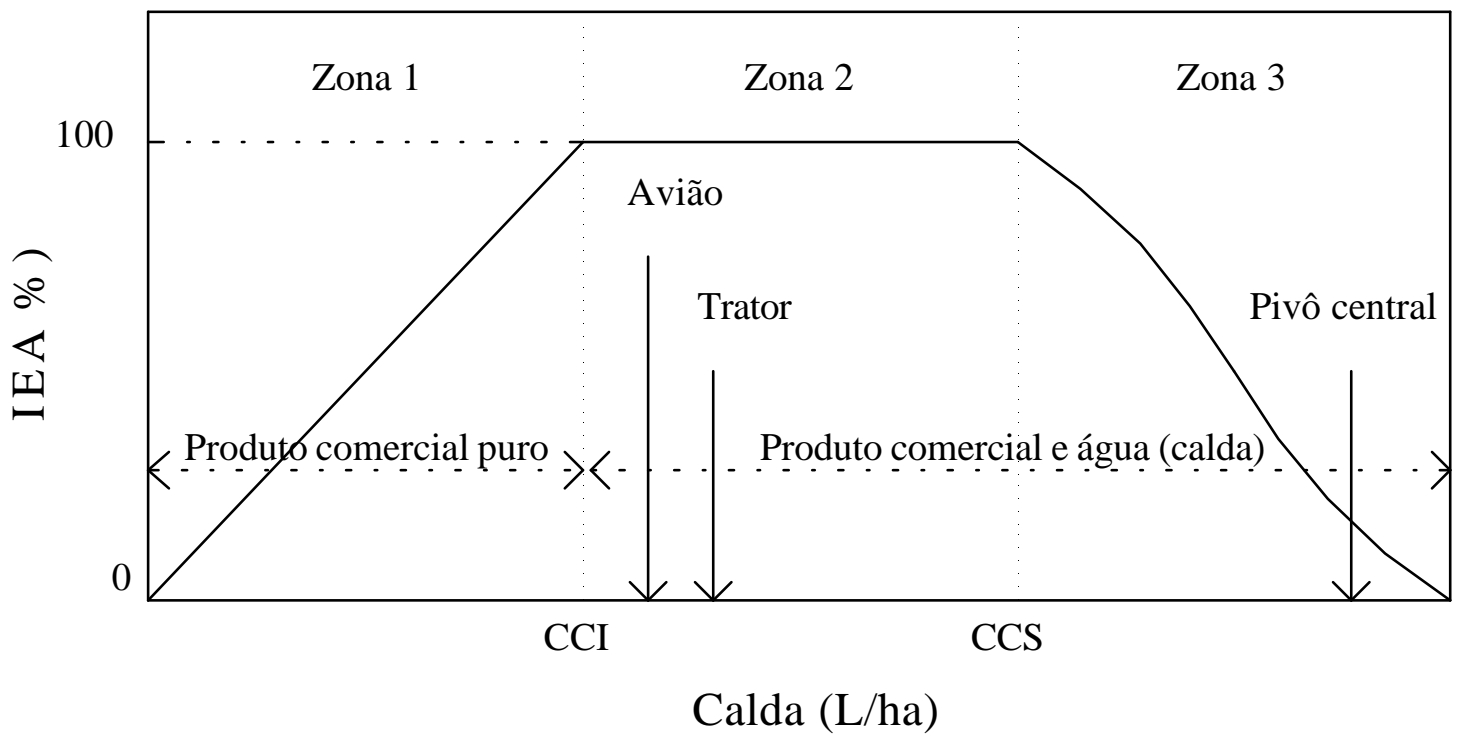

Figura 1 - Representação esquemática do índice de eficiência de aplicação (IEA\%) da calda utilizada (adaptado de Fancelli \& Dourado Neto, 2000). Calda crítica inferior (CCI) e calda crítica superior (CCS).

Desde a década de 70 , no entanto, tem-se obtido sucesso com a aplicação de produtos químicos via pivô central (Young, 1981), ficando a seguinte questão: qual seria o fator de diferenciação entre os produtos que mantinham eficácia comparável à aplicação convencional quando aplicada via pivô e os produtos que não atingiam níveis aceitáveis de controle?

Young (1980) foi o primeiro a discutir que as formulações a base de óleo, preferencialmente sem emulsificante, teriam um desempenho melhor e mais consistente. Chalfant \& Young (1981 e 1982) conduziram um ensaio testando diversos inseticidas dissolvidos ou formulados em óleo sem surfactante sobre diversas pragas e culturas (cereais e hortaliças) e, usando um simulador de pivô verificaram o efeito do volume de calda variando as lâminas aplicadas de 2,5 a $19,0 \mathrm{~mm}$ nos tratamentos testados. Concluíram que na maioria dos casos, a lâmina de água aplicada não influenciou a efetividade dos produtos. 
Stone et al. (1994) coletaram a calda quimigada em diferentes alturas em uma lavoura de milho (Figura 2) e avaliaram o teor de clorpirifós em cada nível. Os resultados (Tabela 9) mostram o efeito funil da cultura de milho, e que o grande volume de água na quimigação favorece o contato do produto com todas as partes da planta.

Cruz (1997), utilizando metodologia similar à de Stone et al. (1994), e avaliando a distribuição e a retenção de clorpirifós, produto nitidamente lipofílico (solubilidade em água igual a 1,2 ppm a $25{ }^{\circ} \mathrm{C}$ ), aplicado via pivô central no dossel da cultura do milho, concluiu que o coeficiente de distribuição de Christiansen (CUC) para o inseticida foi muito próximo do obtido para a água, e que, as concentrações inseticidas obtidas nas alturas de inserção da primeira espiga e abaixo das folhas foram, respectivamente, $58,5 \%$ e 76,0\% menores que a concentração acima do dossel, indicando que houve retenção do inseticida pela parte superior das plantas.

Tabela 9. Concentração média do inseticida $\left(\mathrm{mg} . \mathrm{L}^{-1}\right)$ e volume de água $(\mathrm{mL})$ para a distribuição nos quatro níveis na cultura (Stone et al., 1994).

\begin{tabular}{ccc}
\hline $\begin{array}{c}\text { Nível } \\
(\text { do topo })\end{array}$ & $\begin{array}{c}\text { Concentração do inseticida } \\
\left(\mathrm{mg}^{1} \mathrm{~L}^{-1}\right)\end{array}$ & $\begin{array}{c}\text { Volume de água } \\
(\mathrm{mL})\end{array}$ \\
\hline Acima da cultura & 20,2 & 22,7 \\
Terceira folha & 11,4 & 29,8 \\
Sexta folha & 9,9 & 46,6 \\
Nona folha & 7,9 & 193,3 \\
\hline
\end{tabular}

${ }^{\top}$ Teor do inseticida (mg) pelo volume de água coletado.

Hills \& Waller (1989) avaliaram a concentração de clorpirifós aplicado por quimigação nas folhas de milho em diferentes alturas e com diferentes tipos de óleos. Os resultados são mostrados na Figura 3, e observa-se, para qualquer altura do solo (mesmo na superfície), que o teor do ativo detectado por grama de material é sempre maior que na aplicação em água. Resultado semelhante foi obtido por Wauchope et al. (1991). Novamente esses resultados mostraram que há retenção de produto pelas folhas apesar do grande volume de calda aplicado. 


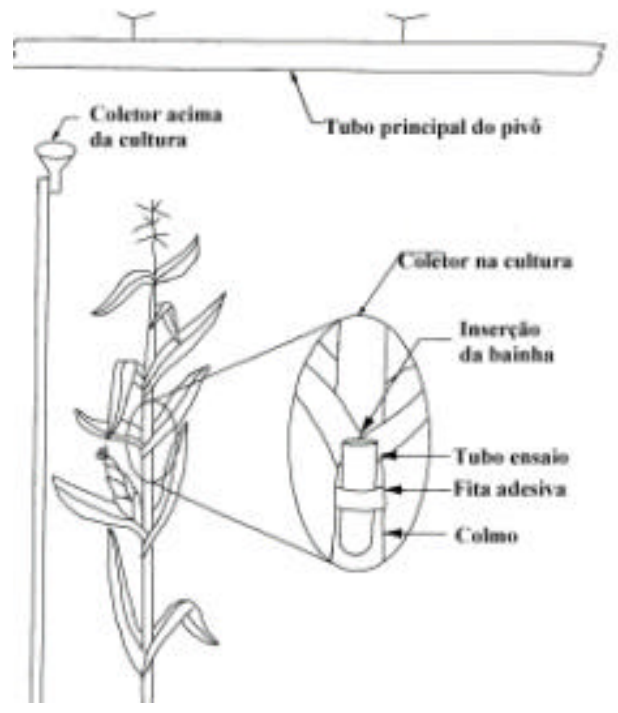

Figura 2 - Disposição dos coletores para amostragem de calda e distribuição do produto quimigado (Stone et al., 1994).

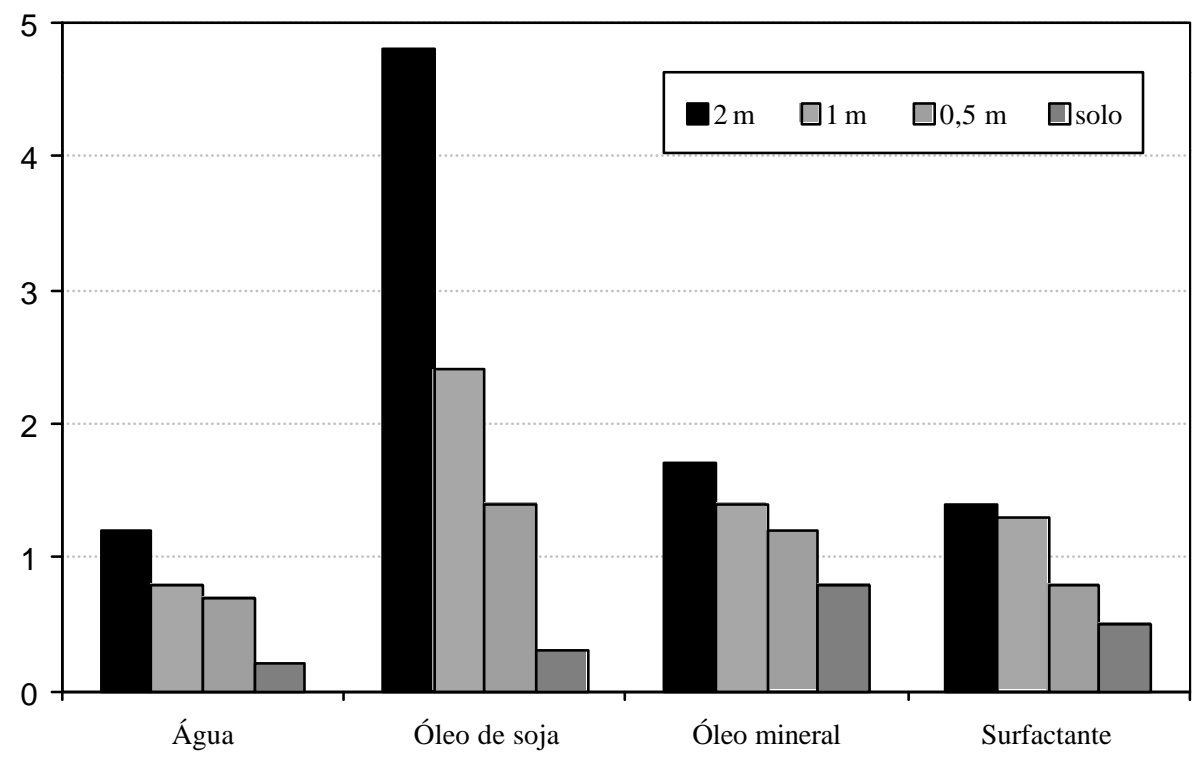

Figura 3 - Concentração média de clorpirifós ( $\mu$ g clorpirifós.g material ${ }^{-1}$ ) nas folhas de milho e na superfície do solo (adaptado de Hills \& Waller, 1989).

Como explicar a eficácia de aplicação obtida por Chalfant \& Young (1982) e Young, (1980) que mostraram a não interferência do volume de calda aplicada, e a 
retenção de ativo nas folhas verificadas por Cruz (1997), Hills \& Waller (1989) e Stansell et al. (1994), com a afirmação e o raciocínio de Dourado Neto \& Fancelli (1999 e 2000); Fancelli \& Dourado Neto (2000) e Vilela (2002) quanto ao volume de calda aplicado?

Silva et al. (1994), estudando a interceptação da água (chuva ou irrigação) na cultura de milho, concluíram que esta pode chegar a 50\% do total aplicado e sugerem que esse aspecto passe a ser considerado no planejamento e manejo dos projetos de irrigação.

Embora a cultura não tenha capacidade de retenção de um volume de calda muito grande, um volume expressivo é interceptado, resultando em uma maior superfície molhada. Como em quimigação, os produtos aplicáveis são lipofílicos e a superfície das plantas e dos insetos também, isso explicaria o porquê das eficiências alcançadas em quimigação.

Apesar do volume de calda, o ingrediente ativo alcançou o alvo na dose certa, que é a premissa de toda tecnologia de aplicação. A argumentação utilizada de que a quimigação foliar seria limitada pelo volume de calda retido pela planta, parece ser válida para água e produtos com característica hidrossolúvel, mas não para produtos lipofílicos (Wauchope et al., 1991).

Segundo Fancelli \& Dourado Neto (2000) o que ocorre é que a irrigação e a quimigação foliar têm critérios de projeto diferentes pois apresentam lâminas desejáveis distintas (Tabela 10). Esse raciocínio leva a duas possibilidades de solução para a questão: (i) hidráulica, basicamente com os sistemas de barras acopladas tipo NOTLIADA (Pereira, 2001; Vilela, 2002); AccuPulse ${ }^{\circledR}$ da Valmont; PASS (University of Georgia), e outras, que permitem aplicar volumes de calda variando de 200 a 4.000 L.ha $^{-1}$ semelhante pois a uma aplicação tratorizada; ou (ii) físico-química, trabalhandose com aquelas moléculas que apresentem por si ou através de formulações específicas, características para a formação de uma emulsão na tubulação, em suma, produtos lipofílicos. 


\subsubsection{Uso de óleos não emulsionáveis}

O primeiro trabalho comentando sobre a possibilidade de formulações a base de óleo, ou a adição de óleo às formulações serem o fator diferencial entre os produtos efetivos e não efetivos via quimigação, é de Young (1980). Young et al. (1995) apresentam uma revisão sobre o papel das formulações de pesticidas para quimigação. Iniciam comentando que as formulações devem prover a que o pesticida chegue e se fixe ao alvo desejado pelo método de aplicação desejado. Comenta ainda a deficiência no desenvolvimento de formulações específicas para aplicações em grandes volumes de água, uma vez que a lâmina mínima possível de ser aplicada pelo pivô é de 2,5 $\mathrm{mm}$ ou 25.000 L.ha ${ }^{-1}$, e que a diluição resultante para os pesticidas solúveis em água, causa um decréscimo na sua efetividade.

Tabela 10. Critérios de projeto referentes às técnicas de irrigação e quimigação (alvo folha).

\begin{tabular}{|c|c|}
\hline Técnica & Critério de projeto \\
\hline Irrigação & $\begin{array}{l}\text { A vazão do sistema de irrigação }\left(\mathrm{Q}_{\mathrm{si}}, \mathrm{m}^{3} \cdot \mathrm{h}^{-1}\right) \text { é calculada em função da máxima } \\
\text { evapotranspiração máxima }\left(\mathrm{ETm}, \mathrm{mm}^{-} \mathrm{dia}^{-1}\right) \text {, da área irrigada }(\mathrm{Ai}, \mathrm{ha}) \text { e do } \\
\text { tempo de funcionamento diário }\left(\mathrm{Tfd}, \mathrm{h}_{\mathrm{dia}}{ }^{-1}\right)(\text { Equação }(1) \text {. }\end{array}$ \\
\hline Quimigação & $\begin{array}{l}\text { A vazão de um suposto sistema de quimigação }\left(\mathrm{Q}_{\mathrm{sq}}, \mathrm{m}^{3} \cdot \mathrm{h}^{-1}\right) \text { poderia ser } \\
\text { calculada em função da área a ser "irrigada" (Ai, ha), do tempo de } \\
\text { funcionamento (Tf, h) do equipamento para aplicar uma lâmina máxima } \\
\text { equivalente ao volume máximo armazenável pela folha }\left(\mathrm{Vm}, \mathrm{L}^{-1} \mathrm{a}^{-1}\right) \text {, o qual é } \\
\left.\text { dependente do índice de área foliar }{ }^{1} \text { (IAF, } \mathrm{m}^{2} \cdot \mathrm{m}^{-2}\right) \text { e da lâmina média (Lm, } \\
\text { mm) de água sobre a folha (valor dependente da arquitetura da planta e } \\
\text { natureza da folha) (Equação (2). }\end{array}$ \\
\hline
\end{tabular}

1 IAF: índice d área foliar (relação entre a área das folhas da cultura pela área de solo que a cultura explora). Extraído de Fancelli \& Dourado Neto (2000).

$$
\begin{gathered}
Q_{s i}=\frac{10 \cdot E T m \cdot A i}{T f d} \\
Q_{s q}=\frac{10 . I A F \cdot L m \cdot A i}{T f}
\end{gathered}
$$

Os pesticidas podem efetivamente ser quimigados quando: (i) injeta-se uma suspensão de uma formulação tipo concentrado emulsionável (CE) em água, (ii) 
suspende-se uma formulação $\mathrm{CE}$ em um pequeno volume de água, o qual é injetado ou sifonado no sistema, (iii) injeta-se o pesticida puro (na sua formulação original), e (iv) dilui-se a formulação $\mathrm{CE}$ pura ou suspende-se o produto técnico em um óleo, sem a adição de um surfactante, que é injetado no sistema. A melhor formulação seria o ingrediente ativo diluído ou suspenso em óleo sem surfactante, porém, a maioria dos métodos propostos não utiliza formulações especialmente desenvolvidas para esse fim. De fato, trabalhou-se com alternativas que procuraram viabilizar a técnica com as formulações existentes. O que se busca é que o produto, ou sua calda (óleo ou água), ao ser injetado, forme uma emulsão na tubulação principal do sistema de irrigação.

Dowler (1995), Johnson et al. (1986), Young (1986), já comentaram a necessidade do desenvolvimento de formulações específicas. As formulações nestes trabalhos foram injetadas por pressão positiva, no meio do tubo principal do pivô variando a sua orientação em função das condições específicas de aplicação como o tipo de produto (foliar com óleo, solúvel em água, e.g.) e o desenho hidráulico do pivô, conforme estudos feitos por Groselle et al. (1986) e Reese (1986).

\subsubsection{Formação de emulsões}

Produzir uma emulsão é misturar duas fases pouco ou não solúveis entre si. Há várias maneiras de se produzi-la, porém, a mais usual é aplicando energia mecânica (Walstra, 1983). Primeiro, a interface entre as fases é deformada em tal extensão que gotas são formadas (Figura 4). Essas gotas ainda muito grandes, são posteriormente quebradas ou rompidas em tamanhos menores. O fracionamento das gotas é uma fase crítica no processo de formação de emulsões. 


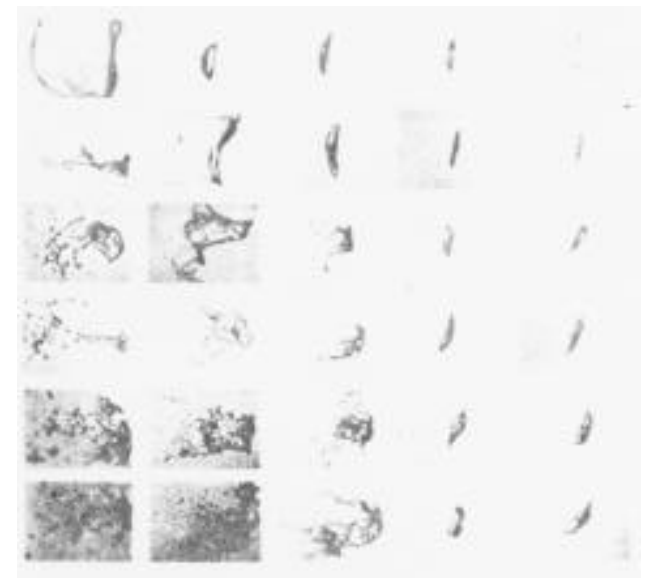

Figura 4 - Processo de ruptura e formação de gotas (Hinze, 1955).

A deformação das gotas é oposta pela pressão de Laplace (Walstra, 1983). A pressão no lado côncavo de uma interface curva com tensão superficial ã é maior que aquela do lado convexo numa ordem de grandeza expressa pela Equação (3):

$$
\Delta p=\gamma\left(\frac{1}{R_{1}}+\frac{1}{R_{2}}\right)=\frac{2 \gamma}{R}
$$

em que $\mathrm{R}_{1}$ e $\mathrm{R}_{2}$ são os raios principais da curvatura. Para uma gota esférica de raio $r$ a equação se torna $2 \tilde{a} . .^{1}$, e qualquer deformação da gota leva a um aumento na diferença de pressão (Äp). Para romper essa gota, uma pressão externa de tal magnitude, aplicada numa distância $r$, faz-se necessária, que significa um gradiente de pressão da ordem de 2ã. $\mathrm{r}^{-2}$. Esse gradiente de pressão é geralmente suprido por meio de agitação mecânica. Quanto menor o tamanho da gota a ser formada maior será a agitação necessária. Walstra (1983) nos mostra esquematicamente como ocorre a ruptura ao nível de superfície da gota (Figura 5) 


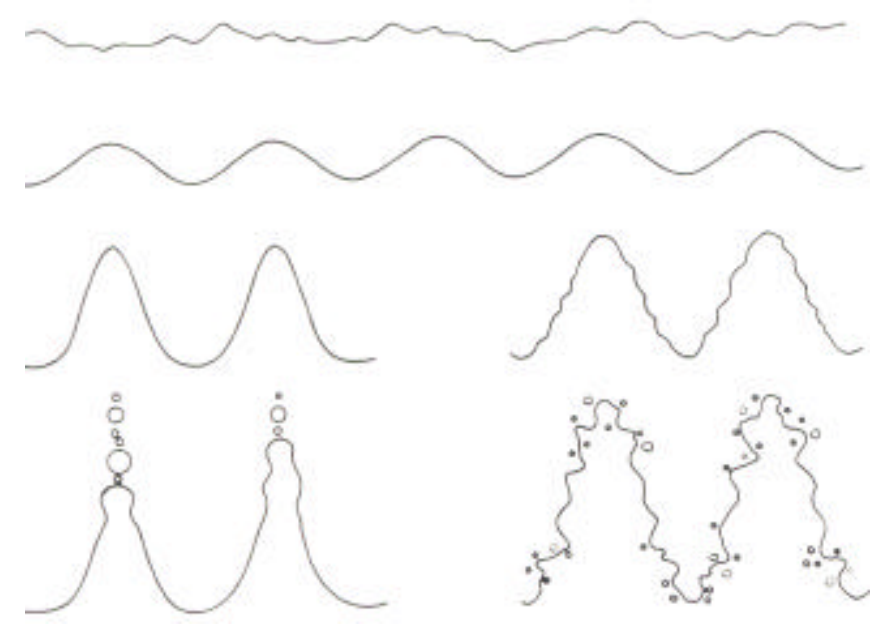

Figura 5 - Processo de ruptura da interface da gota (Walstra, 1983). Do início do processo na parte superior até a ruptura em baixo.

Quando se adiciona um surfactante a uma determinada mistura, ele diminui a energia necessária para a formação da emulsão, daí a ser chamado de emulsificante. Os surfactantes reduzem ã (e.g. de 40 para $5 \mathrm{mN} \cdot \mathrm{m}^{-1}$ ), e conseqüentemente a pressão de Laplace, facilitando a deformação e ruptura. É múltiplo e complicado o papel do surfactante, mas essencial. Para ser ativo, ele precisa ser transportado até a interface onde é adsorvido formando uma película. Esse transporte também é acelerado pela agitação intensa. Uma grande interface é então formada, e a fase contendo o surfactante é rapidamente exaurida durante o processo de emulsificação.

Uma outra etapa crítica, é que as gotas podem coalescer logo após serem formadas. O mecanismo de coalescência e o complexo sistema de formação de emulsões ainda não são bem conhecidos, de modo que não é possível prever com precisão a sua ocorrência e de que modo (Walstra, 1983). O surfactante é de suprema importância, pois determina qual será a fase contínua, comumente aquela na qual ele é solúvel (Lei de Bancroft). A taxa de coalescência das gotas da fase dispersa é variável e depende de muitos fatores, mas principalmente da natureza e concentração do surfactante. As gotas podem também flocular durante a emulsificação, mas os flóculos são em sua maioria rompidos novamente em um curto espaço de tempo. 
Sleicher (1962) afirma que a coalescência numa área turbulenta pode ser desconsiderada se a fase dispersa representar menos que $0,5 \%$ em volume da fase contínua. Collins \& Knudsen (1970), no entanto, não observaram o fenômeno da coalescência numa tubulação com fluxo em regime turbulento para concentrações da fase dispersa acima de $10 \%$ em volume, com número de Reynolds variando entre 90.000 e 130.000 .

\subsubsection{Uso de emulsões na agricultura}

Becher (1985) comenta que é crescente o uso de pesticidas e outros produtos na moderna agricultura, os quais, na grande maioria, são utilizados em baixa dosagem (por unidade de área), necessitando de um veículo para serem distribuídos uniformemente nas lavouras.

A tecnologia de formulações tem por objetivo facilitar a aplicação uniforme. Para tal é imprescindível proporcionar uma adequada solubilização, suspensão ou emulsão do ingrediente ativo no veículo em função do método de aplicação que se deseje utilizar. As formulações podem ser de vários tipos (Tabela 11), porém a maioria envolve a formação e(ou) a estabilização de emulsões. A mais comum é a do tipo concentrado emulsionável (CE).

A formulação tipo concentrado emulsionável é definida como sendo "uma solução não aquosa de um emulsificante num pesticida, dissolvido em um solvente, se necessário, que, quando adicionado a um volume maior de água, forma uma emulsão estável de óleo em água com pouca ou nenhuma agitação mecânica” (Becher, 1985).

A função do surfactante (emulsificante) na formulação é permitir que a fase dispersa se una à fase contínua de modo estável, o que é possível porque a maioria dos surfactantes apresenta um pólo hidrofóbico e outro hidrofílico.

Quando se adiciona óleo sem surfactante, como por exemplo o óleo de soja culinário, a uma formulação $\mathrm{CE}$, dilui-se o surfactante existente na formulação em uma quantidade muito maior de óleo. Desse modo, o surfactante presente não será suficiente para estabilizar a emulsão, principalmente se considerar que o produto estará sendo emulsificado em 40.000 L (4 mm) de água no caso de quimigação, ao invés de $2000 \mathrm{~L}$, 
volume máximo de calda em uma aplicação tratorizada, e para a qual a formulação é geralmente preparada.

Tabela 11. Tipos de formulações de uso agrícola (Becher, 1985).

\begin{tabular}{ll}
\hline Tipo de formulação & \multicolumn{1}{c}{ Aplicação } \\
\hline Grânulos & Aplicado seco (veículo sólido) \\
Pó hidrossolúvel & Ativo hidrossolúvel \\
Solução aquosa concentrada & Ativo hidrossolúvel \\
Pó molhável & Pó dispersível em água \\
Grânulos dispersíveis em água & "Pellet" dispersível em água \\
Suspensão ("flowable") & Suspensão de sólidos em líquidos \\
Concentrado emulsionável & Solução espontaneamente emulsionável \\
Suspensão microencapsulada & Suspensão revestida por polímeros \\
Microemulsão & Usada em mistura de produtos \\
Emulsão & Mistura de líquidos imiscíveis \\
Emulsão em suspensão & Mistura de líquidos e sólidos \\
Emulsão invertida & Pulverização de baixa deriva. \\
\hline
\end{tabular}

Young et al. (1995), revendo o papel das formulações em quimigação, concluíram que quanto menor a característica de formulação sólida (pó molhável, grânulos, ou suspensões), melhor o desempenho em quimigação. Isso significa que a formulação constituída do ingrediente ativo solubilizado em óleo (sem surfactante), seria a ideal, seguida pelo concentrado emulsionável (CE) dissolvido em óleo (sem surfactante), concentrado emulsionável, emulsão concentrada (EC), suspensão ou solução concentrada (SC), pós molháveis (PM), e por último as formulações granuladas (WG, GD). As formulações cujo solvente é a água (solução aquosa e.g.) não seriam adequadas, pois isso seria um indicativo que o produto em questão é hidrossolúvel e portanto não adequado a quimigação.

Pelo que foi visto e apresentado, fica evidente que o que se deseja na quimigação é a formação de uma emulsão óleo em água na tubulação do sistema de irrigação. No entanto, como o movimento da água na mesma tem regime turbulento, não há a necessidade do surfactante (Silveira et al.,1987) que, como já foi dito, teria a função de reduzir a necessidade de agitação, para a formação da emulsão. 


\subsubsection{Propriedades dos óleos}

Ao se dissolver um ingrediente ativo ou uma formulação tipo CE em óleo, sem a adição de um surfactante, é preciso deinir o óleo a ser utilizado. As formulações industriais geralmente utilizam óleos minerais por serem de menor custo (Becher, 1985). Porém, a definição de uma solução utilizável pelo agricultor é dependente da disponibilidade, a baixo custo, de um óleo sem surfactante em sua composição. No Brasil, a resposta é rápida: óleo de soja (culinário), que contudo apresenta um custo relativamente alto se comparado aos óleos de uso agrícola existentes (que contém emulsificantes).

Um modo de se baratear esse custo seria o uso, no lugar do óleo refinado de cozinha, de óleos degomados (Viana \& Costa, 1994), também chamados de bruto ou de primeira extração. Óleo degomado é aquele obtido na primeira etapa do processo de extração, do qual ainda não se retiraram os demais subprodutos, como por exemplo a lecitina e o beta-caroteno no caso da soja.

Nesse universo de óleos disponíveis, temos que lembrar em consideração suas propriedades físico-químicas distintas, como densidade, viscosidade e tensão superficial principalmente, as quais estão sujeitas a influência das condições do meio, como temperatura e o cisalhamento, que é função da velocidade do fluido.

Essas interações foram estudadas por Cochran et al. (1987) que concluíram que: (i) viscosidade diminui com o aumento da temperatura (Figura 6), (ii) viscosidade diminui com o aumento do índice de cisalhamento, (iii) tensão superficial diminui com o aumento da temperatura(Figura 7), (iv) densidade diminui com o aumento da temperatura, e (v) aumentar a concentração do inseticida diminui o efeito da temperatura sobre a viscosidade (Figura 8). 


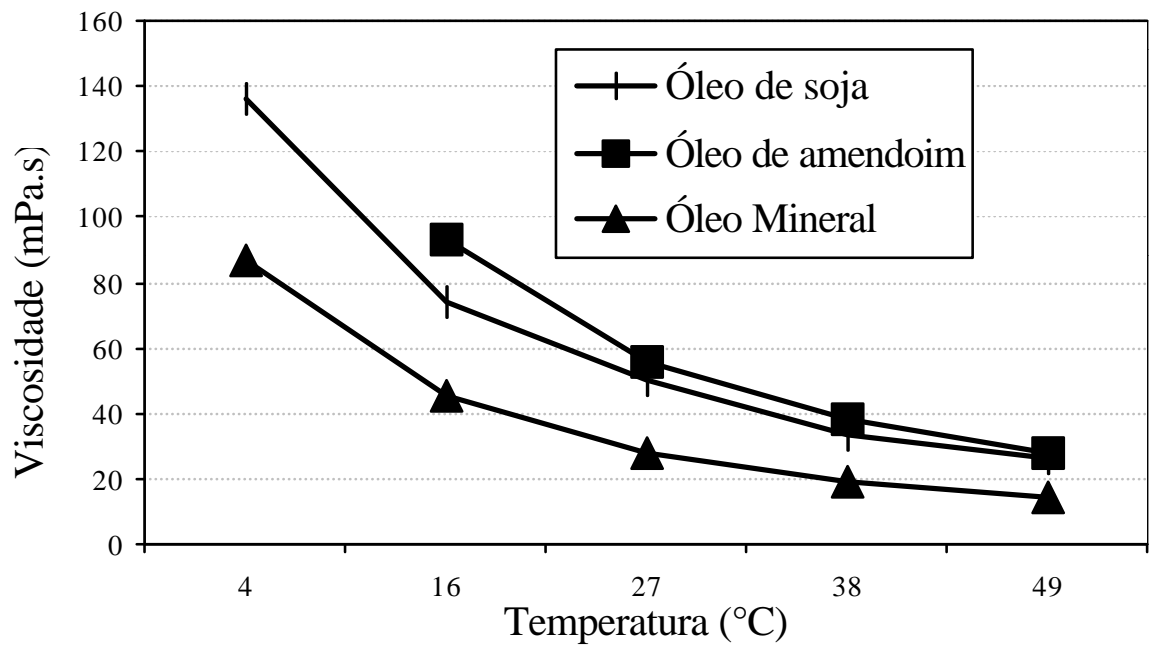

Figura 6 - Influência da temperatura na viscosidade de diferentes tipos de óleos (Cochran et al., 1987).

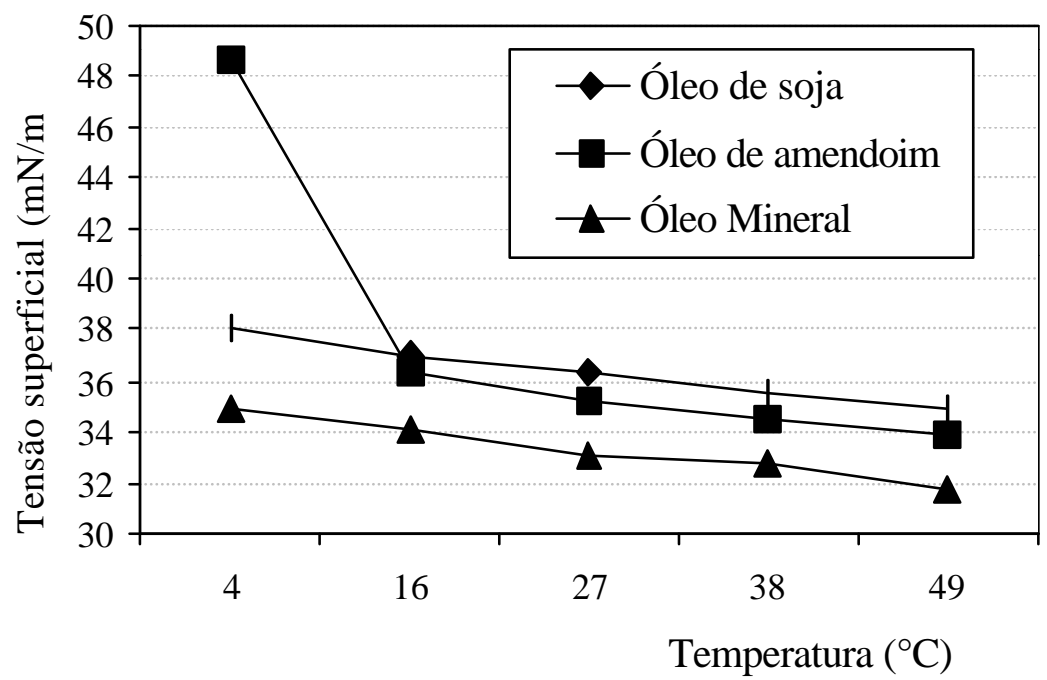

Figura 7 - Influência da temperatura na tensão superficial de diferentes tipos de óleos (Cochran et al., 1987).

Há porém vários outros aspectos que ainda necessitam de estudo, como por exemplo se o desempenho dos diferentes tipos de óleo variam em função do ingrediente 
ativo utilizado. Hills \& Waller (1989) observaram que o tipo de óleo influenciava a quantidade de clorpirifós retido pelas folhas (Figura 3).

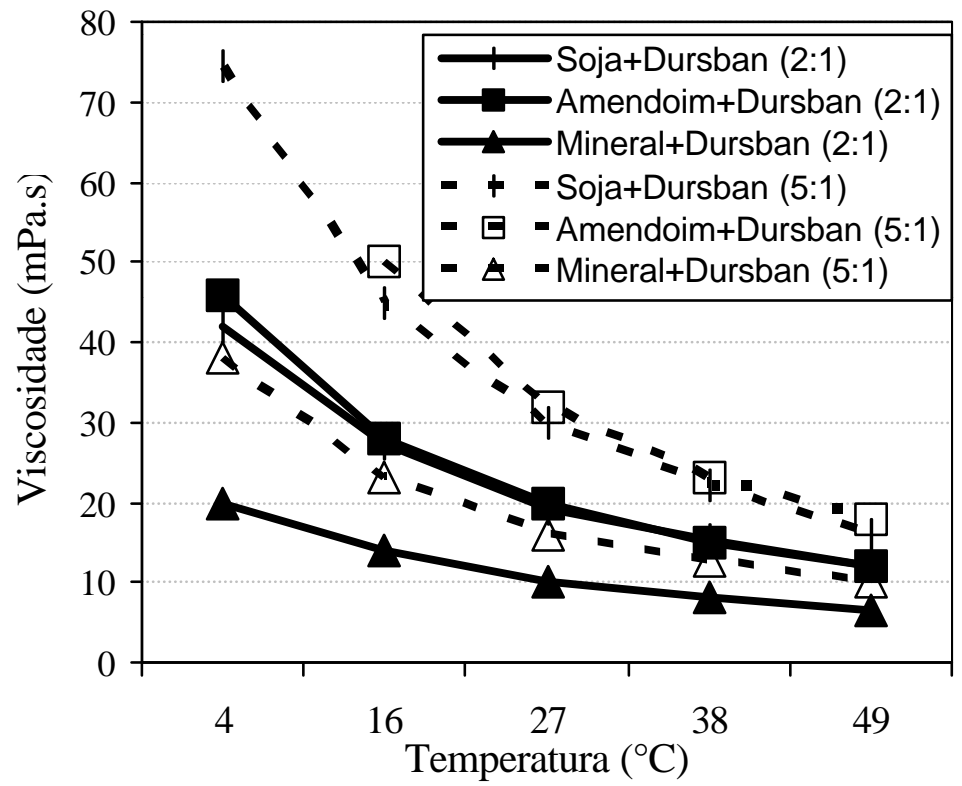

Dursban*, marca registrada da DowElanco Ind. Ltda.- Indianapolis/IN, consiste de uma formulação onde o ingrediente ativo é dissolvido em óleo, sem adição de nenhum outro produto.

Figura 8 - Influência da concentração do inseticida e da temperatura na viscosidade de diferentes tipos de óleos (Cochran et al., 1987).

\subsubsection{Uniformidade da distribuição dos produtos em quimigação}

A quimigação apresenta uma uniformidade de aplicação similar ou superior a da aplicação convencional tratorizada ou aérea (Threadgill, 1985). Essa uniformidade depende de alguns fatores, dentre os quais o principal é a uniformidade de distribuição de água. A uniformidade de distribuição de produtos na quimigação está diretamente relacionada com a uniformidade de distribuição de água.

Porém, ter uma boa distribuição de água não significa uma boa distribuição de produto (Dowler et al.,1982). Um fator determinante é o tamanho da gota de óleo formada no ponto de injeção, que depende: (i) da velocidade da água no ponto de injeção, (ii) da direção do ponto de injeção, e (iii) das características dos emissores quanto ao seu tipo e o diâmetro do bocal. O tamanho da gota formada é que conferirá 
estabilidade à emulsão ao longo da linha lateral. A quantidade e uniformidade do produto retido no dossel (Sumner et al.,1992), é também influenciado pelo tamanho das gotas de óleo-pesticida que chega às plantas e é provavelmente o fator mais importante a ser controlado (Reese, 1986; Sumner et al., 1991). A Figura 9 ilustra da distribuição e tamanho de gotas na tubulação de uma emulsão óleo em água.

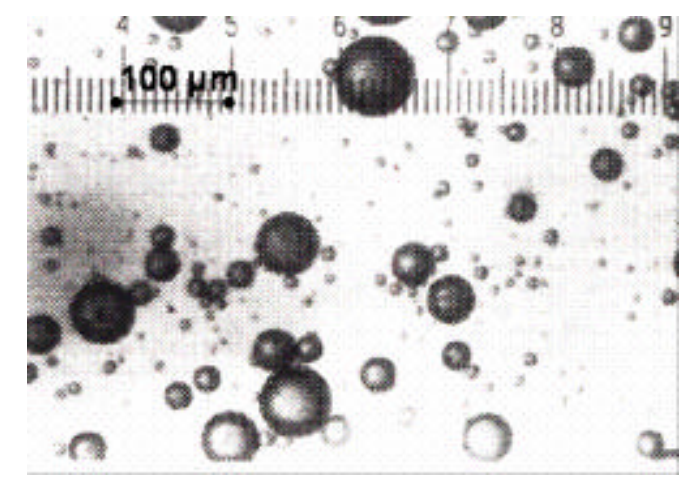

Figura 9 - Distribuição e tamanho de gotas em uma emulsão óleo em água (Groselle et al., 1986).

Karabelas (1978) afirma que para um fluxo horizontal contínuo, a diferença de densidade entre a fase dispersa e a fase contínua pode causar uma distribuição não uniforme, sugerindo haver um movimento das gotas ou partículas da fase dispersa para cima (flutuabilidade) ou para baixo (sedimentação ou decantação). Reese (1986) e Reese \& Loudon (1986) estudaram e modelaram o movimento de gotas ou partículas esféricas num fluído, e as principais conclusões obtidas pelos autores são: (i) as gotas injetadas devem ter um diâmetro menor que $500 \mu \mathrm{m}$ para uma boa distribuição, (ii) partículas com diâmetro inferior a $100 \mu \mathrm{m}$ são desejáveis para uma boa distribuição, e (iii) a razão entre as densidades das duas fases deve ser a mais próxima da unidade possível para que se possa esperar uma boa distribuição, especialmente com gotas grandes. A variação deverá ser inferior a $1 \%$.

Quando a gota formada no ponto de injeção tem um diâmetro superior a $415 \mu \mathrm{m}$, e como a densidade da maioria dos óleos é menor que a da água, as gotas tendem a formar um sobrenadante no início da linha lateral, fazendo com que a distribuição pelos 
emissores seja maior no início da tubulação comprometendo a uniformidade de distribuição. Waller (1992), Waller \& Hills (1995) e Waller et al. (1995 a, b), tomando por base os estudos feitos por Karabelas (1978), Reese (1986) e Groselle (1986), estudaram e modelaram esse movimento que é constituído de duas partes. A primeira descreve pelo método euleriano o movimento da gota em direção à superfície (Figura 10), e a segunda descreve pelo método de Lagrange, o movimento de cada gota individualmente na sua trajetória de um turbilhão a outro dentro da tubulação até que atinja a superfície (Figura 11). O modelo proposto pelos autores conseguiu compatibilizar os dois métodos e assim descrever o movimento como um todo.

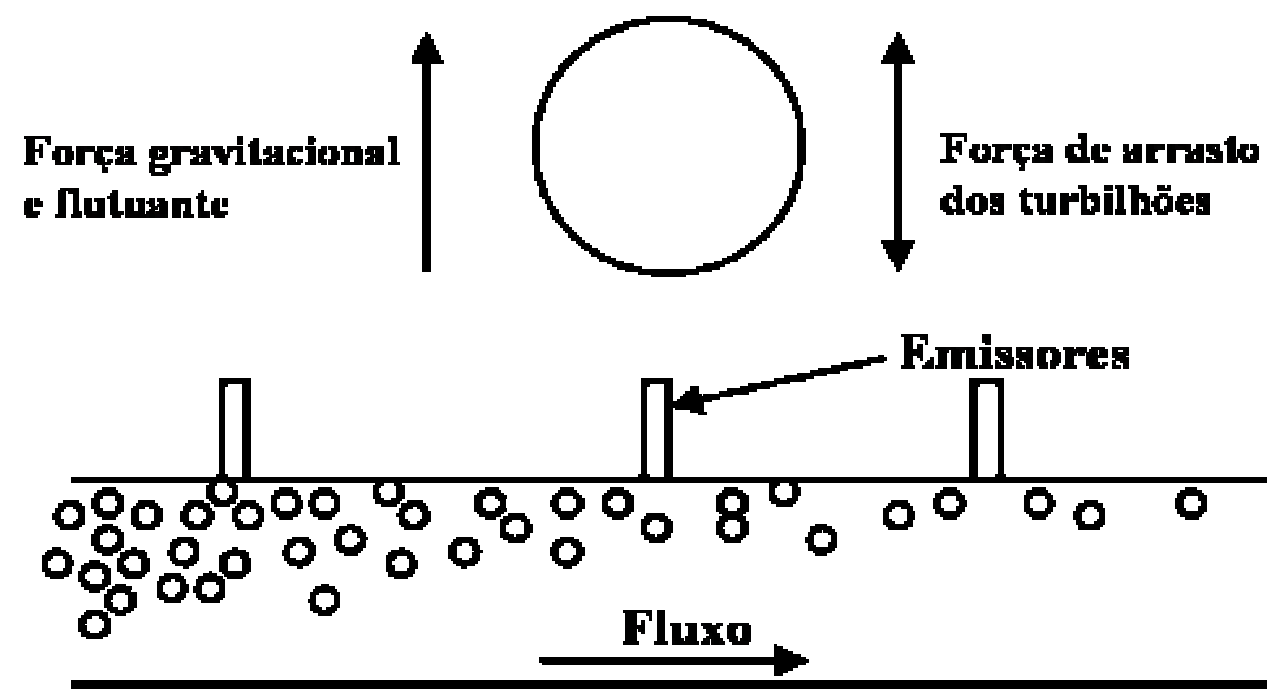

Figura 10 - Esquema do movimento ascendente das gotas grandes de óleo dentro da tubulação (Waller \& Hills, 1995).

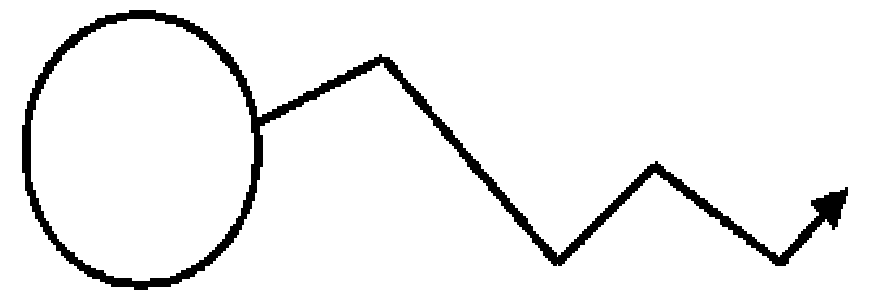

Método Lagrange: segua a gota individual ao longo da tubulaçāo.

Figura 11 - Simulação do movimento de cada gota pela turbulência do fluxo (Waller \& Hills, 1995). 


\subsubsection{Velocidade da água no ponto de injeção}

A velocidade $(V)$ da água é função direta da vazão $(\mathrm{Q})$ do sistema e do inverso da área (A) da tubulação, e é expressa pela equação (4) (Bernardo, 1982):

$$
V\left(m \cdot s^{-1}\right)=\frac{Q\left(m^{3} \cdot s^{-1}\right)}{A\left(m^{2}\right)}=\frac{4 Q\left(m^{3} \cdot s^{-1}\right)}{\pi D^{2}\left(m^{2}\right)}
$$

A velocidade numa tubulação lateral de um sistema tipo pivô decresce do centro até o final do mesmo, reduzindo o potencial de mistura dos produtos químicos dispersos. A impossibilidade prática de se fazer uma tubulação cônica é que causa esse efeito. Tubos cilíndricos com reduções periódicas no seu diâmetro causam variações na velocidade nesses pontos de redução, bem com o espessamento da camada de água junto à tubulação que tem regime de escoamento laminar. Esses aspectos poderiam diminuir a capacidade de agitação e manutenção da emulsão ao longo da linha. Contudo, Fischbach (1982) determinou que esse efeito é desprezível se produtos hidrossolúveis, como os fertilizantes, são injetados. Outros estudos contudo, sugerem que a uniformidade de distribuição mesmo para produtos hidrossolúveis pode divergir da uniformidade de distribuição da água (Dowler et al., 1982).

Sumner et al. (1991) e Sumner \& Cochran (1988) estudando a formação de gotas de óleo-pesticida na tubulação com o auxílio de um simulador, concluíram que (i) o diâmetro volumétrico mediano (DVM) das gotas formadas diminuía a medida em que a velocidade do fluxo de água aumentava, (ii) o volume de gotas menores que $204 \mu \mathrm{m}$ aumentava a medida em que as gotas maiores que $415 \mu \mathrm{m}$ diminuíam com o aumento na velocidade e, (iii) a distribuição de gotas na tubulação principal com a velocidade de fluxo menor que $2 \mathrm{~m} . \mathrm{s}^{-1}$, continha um percentual elevado de gotas com DVM maior que $415 \mu \mathrm{m}$, o que deve ser evitado para evitar a flutuabilidade e coalescência das gotas (Reese, 1986).

Marouelli (1996), Marouelli \& Waller (1997a,b) e Marouelli \& Waller (1999 a,b) estudaram um dispositivo de injeção de produtos, que permitia a formação de um espectro gotas adequado àquele recomendado por outros autores (Groselle et al, 1986; Reese, 1986; Sumner et al.,1991; Sumner \& Cochran, 1988), qual seja com DMV menor 
que $200 \mu \mathrm{m}$, dessa forma conseguiram controlar o DVM para que se mantivesse da faixa considerada ótima.

Hills \& Waller (1989), avaliando a distribuição de clorpirifós em diferentes alturas do dossel de milho e ao longo da linha lateral, obtiveram, para o produto dissolvido em óleo de soja, uma distribuição muito maior no início da tubulação que ao final da mesma e com picos em determinados intervalos. Os autores levantaram a hipótese da formação do sobrenadante para explicar o fato, hipótese essa que foi confirmada pelos mesmos autores em trabalho posterior, uma vez que a velocidade no ponto de injeção do pivô era de apenas 1,01 m.s ${ }^{-1}$ no trabalho feito em 1989.

\subsubsection{Direção do ponto de injeção}

Outro ponto fundamental na determinação do tamanho de gota na emulsão formada dentro da tubulação é a posição do ponto de injeção. Um dos primeiros trabalhos a focar o assunto foi Groselle et al. (1986). Os autores mediram a distribuição do tamanho das gotas formadas: (i) no ponto de injeção variando a sua posição (Figura 12), (ii) na saída dos emissores, e (iii) com diferentes frequiências de pulso da bomba injetora-dosadora.

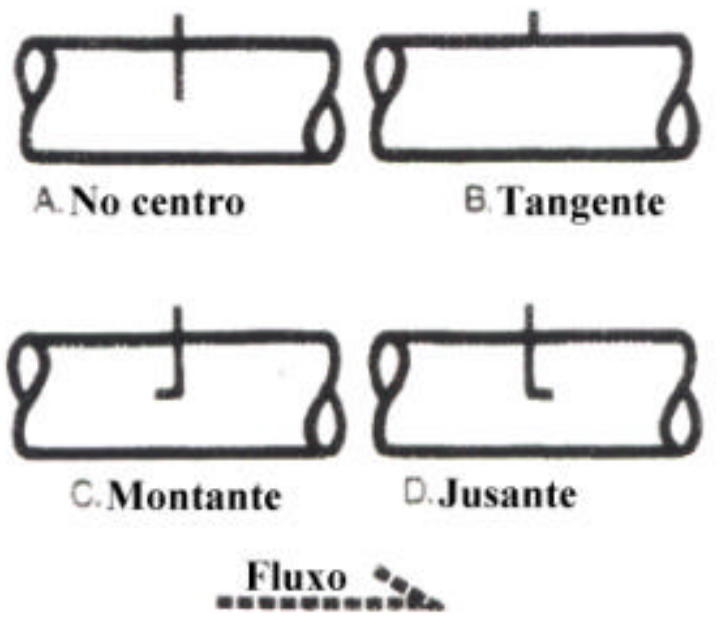

Figura 12 - Posição do ponto de injeção no interior da tubulação.

Na Tabela 12 verifica-se a influência da frequiência de pulso da bomba injetoradosadora. $\mathrm{O}$ diâmetro médio das gotas pode ser observado na Tabela 13. 
Tabela 12. Variação no tamanho das gotas em função da frequiência de pulsos da bomba injetora-dosadora.

\begin{tabular}{ccc}
\hline Freqüência.min $^{-1}$ & Tubulação principal $(\mu \mathrm{m})$ & Emissores $(\mu \mathrm{m})$ \\
\hline 1.725 & $53,5 \mathrm{a}^{(1)}$ & $16,1 \mathrm{a}$ \\
400 & $47,9 \mathrm{~b}$ & $16,8 \mathrm{a}$ \\
72 & $54,7 \mathrm{a}$ & $16,5 \mathrm{a}$ \\
\hline
\end{tabular}

${ }^{(1)}$ Médias seguidas da mesma letra na coluna não diferem estatisticamente entre si pelo teste de Duncan ao nível de $95 \%$ de significância.

Os dados apresentados, corroboram os obtidos por Reese (1986) e Reese \& Loudon (1986), uma vez que o tamanho de gotas situa-se dentro da faixa de ótima obtida por aqueles autores (com tamanho inferior a $100 \mu \mathrm{m}$ ). Groselle et al. (1986) mostraram que o DMV das gotas no ponto de injeção está próximo de $50 \mu \mathrm{m}$, enquanto que no emissor fica próximo a $19 \mu \mathrm{m}$. A diferença de tamanho deveu-se a alta velocidade da água no emissor $\left(26,3 \mathrm{~m} . \mathrm{s}^{-1}\right.$, contra $2,96 \mathrm{~m} . \mathrm{s}^{-1}$ no ponto de injeção) e a força de cisalhamento. $\mathrm{O}$ autor conclui que a posição do ponto de injeção e a velocidade do fluxo são fatores fundamentais para assegurar a formação de gotas no tamanho adequado para garantir uma boa emulsão e, conseqüente, boa uniformidade de distribuição.

Tabela 13. Tamanho médio de gotas em função da posição do ponto de injeção no interior da tubulação.

\begin{tabular}{ccc}
\hline Posição do ponto de injeção & Tubulação principal $(\mu \mathrm{m})$ & Emissores $(\mu \mathrm{m})$ \\
\hline Centro - jusante & $56,2 \mathrm{a}^{(1)}$ & $15,8 \mathrm{a}$ \\
Centro - montante & $49,3 \mathrm{~b}$ & $15,9 \mathrm{a}$ \\
Tangente & $57,2 \mathrm{a}$ & $16,4 \mathrm{a}$ \\
Centro & $47,7 \mathrm{~b}$ & $15,9 \mathrm{a}$ \\
\hline
\end{tabular}

(1) Médias seguidas da mesma letra na coluna não diferem estatisticamente entre si pelo teste de Duncan ao nível de 95\% de significância.

Sumner et al. (1991a) também concluíram que a posição do ponto de injeção no centro a montante produziu melhores resultados quando comparado com o centro a jusante, devido provavelmente a geração de gotas menores. Essa diferença poderia ser contornada segundo os autores mediante o aumento na velocidade da água na tubulação principal. 


\subsubsection{Características dos emissores}

Groselle et al. (1986), embora não tenham trabalhado com diferentes tipos de emissores, alertam para a possibilidade de poder haver diferença no diâmetro da gota formada em função do tipo e do diâmetro do bocal dos mesmos. Sumner et al. (1988) afirmam que é preciso optar corretamente pelo emissor, associado à correta velocidade da água, para garantir uma uniformidade de aplicação consistente e efetiva. Concluíram que é imprescindível entender a relação entre a distribuição do DMV da água e a uniformidade de aplicação do produto.

Bushman et al. (1985) obtiveram resultado melhor no controle da broca do colmo utilizando aspersores de impacto quando comparado a defletores de baixa pressão. Atribuíram o fato a uma maior interceptação da água pela cultura no caso dos defletores associado a uma maior lâmina aplicada em função do tempo. Parece, no entanto, em função de trabalhos posteriores, que a causa está associada à velocidade da fase contínua no emissor e o fracionamento maior da gota de óleo no emissor de alta pressão. Cochran et al. (1985), usando um simulador de pivô semelhante ao utilizado por Groselle (1986) e analisando o efeito de diferentes diâmetros de bocais a diferentes pressões (mantendo a posição do ponto de injeção constante), concluíram que aumentar o diâmetro do bocal permite a passagem de gotas de óleo maiores. Entretanto, após um determinado diâmetro de bocal, a crescente pressão de cisalhamento supera o efeito do aumento do diâmetro, e o tamanho da gota de óleo diminui.

Koo (1990) e Koo et al. (1992a,b e 1993), trabalhando com diferentes tipos de emissores e diferentes concentrações e medindo o tamanho de gota produzido em um simulador de pivô, obtiveram o resultado que pode ser visualizado na Figura 13. Os autores concluíram que o diâmetro do bocal não influi, uma vez que o coeficiente de descarga é função do diâmetro e da velocidade da água. Porém, houve efeito significativo quanto ao tipo de emissor. Entretanto todos os resultados mostram um perfil de distribuição de gotas concentrada em uma faixa menor que $20 \mu \mathrm{m}$, o que é a faixa desejável. 


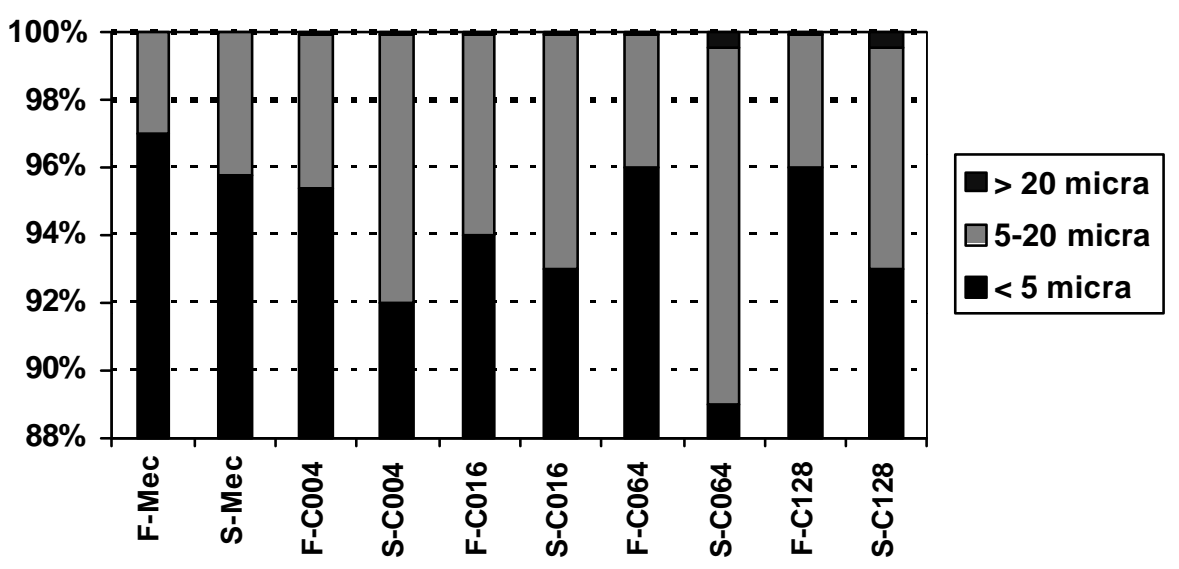

Figura 13 - Efeito do tipo de emissor e concentração da emulsão na distribuição relativa do espectro de gotas. (C004, C016, C064 e C128 indicam emulsificação química para a relação óleo/CE de 25,7, 132,3, 655,7, e 1999,0 respectivamente; e Mec indica emulsificação mecânica. Os prefixos, ' $F$ ' e ' $S$ ' indicam a descarga de bicos planos (Unijet ${ }^{\circledR}$ TP11010) e bico com câmara de turbilhonamento (Whirljet $\left.{ }^{\circledR} 1 / 4 \mathrm{~B} 5-5 \mathrm{~W}\right)$, respectivamente).

Sumner et al. (1991b) concluíram que as gotas grandes de óleo-inseticida geradas na tubulação principal, a baixas velocidades, são fracionadas em gotas menores quando passam pelo emissor (isso se deve ao fato de que a velocidade da água na câmara do bocal é muitas vezes superior à velocidade na tubulação). Desse modo, o efeito do emissor supera o efeito da velocidade na tubulação principal na partição das gotas. Esse efeito, porém, é mais efetivo para gotas grandes que para gotas menores. Cabe salientar que a gota para chegar uniformemente a todos os emissores da linha lateral precisa ter um tamanho tal que não permita a formação de sobrenadante na tubulação.

\subsubsection{Inseticidas}

As primeiras aplicações de inseticidas na água de irrigação foram feitas no início da década de 60 segundo Palmer $(1964)^{2}$ citado por Viana (1994).

\footnotetext{
${ }^{2}$ PALMER, R.E. How to apply everything with a sprinkler. Agrichemical West, v.5, p.7-8, 1964.
} 
Young et al. (1984), revisaram as vantagens e desvantagens do uso da insetigação, assim como sua segurança (Young \& Chalfant, 1985). Excelente controle de insetos foliares foi obtido quando o inseticida foi injetado em gotas de 50 ì m de óleo, em lâminas de irrigação variando de 2,54 a 12 mm (Young et al., 1984). Raun (1981 e 1984) mostrou que quando formulações do tipo CE ou SC ("flowable") eram injetadas diretamente ou pré-diluídas em água, necessitava-se de menores lâminas de irrigação para alcançar uma boa eficácia (menor que 7,62 mm). Sumarizando estudos com lagarta da espiga (Helicoverpa zea) e lagarta do cartucho (Spodoptera frugiperda), Young et al. (1984) e Young (1986) obtiveram excelentes resultados utilizando lâminas de irrigação de até 2,54 mm, para inseticidas formulados em óleo ou diluídos em óleo sem a adição de surfactantes. Esses dados também mostraram que as formulações em óleo devem ser injetadas a jusante na tubulação do pivô com a velocidade de fluxo nesse ponto maior que $2 \mathrm{~m} \cdot \mathrm{s}^{-1}$. Esses dados são corroborados por Chandler \& Sumner (1991), que obtiveram melhores controles inseticidas quando a formulação $\mathrm{CE}$ foi diluída em óleo (sem surfactante), injetada no meio do tubo do pivô, a jusante, com velocidade de água nesse ponto de $2,1 \mathrm{~m} \cdot \mathrm{s}^{-1}$.

Viana \& Costa (1994) afirmam não terem observado diferença na eficiência de clorpirifós com e sem óleo de soja bruto (sem surfactante). No entanto a tabela apresentada no referido trabalho mostra diferença significativa a favor do tratamento sem a mistura. Nesse trabalho, porém, utilizou-se a dose comercial do produto, quando o recomendado em experimento que vise comparar métodos ou adjuvantes (e.g.), é a utilização de uma dose discriminatória (o mais comum seria utilizar a metade da dose comercial). Outro aspecto a considerar é a proporção entre o produto e o óleo utilizado no ensaio, que foi de 1:4,2. Portanto, muito acima do recomendado por Viana (1994) que é de 1:1.

Chandler et al. $(1991)^{3}$ citado por Young (1995), obtiveram melhor controle de lagartas no algodoeiro quando os inseticidas foram aplicados diluídos em óleo sem

\footnotetext{
${ }^{3}$ CHANDLER, L.D.; HERZOG, G.A.; SUMNER, H.R.;DOWLER, C.C. Chemigation me thodology for management
} of cotton insect pests. Cotton Insect Research and Control Conference, 44, Proceedings, p.757-759, 1991. 
emulsificante, em relação a formulações e ou produtos solúveis em água. Também obtiveram melhores produtividades os tratamentos quimigados em comparação aos de aplicação convencional, o que foi atribuído a maior residualidade dos produtos principalmente no controle da lagarta da maçã (Heliothis virescens).

Dados de estudos de resíduo de inseticidas nas folhas do algodoeiro, e a persistência nas folhas do tratamento com óleo sem emulsificante quimigado versus produtos sem a adição de óleo ou hidrossolúveis aplicados de maneira convencional, mostraram teores significativamente mais elevados nos tratamentos quimigados (Chandler et al., 1993). Wauchope et al. (1991) e Young (1981) obtiveram uma deposição três vezes maior de carbaril e clorpirifós em folha de milho com a adição de óleo sem emulsificante à formulação, quando comparado à formulação padrão. Young et al. (1992), em função dos dados coletados, comentam que a adição de óleo sem emulsificante pode reduzir a dosagem de um inseticida foliar quimigado, sem prejuízo do controle das pragas alvo.

Em relação às pragas de solo, a maioria dos estudos feitos se refere ao controle de larva alfinete no milho, principal praga da cultura no mundo (Chalfant et al., 1987; Mayo, 1984; Peters \& Lowry, 1991). Para essa praga, Schmidt (1996), em ensaio de dose resposta de clorpirifós obteve excelente nível de proteção à cultura com dose

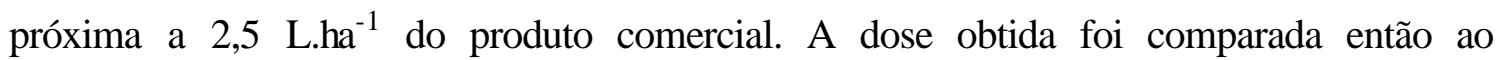
tratamento de sementes e a pulverização no sulco de plantio sendo que a eficiência foi similar ao tratamento no sulco e superior ao tratamento de sementes que se mostrou semelhante à testemunha (Schmidt \& Carneiro, 1997).

Outras pragas de solo já estudadas são a larva arame, Conoderus spp. (Chalfant et al., 1993) e a lagarta elasmo, Elasmopalpus lignosellus (Viana \& Costa, 1992a).

\subsubsection{Herbicidas}

Para os herbicidas aplicados ao solo, pré-plantio ou pré-emergência, é relativamente simples verificar a vantagem da herbigação. Produtos do grupo das dinitroanilinas, por exemplo, que precisam ser incorporadas, ou do grupo das acetanilidas, que são ativados apenas em função de um maior teor de água no solo, são 
favorecidos com a herbigação. No entanto, mesmo para aplicações ao solo, produtos com alta solubilidade em água têm se mostrado inconsistentes quanto aos resultados obtidos (Dowler, 1984). Nesse mesmo trabalho o autor comenta que esses herbicidas hidrossolúveis seriam diluídos além da dose efetiva, mesmo aplicados com a mínima lâmina possível via pivô $(2,54 \mathrm{~mm})$, e que para as aplicações ao solo, grandes lâminas de água, no momento da aplicação, podem carregar parte da dose aplicada do herbicida para além da camada onde está o banco de sementes das plantas daninhas, diminuindo dessa maneira sua eficiência.

A aplicação de herbicidas foliares, que não tenham efeito de solo, via quimigação, é a grande questão, pois, a percepção geral é de que os produtos seriam lavados das folhas (Dourado Neto \& Fancelli, 2000; Dowler, 1995; Vilela, 2002). Vários trabalhos têm apresentado bons resultados, sobretudo com a adição de óleo sem emulsificante. Dowler (1995), trabalhando com acifluorfen, sethoxydin, bentazon, fluazifop-buthyl, metolachlor, chloramben, naptalan e dinozeb, conclui que "a adição de um óleo sem emulsificante como por exemplo o óleo de amendoim, como veículo para injeção do herbicida produz consistentes resultados herbicidas independentemente da lâmina de água aplicada. Estes dados indicam que herbicidas pós-emergentes não são necessariamente lavados da superfície das folhas como esperado inicialmente, e que os mesmos podem ser absorvidos muito rapidamente pelos tecidos da planta durante e logo após a aplicação".

Do mesmo modo, Guy et al. (1985) trabalhando com fluazifop-P, haloxyfop e quizalofop, aplicados por aspersão, também concluíram que a eficácia dos produtos testados quando comparados à aplicação convencional foi semelhante, e que a adição de concentrações crescentes de óleo sem emulsificante na solução aumenta a deposição e retenção dos produtos nas folhas. Esse resultado também foi obtido por Sumner et al. (1993) trabalhando com desfolhadores em algodão, comparando aplicações convencionais com herbigação, com e sem a adição de óleo. Concluíram que a adição de um óleo sem emulsificante melhora o desempenho do desfolhante quando herbigado, removendo de 80 a $95 \%$ das folhas, de modo que, concluem os autores: "a herbigação é um método de aplicação aceitável para a aplicação de desfolhantes em algodão". 


\subsubsection{Fungicidas e nematicidas}

Vieira \& Sumner (1999), em revisão sobre fungigação foliar via irrigação por aspersão verificaram que 23 fungicidas já haviam sido testados em 10 culturas diferentes. Em alguns ensaios a fungigação foi comparada apenas a uma testemunha absoluta, em outros a diferentes métodos de aplicação como a tratorizada (convencional) ou aérea. Clorotalonil, seguido de mancozeb, fentin hidróxido e captafol foram as moléculas mais estudadas, enquanto que amendoim (Arachis hypogea), batata (Solanum tuberosum), tomate (Lycopersicum sculentum) e feijão (Phaseolus vulgaris) foram as culturas mais pesquisadas. Pivô central e aspersão convencional foram os sistemas de irrigação mais utilizados nos ensaios. Dos 102 ensaios identificados, a fungigação mostrou efeito equivalente ou superior a aplicação convencional em 56 ensaios. Ao se buscar a causa de insucesso dos demais, observa-se que em muitos a infecção era muito baixa ou extremamente severa. Os produtos foram aplicados em subdosagens, ou não apresentavam as propriedades físico-químicas necessárias à quimigação. Alguns ensaios foram instalados comparando-se os tratamentos fungigados apenas com uma testemunha absoluta, não tendo sido comparados a outros métodos de aplicação.

Cunha et al. (2001), estudando a influência de diferentes lâminas de irrigação sobre a eficácia do epoxiconazole no controle de mancha de alternária (Alternaria spp.) e mancha angular (Phaeoisariopsis griseola) em feijoeiro, não obtiveram diferenças significativas. Isso mostra que também para fungicidas é válido o que foi comentado para inseticidas e herbicidas de que, se as propriedades do produto atender aos prérequisitos para quimigação, o volume de calda aplicado é indiferente.

Vieira \& Sumner (1999) justificam bom desempenho da fungigação em função de alguns fatores: (i) aplicação no momento em que os fungos estão em plena atividade (função do molhamento foliar), (ii) completa cobertura das plantas, (iii) redução acentuada do potencial de inóculo na superfície da planta e do solo (inclusive restos culturais pelo molhamento total), (iv) melhor controle de alguns patógenos em função de sua etiologia (mofo branco - Sclerotinea sclerotiorum, e.g.), e (v) distribuição mais uniforme dos fungicidas quando via pivô central. Essa última afirmativa dos autores irá depender porém da uniformidade de distribuição de água, e do tamanho de gota no ponto 
de injeção e nos emissores. Além disso a fungigação diminui a compactação de solo e o dano mecânico às culturas.

As propriedades físico-químicas dos fungicidas e o tipo de formulação são as chaves para minimizar a 'lavagem' dos produtos do alvo folha. Clorotalonil, por exemplo, quando aplicado na formulação pó-molhável não mostrou controle adequado da doença, o que contudo ocorreu quando se aplicou a formulação tipo suspensão concentrada - SC (Franc et al., 1983).

A diluição do produto em óleo sem emulsificante antes da injeção parece ser uma alternativa promissora (Vieira \& Sumner, 1999). Brenneman \& Sumner (1988) obtiveram controle semelhante à aplicação convencional quando o etiltrianol foi diluído em óleo sem emulsificante. Reese et al. (1986) obtiveram controle significativo da podridão de frutos causada por Cercospora phomoides com o uso de mancozeb + sulfato cúprico + óleo vegetal na água de irrigação.

Conclui-se que, também para fungicidas, a questão da formulação e sua relação com a capacidade de formar emulsões é fundamental, pois, a eficácia da fungigação dependerá da quantidade de produto que atinge o alvo, que por sua vez depende da uniformidade de distribuição do produto, que é função do tamanho de gota no ponto de injeção e nos emissores, e que é determinado pelo tipo de formulação utilizada (Irrigation Association, 1997).

Para fungos de solo ou nematóides, a redistribuição dos produtos no perfil do solo, o posicionamento na profundidade desejada, e a uniformidade de distribuição (considerando-se uniforme a distribuição de água), além de prover a umidade necessária para a ativação, são vantagens incontestáveis da nematigação (Csinos et al., 1985 e 1986; Culbreath et al., 1993; Johnson, 1981 e 1985; Santo, 1982; Santo \& Qualls, 1984). 


\section{MATERIAL E MÉTODOS}

\subsection{Metodologia para instalação de ensaios de quimigação via pivô central}

A maioria dos ensaios citados em literatura foi conduzida com simuladores de pivô ou em pivôs experimentais localizados dentro de estações experimentais. Apesar disso, não há uma normatização de procedimento para instalação de ensaios de quimigação via pivô central.

Os ensaios são conduzidos tomando-se por base o raio irrigado do pivô, para então calcular-se a área irrigada e o perímetro. Cada parcela (seção do pivô) deve ter no seu perímetro distância suficiente para que não haja contaminação entre tratamentos (considere também a direção e intensidade do vento). Esse cuidado se faz necessário uma vez que ao contrário das formas convencionais de aplicação, o pivô não aplica em linha mas sim numa faixa, decorrente do raio de abrangência de seus emissores que é variável em função do projeto hidráulico e do modelo utilizado. Isso causa uma sobreposição de tratamentos e uma perda significativa em termos de área amostrável. Considera-se também que o produto injetado leva, a partir da base, cerca de cinco minutos para alcançar a extremidade do pivô (com base numa velocidade de água de 2 $\mathrm{m} . \mathrm{s}^{-1}$ na base e um raio de $500 \mathrm{~m}$ ). É desprezada para efeito de amostragem, a área irrigada com o canhão terminal quando presente, pois esse é bastante sujeito à ação do vento, com menor uniformidade de aplicação de água e, conseqüentemente, causando maior variabilidade nos tratamentos testados.

Cada parcela apresenta uma área aproximada de um hectare, sem repetição, e os ensaios foram realizados em equipamentos comerciais.

A testemunha que foi utilizada nos ensaios, é uma parcela sem tratamento, do mesmo tamanho e forma dos demais tratamentos. 


\subsubsection{Sinalização das parcelas}

A marcação das parcelas inicia-se tomando como ponto referencial o carreador que conduz ao centro. Ao trocar-se o tratamento (outra dose ou produto), sinaliza-se a um auxiliar que marca, com uma estaca próximo ao rastro da primeira torre distante 45 a $50 \mathrm{~m}$ do centro, e assim sucessivamente até completarem-se os tratamentos previstos no ensaio. Nos pivôs que dispõem do equipamento, anota-se também o ângulo de referência.

Ao término das aplicações, ou no dia seguinte, parte-se da estaca marcada e mirando o centro do pivô completa-se a marcação em direção a periferia do mesmo no sentido radial. As estacas, espaçadas cerca de dez metros entre si, deverão ser facilmente identificáveis à distância, mesmo com o crescimento da cultura.

A velocidade e a direção predominante do vento são medidas e anotadas para cada troca de tratamento, pois em função da posição do pivô em relação àdireção do vento, a margem de bordadura para se definir a área útil amostrável poderá variar.

\subsubsection{Cálculo da vazão injetada no sistema}

Tendo-se a área irrigada do pivô e o tempo de revolução, ou seja, o tempo que ele demora para dar uma volta completa, calcula-se o tempo necessário para um hectare. Sabendo-se o volume de calda a ser injetado por hectare, com o auxílio de uma proveta graduada (com o orifício da sucção na sua parte inferior) e de um cronômetro, calibra-se a bomba injetora-dosadora em $\mathrm{mL} \cdot \mathrm{min}^{-1}$ até atingir-se a vazão desejada.

\subsubsection{Calibração do equipamento}

A calibração do equipamento deve preferencialmente ser feita antes de todo ensaio. É porém uma atividade muito trabalhosa e na maioria das vezes a fazenda já dispõe da informação. A calibração do equipamento e a sua curva de distribuição de água deverão ser determinados em conformidade com a norma técnica NBR 14244.(Associação Brasileira de Normas Técnicas, s.d.) Uma avaliação visual cuidadosa permite identificar e sanar problemas como vazamentos em juntas ou emissores entupidos. 


\subsection{Metodologia dos ensaios de inseticidas para o controle de lagarta do cartucho em milho}

Durante as safras de 1995 a 1997 foram conduzidos três ensaios com inseticidas em milho visando o controle da lagarta do cartucho (Spodoptera frugiperda, Lepidoptera: Noctuidae). O resumo dos ensaios pode ser visto na Tabela 14.

Tabela 14. Caracterização resumida dos três ensaios.

\begin{tabular}{lccc}
\hline Descrição & Ensaio I & Ensaio II & Ensaio III \\
\hline Local & Florestópolis/PR & Nova Fátima/PR & Nova Fátima/PR \\
Híbrido & C-701 & C-805 & P-3069 \\
Semeadura & 28 mar 1996 & 25 mar1997 & 10 set 1997 \\
Data da aplicação & 24 abr 1996 & 22 abr 1997 & 7 out 1997 \\
Horário de aplicação & $22: 30-2: 00$ & $15: 30-18: 00$ & $00: 00-4: 30$ \\
Estádio da cultura (BBCH) ${ }^{1}$ & B16 & B14 & B14 \\
Infestação na aplicação & $50 \%$ & $60 \%$ & $45 \%$ \\
Temperatura $\left({ }^{\circ}\right.$ C) & 12 & 26 & 22 \\
Umidade relativa (\%) & 100 & 78 & 100 \\
Avaliações: & & 2,6 e 10 DAA & 2 e 6 DAA \\
\multicolumn{1}{c}{ Contagem larvas vivas } & 3,6 e 9 DAA ${ }^{2}$ & 6,10 e 14 DAA & 2,6 e 10 DAA \\
\multicolumn{1}{c}{ Percentagem visual de dano } & 6 e 9 DAA & &
\end{tabular}

' BBCH, código de estádios fenológicos (Bleiholder et al, 1992).

${ }^{2}$ Dias Após Aplicação (DAA).

O ensaio de uniformidade de distribuição do equipamento foi realizado por empresa contratada pelo proprietário da fazenda, tendo sido declarado que os coeficientes de uniformidade de distribuição, calculados segundo Christiansen (1942), estavam acima de 85\%, o que foi considerado satisfatório. A curva de distribuição de água apresentava-se aceitável.

\subsubsection{Aplicação dos tratamentos}

Os produtos foram injetados na base do sistema de irrigação, usando-se pressão positiva, provida por uma bomba injetora-dosadora de diafragma, marca Hidroflo (Figura 14), acionada por motor elétrico. A faixa de vazão dessa bomba permite a 
injeção de produtos puros (sem a necessidade de pré-diluição em água) no sistema, o que foi necessário para aqueles tratamentos misturados ou formulados em óleo sem emulsificante.

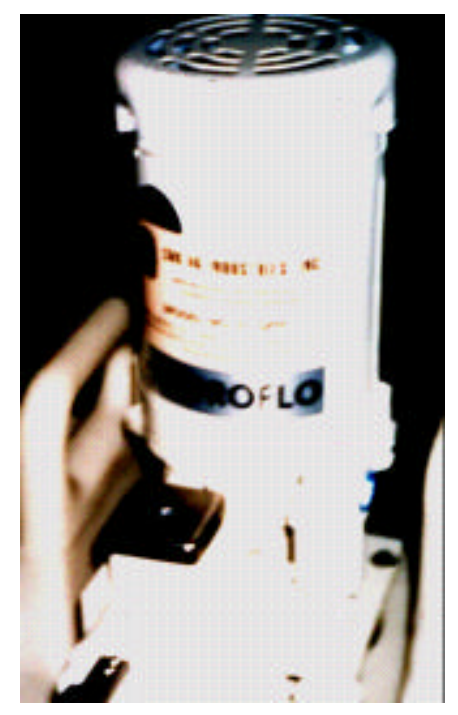

Figura 14- Bomba injetora-dosadora de diafragma, marca Hidroflo.

O ponto de injeção estava instalado na base do pivô, e inserido até o meio da tubulação, favorecendo desse modo a formação de gotas menores, e a homogeneização do sistema conforme descrito por vários autores (Groselle, 1986; Threadgill, 1985; Vieira, 1994).

\subsubsection{Metodologia de avaliação}

Em cada parcela aplicada foram fixados quatro ou seis pontos de amostragem distribuídos conforme mostra a Figura 15. De cada ponto foram coletados e abertos de 15 a. 25 cartuchos de milho, procedendo-se à contagem de larvas vivas, as quais foram separadas em função de seu tamanho em: (i) recém eclodidas; (ii) primeiro a terceiro ínstar, chamadas de pequenas; e (iii) quarto a sexto ínstar, consideradas como grandes. A razão da separação por tamanho deve-se ao fato de que a maioria dos produtos apresenta um efeito diferenciado em função do tamanho das lagartas. 


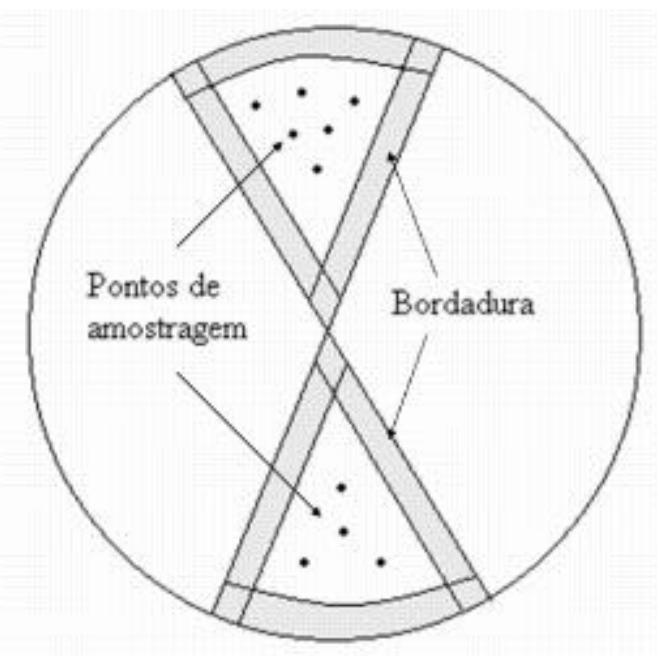

Figura 15- Esquema do posicionamento das áreas de bordadura e dos pontos de amostragem para quatro e seis pontos, utilizado para todos os ensaios.

Em função do hábito da praga de ovipositar em grandes massas (200 a 500 ovos) e o canibalismo, desconsidera-se, para efeito de análise, as recém eclodidas, pois geram uma distorção na análise de variância que não reflete os tratamentos testados.

O percentual de controle (PC, \%) foi obtido utilizando-se a fórmula - Equação (5) - sugerida por Abbott (1925).

$$
P C=\frac{\text { Testemunha }- \text { Tratamento }}{\text { Testemunha }} .100
$$

Avaliou-se também o percentual de plantas danificadas contando-se o número de cartuchos novos com sinal de dano em cinqüenta plantas consecutivas. $\mathrm{O}$ dobro do resultado obtido nos dá o percentual de ataque. Esse é o parâmetro recomendado para se determinar o momento de aplicação. As avaliações foram feitas a partir dos três dias após a aplicação prosseguindo com intervalo de três dias, até que não houvesse mais diferença entre tratamentos e testemunha, ou que o nível de ataque tenha caído por algum motivo.

\subsubsection{Análise estatística}

Foi feita de duas maneiras: (i) cada ensaio individualmente, e (ii) de forma consolidada. 
A análise individual foi feita nos moldes convencionais através da análise de variância e o teste de médias (teste de Tukey) ao nível de significância de $10 \%$. Esse foi escolhido uma vez que os ensaios foram todos conduzidos em áreas e equipamentos comerciais, causando naturalmente uma variabilidade maior, devido a um menor controle sobre a área experimental. Portanto, se houvesse uma restrição maior na análise, seria difícil a detecção de diferenças.

Após a análise de variância (ANOVA), realizou-se uma análise de dispersão dos dados para se verificar a necessidade ou não da transformação dos mesmos. Verificou-se então que a transformação que proporcionava a melhor distribuição normal foi a de $\sqrt{x+0,5}$ para os dados de contagem de lagartas vivas, e $\arcsin \sqrt{x+0,5}$ para os dados de percentagem visual calculada de dano.

A análise consolidada foi feita utilizando-se uma ferramenta gráfica conhecida como 'Box and Whisker Box-plots" que permite avaliar a consistência de resultados para múltiplos ensaios que tenham evidentemente tratamentos em comum. O retângulo (Box) mostrado representa a metade dos pontos de dados sumarizados indicando a mediana. Cada repetição é considerada um ponto. O traço acima do retângulo (Whisker) representa a quarta parte superior enquanto que o traço inferior a quarta parte inferior evidentemente. $\mathrm{O}$ traço no meio do retângulo representa a mediana enquanto que o xis (+) marca a média. Quando eventualmente um ponto foge muito da distribuição normal dos dados, ele aparece no gráfico de modo destacado e é chamado de outlier. Nenhuma conclusão estatística pode ser tirada desse tipo de gráfico. Apenas a consistência do tratamento pode ser visualizada pelo tamanho do retângulo formado, quanto menor mais consistentes são os resultados obtidos.

Para a análise estatística consolidada, separaram-se os tratamentos comuns a pelo menos dois ensaios, e considerou-se cada ensaio como sendo um bloco, prosseguindo-se então na análise convencional usando-se Tukey (nível de significância: 10\%) no teste de médias. 


\subsection{Descrição do produto utilizado}

Tabela 15. Caracterização sumarizada do produto clorpirifós (Ware, 1993).

Nome comum

Nome químico

Formula estrutural clorpirifós

O,O-diethyl O-3,5,6-(trichloro-2-

pyridyl) phosphorothioate

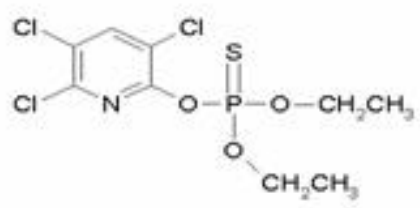

Peso molecular

Estado físico $\left(25^{\circ} \mathrm{C}\right)$

Ponto de fusão $\left({ }^{\circ} \mathrm{C}\right)$

Constante de dissociação (pKa)

Coeficiente de partição octanol/água $(\log \mathrm{P})\left(\mathrm{K}_{\mathrm{ow}}\right)$

Pressão de vapor (mmHg a $25^{\circ} \mathrm{C}$ )

Ponto de fulgor (Formulação CE) $\left({ }^{\circ} \mathrm{C}\right.$ )

Solubilidade em água $\left(\mathrm{mg} . \mathrm{L}^{-1}\right)\left({ }^{\circ} \mathrm{C}\right)$

$$
\text { Água (25) }
$$

Água tamponada (25) $\mathrm{pH} 7$

Água tamponada (25) $\mathrm{pH} 4$

Solubilidade em solventes orgânicos $\left(\mathrm{g} .100 \mathrm{~g}^{-1}\right)$

Acetona

Benzeno

Dietil éter

Etanol

Propileno glicol

Tolueno

Xileno
350,6

sólido

42,5

Não aplicável

5,267

$1,87 \times 10^{-5}$

62

1,2

1,07

1,04

650

790

510

63

4

150

400

\subsection{Ensaio I}

Foi instalado na safrinha de 1996. Utilizoutse o ensaio para se fazer um primeiro teste do efeito do produto na formulação CE (concentrado emulsionável) quando uma subdosagem foi diluída em óleo sem emulsificante, e comparada a um padrão comercial (o próprio clorpirifós na sua formulação e dose comercial) e a uma formulação constituída do ingrediente ativo diluído em óleo sem emulsificante. 


\subsection{1 Área experimental}

O trabalho foi conduzido em um pivô central da marca Asbrasil, instalado em 1986, com 70,3 ha de área irrigada, instalado na fazenda São Francisco, município de Florestópolis, no estado do Paraná (Figura 16), a qual se encontra nas coordenadas geográficas de $22^{\circ} 52^{\prime}$ de latitude sul e $51^{\circ} 22^{\prime}$ de longitude oeste.

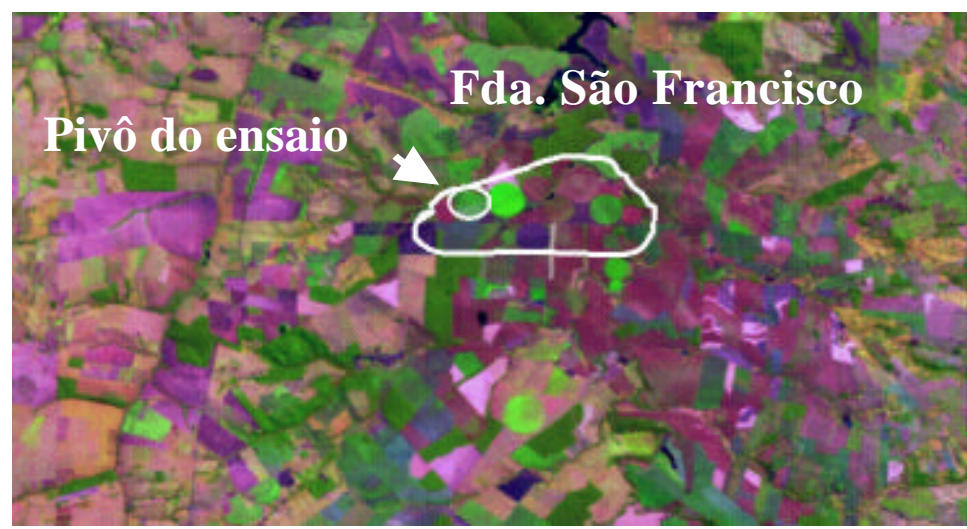

Figura 16 - Localização do ensaio I a partir de imagem do satélite Landsat, escala 1:25.000 (Miranda, 2001).

\subsubsection{Do delineamento do ensaio}

O delineamento estatístico foi o de blocos inteiramente casualizados. Cada parcela sendo uma seção de pivô, com $50 \mathrm{~m}$ no perímetro para não haver contaminação entre os tratamentos. A amostragem foi feita em quatro pontos, e foram amostrados vinte e cinco cartuchos coletados aleatoriamente em cada ponto. A área abrangida pelo canhão terminal foi desconsiderada para efeito de avaliação.

\subsubsection{Da cultura}

O milho híbrido C-701 foi semeado no dia 28 de março de 1996, em linhas, no espaçamento entre linhas de $0,9 \mathrm{~m}$, e densidade média de cinco plantas por metro linear. A semente foi tratada com tiodicarb na dose de $0,7 \mathrm{~kg}$ de ingrediente ativo para cada cem quilos de emente, o que equivale a dois litros do produto comercial por cem quilos. O controle de plantas invasoras foi feita com atrazina aplicada via quimigação na dose recomendada pelo fabricante. 


\subsubsection{Da aplicação}

A aplicação foi feita do dia 24 de abril de 1996, quando o nível médio de infestação atingiu 50\% das plantas com sinal de ataque (cartucho raspado). Fancelli \& Dourado Neto (2000), recomendam como sendo de $20 \%$ o nível de dano econômico para início de aplicações comerciais, esse nível varia no entanto em função da relação entre o custo do tratamento e a expectativa de preço da produção, além das condições climáticas, e estádio da cultura.

O milho estava no estádio de seis folhas, descrito como 16 pelo $\mathrm{BBCH}$ (Bleiholder et al., 1991). O teste foi aplicado a noite no período das 22:30 horas até às 2:00 horas do dia seguinte. Durante o ensaio, a temperatura situou-se em $12^{\circ} \mathrm{C}$ e a umidade relativa do ar em 100\%. Não havia vento no momento da aplicação. O percentímetro do pivô foi regulado à velocidade máxima (100\%), proporcionando uma lâmina de três milímetros.

\subsubsection{Dos tratamentos}

Os tratamentos aplicados podem ser visualizados na Tabela 16.

Tabela 16. Descrição dos tratamentos do Ensaio I.

\begin{tabular}{|c|c|c|c|c|c|}
\hline \multirow{2}{*}{ Número } & \multicolumn{2}{|c|}{ Tratamento } & \multirow{2}{*}{ Formulação } & \multicolumn{2}{|c|}{ Dose } \\
\hline & Marca Comercial & Ingrediente ativo & & g.ha ${ }^{-1}$ i.a. ${ }^{1}$ & L.ha $^{-1}$ p.c. ${ }^{2}$ \\
\hline T1 & Lorsban*480BR ${ }^{4}$ & clorpirifós & $480 \mathrm{CE}$ & 144 & 0,3 \\
\hline $\mathrm{T} 2$ & Lorsban*480BR & clorpirifós & $480 \mathrm{CE}$ & 192 & 0,4 \\
\hline $\mathrm{T} 3$ & Lorsban*480BR & clorpirifós & $480 \mathrm{CE}$ & 288 & 0,6 \\
\hline $\mathrm{T} 4$ & Lorsban*480BR & clorpirifós & $480 \mathrm{CE}$ & 144 & 0,3 \\
\hline 14 & & óleo de soja ${ }^{3}$ & & - & 0,3 \\
\hline T5 & Dursban* $6^{4}$ & $\begin{array}{l}\text { clorpirifós formulado } \\
\text { sem surfactante }\end{array}$ & $720 \mathrm{CE}$ & 144 & 0,2 \\
\hline T6 & & Testemunha & - & - & - \\
\hline
\end{tabular}

Gramas de ingrediente ativo por hectare.

${ }^{2}$ Litro de produto comercial por hectare.

3 Óleo de soja comercial para fins culinários.

${ }^{4}$ Marcas registradas da Dow AgroSciences Industrial Ltda: Indianapolis/IN, EUA.

\subsection{Ensaio II}

Instalado na safrinha de 1997, tinha como objetivo avaliar a eficiência de uma subdosagem de clorpirifós, formulação concentrado emulsionável (CE), adicionado a diferentes concentrações de óleo sem emulsificante comparado à dose de rótulo sem 
óleo e a uma formulação técnica do produto dissolvido em óleo sem emulsificante. aplicado via quimigação.

\subsection{1 Área experimental}

O trabalho foi conduzido em um pivô central da marca Carborundun, instalado em 1988 com uma área irrigada de 44,3 ha, na fazenda Canadá, município de Nova Fátima, no estado do Paraná (Figura 17), a qual se encontra nas coordenadas geográficas de $23^{\circ} 22^{\prime}$ de latitude sul e $50^{\circ} 38^{\prime}$ de longitude oeste.

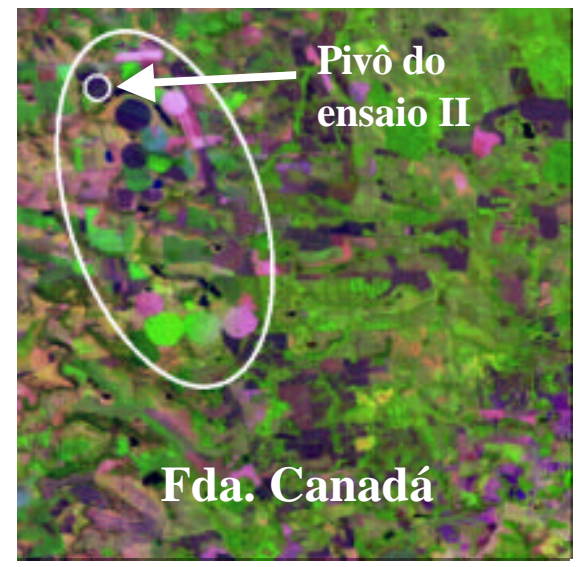

Figura 17- Localização do ensaio II a partir de imagem do satélite Landsat escala 1:25.000 (Miranda, 2001).

\subsubsection{Do delineamento do ensaio}

O delineamento estatístico foi em blocos inteiramente casualizados. Cada parcela sendo uma seção de pivô, com 70 m no perímetro para não haver contaminação entre os tratamentos. A amostragem foi feita em quatro pontos, e foram amostrados quinze cartuchos coletados aleatoriamente em cada ponto. A área abrangida pelo canhão terminal foi desconsiderada para efeito de avaliação.

\subsubsection{Da cultura}

O milho híbrido C-805 foi semeado no dia 25 de março de 1997, em linhas, no espaçamento entre linhas de 0,9 m, e densidade média de cinco plantas por metro linear. A semente foi tratada com carbofuran + zinco na dose de $0,7 \mathrm{~kg}$ de ingrediente ativo para cada cem quilos de semente, o que equivale a 2,2 L do produto comercial por cem 
quilos. O controle de plantas invasoras foi feita com atrazina aplicada via quimigação na dose recomendada pelo fabricante.

\subsubsection{Dos tratamentos}

A Tabela 17 descreve os tratamentos referentes ao ensaio II.

Tabela 17. Descrição dos tratamentos do Ensaio II.

\begin{tabular}{|c|c|c|c|c|c|}
\hline \multirow[b]{2}{*}{ Número } & \multicolumn{2}{|c|}{ Tratamento } & \multirow{2}{*}{$\begin{array}{l}\text { Formulação } \\
\text { Produto:óleo }\end{array}$} & \multicolumn{2}{|c|}{ Dose } \\
\hline & $\begin{array}{c}\text { Marca } \\
\text { Comercial }\end{array}$ & Ingrediente ativo & & g.ha ${ }^{-1}$ i.a. ${ }^{1}$ & L.ha ${ }^{-1}$ p.c. ${ }^{2}$ \\
\hline $\mathrm{T} 1$ & Lorsban*480BR & $\begin{array}{c}\text { clorpirifós } \\
\text { óleo de soja }^{3}\end{array}$ & $\begin{array}{c}480 \mathrm{CE} \\
0\end{array}$ & 144 & $\begin{array}{c}0,3 \\
0\end{array}$ \\
\hline $\mathrm{T} 2$ & Lorsban*480BR & $\begin{array}{l}\text { clorpirifós } \\
\text { óleo de soja }\end{array}$ & $\begin{array}{c}480 \mathrm{CE} \\
1: 1\end{array}$ & 144 & $\begin{array}{l}0,3 \\
0,3\end{array}$ \\
\hline $\mathrm{T} 3$ & Lorsban*480BR & $\begin{array}{l}\text { clorpirifós } \\
\text { óleo de soja }\end{array}$ & $\begin{array}{c}480 \mathrm{CE} \\
1: 2\end{array}$ & $\begin{array}{c}144 \\
-\end{array}$ & $\begin{array}{l}0,3 \\
0,6\end{array}$ \\
\hline $\mathrm{T} 4$ & Lorsban*480BR & $\begin{array}{l}\text { clorpirifós } \\
\text { clorpirifós }\end{array}$ & $480 \mathrm{CE}$ & 288 & 0,6 \\
\hline T5 & Dursban*6 & $\begin{array}{l}\text { formulado sem } \\
\text { surfactante }\end{array}$ & $720 \mathrm{CE}$ & 144 & 0,2 \\
\hline T6 & & testemunha & - & - & - \\
\hline
\end{tabular}

Gramas de ingrediente ativo por hectare.

${ }^{2}$ Litro de produto comercial por hectare.

${ }^{3}$ Óleo de soja comercial para fins culinários.

\subsubsection{Da aplicação}

A aplicação foi feita do dia 22 de abril de 1997, quando o nível médio de infestação era de $60 \%$ das plantas com sintoma de ataque (cartucho raspado).

$\mathrm{O}$ milho estava no estádio de quatro folhas (14 pelo $\mathrm{BBCH})$. O teste foi aplicado à tarde no período das 15:30 horas até às 18:00 horas. Durante o ensaio a temperatura situou-se em $26^{\circ} \mathrm{C}$ e a umidade relativa do ar em $78 \%$. Não havia vento no momento da aplicação. O percentímetro do pivô foi regulado à velocidade máxima (100\%), proporcionando uma lâmina de seis milímetros.

\subsection{Ensaio III}

O ensaio III foi instalado na safra de verão de 1997, o qual teve por objetivo comparar a eficiência de uma subdosagem de clorpirifós, formulação concentrado 
emulsionável, com a dose comercial de rótulo, adicionado a diferentes concentrações de óleo vegetal sem emulsificante e a uma formulação técnica do produto dissolvido em óleo sem emulsificante. aplicado via quimigação. Avaliou-se um único tratamento em subdosagem com óleo mineral, ao invés de óleo vegetal como solvente, com o objetivo de se verificar a possibilidade de interferência do tipo de óleo.

\subsection{1 Área experimental}

O trabalho foi conduzido em um pivô central da marca Asbrasil, instalado em 1989 com uma área irrigada de 76 ha, na fazenda Canadá, município de Nova Fátima, no estado do Paraná (Figura 18), a qual se encontra nas coordenadas geográficas de $23^{\circ} 22^{\prime}$ de latitude sul e $50^{\circ} 38^{\prime}$ de longitude oeste.

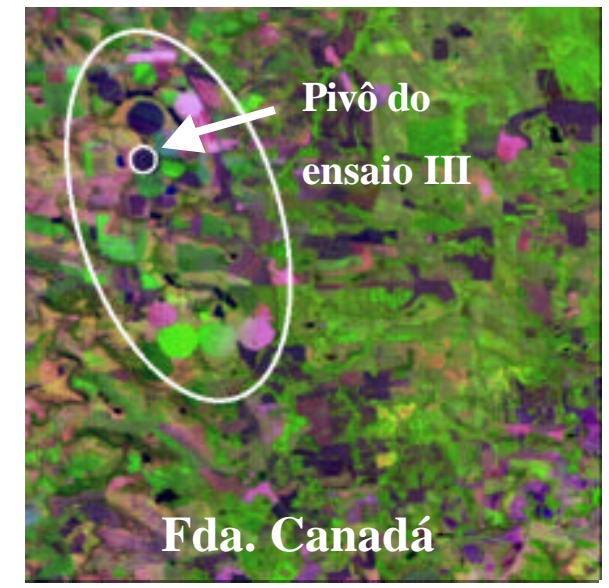

Figura 18 - Localização do ensaio III a partir de imagem do satélite Landsat escala 1:25.000 (Miranda, 2001).

\subsubsection{Do delineamento do ensaio}

O delineamento estatístico foi o de fatorial em blocos inteiramente casualizados. O primeiro fator (A) é dose de produto, e o segundo (B) é dose de óleo. A amostragem foi feita em seis pontos, e foram amostrados quinze cartuchos coletados aleatoriamente em cada ponto. Cada parcela sendo uma seção de pivô, com 70 m no perímetro para não haver contaminação entre os tratamentos. A área abrangida pelo canhão terminal foi desconsiderada para efeito de avaliação. 


\subsubsection{Da cultura}

O milho híbrido P-3069 foi semeado no dia 10 de setembro de 1997, em linhas, no espaçamento entre linhas de $0,9 \mathrm{~m}$, e densidade média de cinco plantas por metro linear. A semente foi tratada com tiodicarb na dose de $0,7 \mathrm{~kg}$ de ingrediente ativo para cada cem quilos de semente, o que equivale a dois litros do produto comercial por cem quilos. O controle de plantas invasoras foi feita com atrazina aplicada via quimigação na dose recomendada pelo fabricante.

\subsubsection{Da aplicação}

A aplicação foi feita no dia 7 de outubro de 1997, quando o nível médio de infestação atingiu 45\% das plantas com sinal de ataque (cartucho raspado), infestação essa que caiu significativamente em função de chuvas ocorridas entre a aplicação e as avaliações subseqüentes, não permitindo a continuidade das avaliações até os 10 a 15 dias após a aplicação como estava planejado.

O milho estava no estádio de quatro folhas (14 pelo $\mathrm{BBCH})$. O teste foi aplicado à noite no período das 00:00 horas até às 4:30 horas. Durante o ensaio, a temperatura situou-se em $22^{\circ} \mathrm{C}$ e a umidade relativa do ar em $100 \%$. Não havia vento no momento da aplicação. O percentímetro do pivô foi regulado à velocidade máxima (100\%), proporcionando uma lâmina de seis milímetros.

\subsubsection{Dos tratamentos}

Os tratamentos aplicados podem ser visualizados na Tabela 18. Incluiu-se nesse ensaio também um tratamento de comparação com óleo mineral ao invés de óleo vegetal, no intuito de colher informação sobre a influência da cadeia de hidrocarbonetos no desempenho da mistura. Cabe lembrar que a maioria das formulações em óleo (tipo CE) utilizam óleos minerais. 
Tabela 18. Descrição dos tratamentos do Ensaio III.

\begin{tabular}{|c|c|c|c|c|c|}
\hline \multirow{2}{*}{ Número } & \multicolumn{2}{|c|}{ Tratamento } & \multirow{2}{*}{ Formulação } & \multicolumn{2}{|c|}{ Dose } \\
\hline & Marca Comercial & Ingrediente Ativo & & g.ha ${ }^{-1}$ i.a. ${ }^{1}$ & L.ha $^{-1}$ p.c. $^{2}$ \\
\hline \multirow[t]{2}{*}{$\mathrm{T} 1$} & Lorsban*480BR & clorpirifós & $480 \mathrm{CE}$ & 144 & 0,3 \\
\hline & & óleo de soja ${ }^{3}$ & 1:0 & & 0 \\
\hline \multirow[t]{2}{*}{$\mathrm{T} 2$} & Lorsban*480BR & clorpirifós & $480 \mathrm{CE}$ & 144 & 0,3 \\
\hline & & óleo de soja & $1: 1$ & & 0,3 \\
\hline \multirow[t]{2}{*}{$\mathrm{T} 3$} & Lorsban*480BR & clorpirifós & $480 \mathrm{CE}$ & 144 & 0,3 \\
\hline & & óleo de soja & $1: 2$ & - & 0,6 \\
\hline \multirow[t]{2}{*}{$\mathrm{T} 4$} & Lorsban*480BR & clorpirifós & $480 \mathrm{CE}$ & 288 & 0,6 . \\
\hline & & óleo de soja & $1: 0$ & & 0 \\
\hline \multirow[t]{2}{*}{ T5 } & Lorsban*480BR & clorpirifós & $480 \mathrm{CE}$ & 288 & 0,6 \\
\hline & & óleo de soja & $1: 1$ & & 0,6 \\
\hline \multirow[t]{2}{*}{ T6 } & Lorsban*480BR & clorpirifós & $480 \mathrm{CE}$ & 288 & 1,2 \\
\hline & & óleo de soja & $1: 2$ & - & 0,6 \\
\hline $\mathrm{T} 7$ & Dursban*6 & clorpirifós formulado & $720 \mathrm{CE}$ & 144 & 0,2 \\
\hline & & sem surfactante & & & \\
\hline \multirow[t]{2}{*}{$\mathrm{T} 8$} & Lorsban*480BR & clorpirifós & $480 \mathrm{CE}$ & 144 & 0,3 \\
\hline & & óleo mineral & $1: 1$ & & 0,3 \\
\hline T9 & & testemunha & - & - & - \\
\hline
\end{tabular}

${ }^{1}$ Gramas de ingrediente ativo por hectare.

${ }^{2}$ Litro de produto comercial por hectare.

${ }^{3}$ Óleo de soja comercial para fins culinários. 


\section{RESULTADOS E DISCUSSÃO}

\subsection{Sobre a metodologia utilizada}

A metodologia sugerida mostrou-se efetiva e prática na sua implementação. Há um aspecto porém que levanta certa ansiedade para o produtor, que é a testemunha. A característica desse tipo de ensaio, faz com que todas as parcelas tenham uma área grande, inclusive a testemunha. Dependendo do alvo biológico a ser avaliado, o prejuízo pode ser substancial para o produtor que está cedendo a área, uma vez que a perda ocorre não apenas na área da testemunha em si (poderia ser contornado através de indenização), mas em muitos casos a testemunha serve de fonte de inóculo para o restante das áreas, dificultando e encarecendo o seu manejo.

Uma alternativa prática principalmente para ensaios é a distribuição de lonas plásticas na área a ser aplicada. Essa lona deve ser de tamanho adequado para que não haja contaminação da testemunha pelo escorrimento da calda pela beirada. Quando a cultura já está instalada, essa opção é dificultada e cuidados adicionais devem ser tomados principalmente para não deixar a lona tempo demasiado sobre a cultura. Ao se optar pelo uso da lona, é preciso ter o cuidado para que o número dessas parcelas seja suficiente e representativo da área. Recomenda-se que sejam posicionadas próximas ao rastro de uma torre do pivô, que serviria como referência no momento da avaliação facilitando também a movimentação dentro da área do ensaio.

Quando o ensaio visa comparar métodos de aplicação (pivô versus convencional e.g.), essa área poderá ser utilizada para se instalar os tratamentos de aplicação convencional (normalmente feitas com pulverizadores costais pressurizados com dióxido de carbono e em parcelas menores). 


\subsection{Análise individual dos ensaios}

\subsubsection{Ensaio I}

O que se pode observar dos dados brutos (Tabela 19) é que a dose de 144 g.ha $^{-1}$ i.a. de clorpirifós (CE) dissolvido em óleo sem emulsificante (T4) mostrou controle estatisticamente semelhante ao tratamento (T5) e às demais dosagens testadas sem óleo para as avaliações de contagem aos três, seis e nove dias após aplicação (DAA) e aos seis dias após aplicação para dano visual. Porém, na avaliação de dano visual aos nove dias é nítida a tendência dos tratamentos dissolvidos em óleo proporcionarem uma melhor proteção à cultura, embora ainda estatisticamente semelhantes ao nível de significância de 10\%. Ao se analisar os dados transformados (Tabela 20), essa tendência fica mais evidente. O tratamento (T4) é estatisticamente diferente do tratamento padrão (T3), apesar de ter apenas metade da dose de ingrediente ativo.

O nível de controle obtido é considerado comercialmente aceitável, mesmo para o nível inicial de infestação duas vezes e meio maior que o nível de dano econômico sugerido.

As avaliações não prosseguiram pelo fato da testemunha aos 9 DAA, já não apresentava nível de dano econômico pela redução acentuada na infestação ocasionada pela queda de temperatura e chuvas.

Os resultados obtidos confirmam dados de literatura onde o melhor tratamento é o ingrediente ativo dissolvido em óleo sem emulsificante, seguido da formulação CE dissolvido em óleo e por último a formulação comercial sem mistura (Young et al., 1995). Após esse resultado, questionou-se se não haveria influência na proporção de óleo adicionado ao produto, questão essa que originou a condução do ensaio realizado na safra seguinte. 
Tabela 19. Eficiência dos tratamentos no controle da lagarta do cartucho em milho. Florestópolis/PR, safrinha de 1996 (Ensaio I).

\begin{tabular}{|c|c|c|c|c|c|c|c|}
\hline \multirow[b]{3}{*}{1} & \multirow{3}{*}{$\begin{array}{l}\text { Tratamento } \\
\text { Produto }\end{array}$} & \multirow{3}{*}{$\begin{array}{c}\text { Dose } \\
\text { g.ha }{ }^{-1} \text { i.a. }\end{array}$} & \multicolumn{5}{|c|}{ Avaliações } \\
\hline & & & \multicolumn{3}{|c|}{$\begin{array}{l}\text { Contagem }^{1} \\
\left(\% \text { controle }^{2}\right)\end{array}$} & \multicolumn{2}{|c|}{$\begin{array}{l}\text { Dano visual } \\
\text { (\% calculada) }\end{array}$} \\
\hline & & & $3 \mathrm{DAA}^{3}$ & 6DAA & 9DAA & 6DAA & 9DAA \\
\hline $\mathrm{T} 1$ & clorpirifós & 144 & $\begin{array}{l}3,3 \mathrm{~b}^{4} \\
(83,8)\end{array}$ & $\begin{array}{l}1,0 \mathrm{~b} \\
(92,7)\end{array}$ & $\begin{array}{l}0,8 \mathrm{~b} \\
(95,3)\end{array}$ & $1,0 \mathrm{~b}$ & $8,5 \mathrm{ab}$ \\
\hline $\mathrm{T} 2$ & clorpirifós & 192 & $\begin{array}{l}1,0 \mathrm{~b} \\
(95,0)\end{array}$ & $\begin{array}{c}0,0 \mathrm{~b} \\
(100,0)\end{array}$ & $\begin{array}{l}4,3 \mathrm{~b} \\
(73,4)\end{array}$ & $4,0 \mathrm{~b}$ & $9,5 \mathrm{ab}$ \\
\hline $\mathrm{T} 3$ & clorpirifós & 288 & $\begin{array}{l}0,5 \mathrm{~b} \\
(97,5)\end{array}$ & $\begin{array}{l}1,0 \mathrm{~b} \\
(92,7)\end{array}$ & $\begin{array}{l}2,0 \mathrm{~b} \\
(87,5)\end{array}$ & $4,0 \mathrm{~b}$ & $15,5 \mathrm{a}$ \\
\hline $\mathrm{T} 4$ & $\begin{array}{l}\text { clorpirifós + óleo de } \\
\text { soja }\end{array}$ & 144 & $\begin{array}{c}0,0 \mathrm{~b} \\
(100,0)\end{array}$ & $\begin{array}{c}0,0 \mathrm{~b} \\
(100,0)\end{array}$ & $\begin{array}{l}3,3 \mathrm{~b} \\
(79,7)\end{array}$ & $4,0 \mathrm{~b}$ & $4,5 b$ \\
\hline $\mathrm{T} 5$ & $\begin{array}{l}\text { clorpirifós formulado } \\
\text { sem surfactante }\end{array}$ & 144 & $\begin{array}{l}1,0 \mathrm{~b} \\
(95,0)\end{array}$ & $\begin{array}{l}1,0 \mathrm{~b} \\
(92,7)\end{array}$ & $\begin{array}{l}0,3 \mathrm{~b} \\
(98,4)\end{array}$ & $2,0 \mathrm{~b}$ & $4,0 \mathrm{~b}$ \\
\hline T6 & Testemunha & - & $\begin{array}{l}20,0 \mathrm{a} \\
(0,0)\end{array}$ & $\begin{array}{c}13,8 \mathrm{a} \\
(0,0)\end{array}$ & $\begin{array}{c}16,0 \mathrm{a} \\
(0,0)\end{array}$ & $41,0 \mathrm{a}$ & $17,3 \mathrm{a}$ \\
\hline & $\mathrm{CV}(\%)$ & & 96,06 & 68,36 & 64,62 & 78,05 & 52,62 \\
\hline & Desvio Padrão & & 4,12 & 1,91 & 2,85 & 7,28 & 5,20 \\
\hline
\end{tabular}


Tabela 20. Eficiência dos tratamentos no controle da lagarta do cartucho em milho. Florestópolis/PR, safrinha de 1996 (Ensaio I). Dados transformados.

\begin{tabular}{|c|c|c|c|c|c|c|c|}
\hline \multirow[b]{3}{*}{1} & \multirow[b]{2}{*}{ Tratamento } & \multirow{3}{*}{$\begin{array}{c}\text { Dose } \\
\text { g.ha }{ }^{-1} \text { i.a. }\end{array}$} & \multicolumn{5}{|c|}{ Avaliações } \\
\hline & & & \multicolumn{3}{|c|}{ Contagem $^{1}$} & \multicolumn{2}{|c|}{ Dano visual ${ }^{2}$} \\
\hline & Produto & & $3 \mathrm{DAA}^{3}$ & $6 \mathrm{DAA}$ & 9DAA & $6 \mathrm{DAA}$ & 9DAA \\
\hline $\mathrm{T} 1$ & clorpirifós & 144 & $1,60 \mathrm{~b}^{4}$ & $1,06 \mathrm{~b}$ & $1,14 \mathrm{bc}$ & $4,07 \mathrm{~b}$ & $16,08 \mathrm{abc}$ \\
\hline $\mathrm{T} 2$ & clorpirifós & 192 & $1,14 \mathrm{~b}$ & $0,71 \mathrm{~b}$ & $2,19 \mathrm{~b}$ & $11,06 \mathrm{~b}$ & $17,66 \mathrm{abc}$ \\
\hline $\mathrm{T} 3$ & clorpirifós & 288 & $0,93 \mathrm{~b}$ & $1,14 \mathrm{~b}$ & $1,58 \mathrm{bc}$ & $9,69 \mathrm{~b}$ & $22,52 \mathrm{ab}$ \\
\hline $\mathrm{T} 4$ & $\begin{array}{l}\text { clorpirifós + } \\
\text { óleo de soja }\end{array}$ & $\begin{array}{l}144 \\
1: 1\end{array}$ & $0,71 \mathrm{~b}$ & $0,71 \mathrm{~b}$ & $1,95 \mathrm{~b}$ & $9,98 \mathrm{~b}$ & $10,54 \mathrm{c}$ \\
\hline T5 & $\begin{array}{l}\text { clorpirifós formulado } \\
\text { sem surfactante }\end{array}$ & 144 & $1,14 \mathrm{~b}$ & $1,14 \mathrm{~b}$ & $0,89 \mathrm{c}$ & $5,58 \mathrm{~b}$ & $11,35 \mathrm{bc}$ \\
\hline T6 & Testemunha & - & $4,43 \mathrm{a}$ & $3,75 \mathrm{a}$ & $4,06 \mathrm{a}$ & $39,44 \mathrm{a}$ & $24,53 \mathrm{a}$ \\
\hline & $\mathrm{CV}(\%)$ & & 47,13 & 33,94 & 32,08 & 52,74 & 32,82 \\
\hline & Desvio Padrão & & 0,782 & 0,482 & 0,719 & 7,015 & 5,617 \\
\hline
\end{tabular}

${ }^{1}$ Número médio de lagartas vivas em 25 plantas (dados transformados por $\sqrt{x+0,5}$ ).

${ }^{2}$ Dados originais transformados por $\arcsin \sqrt{x+0,5}$

${ }^{3}$ Dias após aplicação (DAA)

${ }^{4}$ Médias seguidas pela mesma letra na coluna não diferem estatisticamente entre si pelo teste de Tukey ao nível de significância de $10 \%$.

\subsubsection{Ensaio II}

Aplicado durante o dia, numa pressão de infestação extremamente elevada, pressão essa que teve uma queda, de motivo desconhecido, por ocasião da primeira avaliação mas que se elevou sobremaneira a partir da segunda avaliação. No momento da aplicação do tratamento (T5), houve problemas com o equipamento de injeção, de modo que o mesmo não deve ser considerado para efeito de análises mais detalhadas.

Manteve-se o tratamento (T5) no ensaio pois, embora a dose efetivamente aplicada devesse ter sido menor que a programada, o tratamento mostrou uma proteção à cultura satisfatória até os 14 DAA, comparável aos demais tratamentos na mesma dose. Esse resultado poderia ser explicado pela quantidade de ativo retido pela folha em função da formulação nitidamente lipofílica. Os dados originais podem ser visualizados na Tabela 21, e os dados transformados na Tabela 22. 
Tabela 21. Eficiência dos tratamentos no controle da lagarta do cartucho em milho, Nova Fátima/PR, safrinha de 1997 (Ensaio II).

\begin{tabular}{|c|c|c|c|c|c|c|c|c|}
\hline \multirow[b]{3}{*}{1} & \multirow{3}{*}{ Tratamento } & \multirow[b]{3}{*}{ g.ha ${ }^{-1}$ i.a. } & \multicolumn{6}{|c|}{ Avaliações } \\
\hline & & & \multicolumn{3}{|c|}{$\begin{array}{l}\text { Contagem }^{1} \\
\left(\% \text { controle }^{2}\right)\end{array}$} & \multicolumn{3}{|c|}{$\begin{array}{l}\text { Dano visual } \\
\text { (\% calculado })\end{array}$} \\
\hline & & & $2 \mathrm{DAA}^{3}$ & $6 \mathrm{DAA}$ & 10DAA & $6 \mathrm{DAA}$ & 10DAA & 14DAA \\
\hline $\mathrm{T} 1$ & $\begin{array}{l}\text { clorpirifós + óleo de } \\
\text { soja }\end{array}$ & $\begin{array}{c}144 \\
0\end{array}$ & $\begin{array}{l}1,3 \mathrm{~b}^{4} \\
(85,7)\end{array}$ & $\begin{array}{c}3,0 \text { bcd } \\
(85,4)\end{array}$ & $\begin{array}{l}11,5 \mathrm{a} \\
(37,0)\end{array}$ & $7,5 \mathrm{bc}$ & $14,5 \mathrm{bc}$ & $23,0 \mathrm{~b}$ \\
\hline $\mathrm{T} 2$ & $\begin{array}{l}\text { clorpirifós + óleo de } \\
\text { soja }\end{array}$ & $\begin{array}{l}144 \\
1: 1\end{array}$ & $\begin{array}{l}3,0 \mathrm{ab} \\
(65,7)\end{array}$ & $\begin{array}{l}2,0 \mathrm{~cd} \\
(90,2)\end{array}$ & $\begin{array}{l}13,3 \mathrm{a} \\
(27,4)\end{array}$ & $7,0 \mathrm{bc}$ & $9,0 \mathrm{~cd}$ & $14,5 \mathrm{~b}$ \\
\hline $\mathrm{T} 3$ & $\begin{array}{l}\text { clorpirifós + óleo de } \\
\text { soja }\end{array}$ & $\begin{array}{r}144 \\
1: 2\end{array}$ & $\begin{array}{l}0,3 \mathrm{~b} \\
(97,1)\end{array}$ & $\begin{array}{c}0,0 \mathrm{c} \\
(100,0)\end{array}$ & $\begin{array}{l}5,8 \mathrm{a} \\
(68,5)\end{array}$ & $3,0 \mathrm{c}$ & $2,5 \mathrm{~d}$ & $10,5 \mathrm{~b}$ \\
\hline $\mathrm{T} 4$ & clorpirifós & 288 & $\begin{array}{l}0,8 \mathrm{~b} \\
(91,4)\end{array}$ & $\begin{array}{l}9,8 \mathrm{bc} \\
(52,4)\end{array}$ & $\begin{array}{c}18,0 \mathrm{a} \\
(1,4)\end{array}$ & $11,5 \mathrm{bc}$ & $20,0 \mathrm{~b}$ & $46,0 \mathrm{a}$ \\
\hline $\mathrm{T} 5$ & $\begin{array}{l}\text { clorpirifós formulado } \\
\text { sem surfactante }\end{array}$ & 144 & $\begin{array}{l}9,0 \mathrm{a} \\
(-2,9)\end{array}$ & $\begin{array}{l}11,0 \mathrm{~b} \\
(46,3)\end{array}$ & $\begin{array}{l}10,5 \mathrm{a} \\
(42,5)\end{array}$ & $20,5 \mathrm{~b}$ & $20,0 \mathrm{~b}$ & $13,0 \mathrm{~b}$ \\
\hline T6 & Testemunha & - & $\begin{array}{l}8,8 \mathrm{a} \\
(0,0)\end{array}$ & $\begin{array}{c}20,5 \mathrm{a} \\
(0,0)\end{array}$ & $\begin{array}{c}18,3 \mathrm{a} \\
(0,0)\end{array}$ & $36,8 \mathrm{a}$ & $75,3 \mathrm{a}$ & 56,5 a \\
\hline & $\mathrm{CV}(\%)$ & & 89,53 & 51,27 & 62,84 & 50,7 & 21,64 & 24,22 \\
\hline & Desvio Padrão & & 3,43 & 3,95 & 8,09 & 7,29 & 5,09 & 6,60 \\
\hline
\end{tabular}

No parâmetro contagem de larvas vivas, aos 2 dias após aplicação, os tratamentos T5 e T2 não diferiram da testemunha. Porém, o tratamento (T2) também não diferiu dos demais tratamentos (T1, T3 e T4) todos estatisticamente diferentes da testemunha.

Aos seis DAA, o tratamento padrão (T4) e o tratamento T5, embora diferindo da testemunha não alcançaram controle satisfatório (52,4 e 46,3\%, respectivamente). $\mathrm{O}$ melhor tratamento (100\% de controle) foi o tratamento (T3), formulação CE dissolvida no maior teor de óleo, que juntamente com os outros tratamentos misturados com óleo (T1 e T2), dos quais não diferiu, foram os que alcançaram nível comercial de controle. Em função da forte pressão de infestação, aos dez dias nenhum tratamento apresentava controle aceitável, não se prosseguindo nas avaliações de contagem. 
O dano visual reflete o número de lagartas de alguns dias antes. Essa é a razão de se ter avaliação visual de dano ainda 4 dias após a última avaliação de contagem.

Tabela 22. Eficiência dos tratamentos no controle da lagarta do cartucho em milho. Nova Fátima/PR, safrinha de 1997 (Ensaio II). Dados transformados.

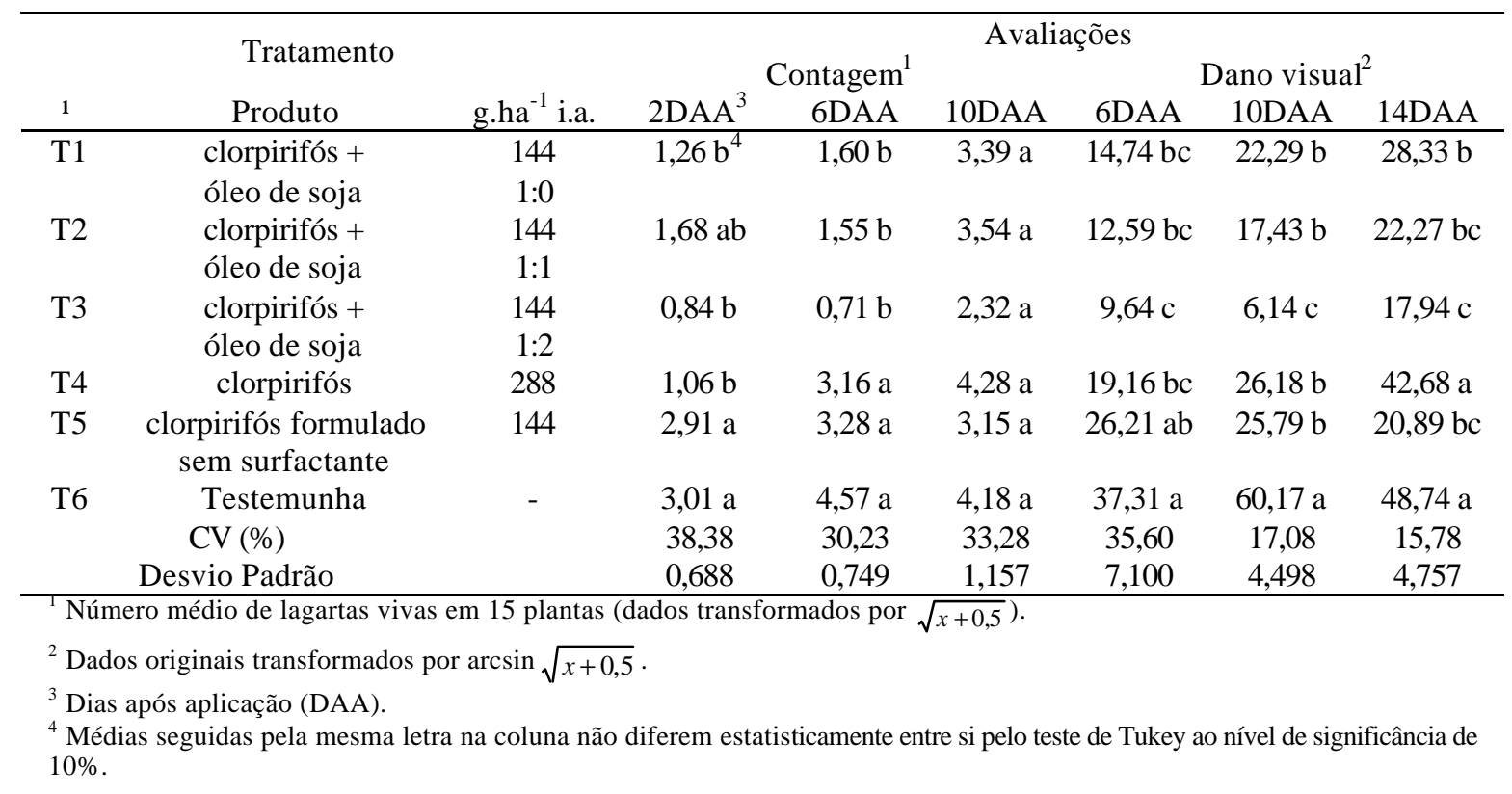

No aspecto de dano visual, aos seis dias apenas o tratamento (T5) não reduziu o dano abaixo do nível econômico, embora diferindo da testemunha e do tratamento com a maior dose de óleo (tratamento T3). Os demais tratamentos não diferiram entre si.

É possível se observar na Tabela 22 (dados transformados),aos 10 e 14 DAA, uma nítida tendência à dose resposta para o teor de óleo, tendência que se mostra estatisticamente. O tratamento padrão (T4) aos quatorze dias não diferia da testemunha, o que foi inesperado. Uma explicação possível pode ser o fato de por ter sido aplicado durante o dia, ter sofrido uma degradação mais rápida por fotólise, além da planta estar menos receptiva com suas estruturas de absorção (ranhuras da cutícula foliar), que estão fechadas para minimizar a perda de água em função do calor e ser esse o horário de maior taxa evapotranspirométrica.

Por outro lado, o tratamento T5 mostrou uma proteção adequada à cultura, não diferindo dos tratamentos dissolvidos em óleo até os quatorze dias após aplicação, 
embora não tenha mostrado controle satisfatório nas primeiras avaliações. Isso poderia ser explicado em função da dose efetivamente aplicada ter sido menor, proporcionando um menor efeito de choque, mas mantendo o efeito residual pela rápida absorção do ativo pela cutícula da folha (formulação lipofílica).

Ao se observar a tendência de dose resposta, os dados obtidos sugerem uma relação entre 1:1 e 1:2 de formulação CE e óleo, corroborando os dados citados em literatura (Costa et al., 1994; Young et al., 1995) que recomendam a proporção de 1:1,6 (produto:óleo) e novamente confirma a melhora no desempenho agronômico dos produtos aplicados dissolvidos em óleos não emulsionáveis quando quimigados.

Face aos problemas havidos na condução desse ensaio sugeriu-se que fosse repetido e dessa vez como um fatorial em blocos para que se pudesse chegar a conclusões mais definitivas sobre o teor de óleo.

\subsubsection{Ensaio III}

Os resultados obtidos nesse ensaio (Tabela 23), que foi aplicado no início da safra de verão de 1997, mostram que a infestação no momento da aplicação era bastante elevada (50\% de folhas raspadas), porém em virtude de condições climáticas (chuvas e reduções bruscas de temperatura), essa infestação caiu rapidamente impossibilitando avaliações após o sexto dia, além de contribuir para o aumento na variabilidade no ensaio.

$\mathrm{Na}$ avaliação de larvas vivas aos 2 DAA, todos os tratamentos mostraram controles satisfatórios, excetuando-se o tratamento T5 que porém não diferiu dos demais tratamentos. O fato foi considerado como variação experimental, variabilidade essa que está um pouco acima do que seria considerado normal para esse tipo de experimento, o que fez levantar a possibilidade da transformação dos dados.

Aos seis dias, os resultados foram totalmente erráticos sendo que nenhum tratamento mostrou qualquer nível de controle, reflexo da interferência climática no ensaio que diminuiu bastante a infestação na área, tanto que não se prosseguiu as avaliações. O tratamento com óleo mineral (T8) mostrou um baixo desempenho o que aponta para a necessidade de maiores estudos em relação a essa variável. 
Tabela 23. Eficiência dos tratamentos no controle da lagarta do cartucho em milho, Nova Fátima/PR, safra de 1997 (Ensaio III).

\begin{tabular}{|c|c|c|c|c|c|c|c|}
\hline \multirow{2}{*}{\multicolumn{3}{|c|}{ Tratamento }} & \multicolumn{5}{|c|}{ Avaliações } \\
\hline & & & \multicolumn{2}{|c|}{$\begin{array}{l}\text { Contagem }^{1} \\
\left(\% \text { controle }^{2}\right)\end{array}$} & \multicolumn{3}{|c|}{$\begin{array}{l}\text { Dano visual } \\
\text { (\% calculada) }\end{array}$} \\
\hline 1 & Produto & g/ha i.a. & $2 \mathrm{DAA}^{3}$ & $6 \mathrm{DAA}$ & 2DAA & 6DAA & 10DAA \\
\hline $\mathrm{T} 1$ & $\begin{array}{l}\text { clorpirifós + óleo de } \\
\text { soja }\end{array}$ & $\begin{array}{c}144 \\
0\end{array}$ & $\begin{array}{l}2,5 b^{4} \\
(87,4)\end{array}$ & $\begin{array}{l}10,2 \mathrm{a} \\
(-24,5)\end{array}$ & $13,0 \mathrm{abc}$ & $13,0 \mathrm{a}$ & $39,3 \mathrm{ab}$ \\
\hline $\mathrm{T} 2$ & $\begin{array}{l}\text { clorpirifós + óleo de } \\
\text { soja }\end{array}$ & $\begin{array}{l}144 \\
1: 1\end{array}$ & $\begin{array}{l}2,2 \mathrm{~b} \\
(89,1)\end{array}$ & $\begin{array}{l}6,0 \mathrm{a} \\
(26,5)\end{array}$ & $4,7 \mathrm{c}$ & $8,7 \mathrm{a}$ & $30,7 \mathrm{ab}$ \\
\hline $\mathrm{T} 3$ & $\begin{array}{l}\text { clorpirifós + óleo de } \\
\text { soja }\end{array}$ & $\begin{array}{c}144 \\
1: 2\end{array}$ & $\begin{array}{l}1,5 \mathrm{~b} \\
(92,4)\end{array}$ & $\begin{array}{c}5,5 \mathrm{a} \\
(32,7)\end{array}$ & $9,0 \mathrm{c}$ & $9,3 \mathrm{a}$ & $25,3 \mathrm{ab}$ \\
\hline $\mathrm{T} 4$ & $\begin{array}{c}\text { clorpirifós + óleo de } \\
\text { soja }\end{array}$ & $\begin{array}{c}288 \\
0\end{array}$ & $\begin{array}{l}1,5 \mathrm{~b} \\
(92,4)\end{array}$ & $\begin{array}{c}7,0 \mathrm{a} \\
(14,3)\end{array}$ & $3,0 \mathrm{c}$ & $10,7 \mathrm{a}$ & $18,7 \mathrm{~b}$ \\
\hline T5 & $\begin{array}{l}\text { clorpirifós + óleo de } \\
\text { soja }\end{array}$ & $\begin{array}{c}288 \\
1: 1\end{array}$ & $\begin{array}{l}6,5 \mathrm{~b} \\
(67,2)\end{array}$ & $\begin{array}{l}14,5 \mathrm{a} \\
(-77,5)\end{array}$ & $23,7 \mathrm{abc}$ & $28,3 \mathrm{a}$ & $35,6 \mathrm{ab}$ \\
\hline T6 & $\begin{array}{l}\text { clorpirifós + óleo de } \\
\text { soja }\end{array}$ & $\begin{array}{r}288 \\
1: 2\end{array}$ & $\begin{array}{l}2,6 \mathrm{~b} \\
(87,0)\end{array}$ & $\begin{array}{l}8,9 \mathrm{a} \\
(-9,5)\end{array}$ & $13,8 \mathrm{abc}$ & $12,5 \mathrm{a}$ & $19,6 \mathrm{~b}$ \\
\hline $\mathrm{T} 7$ & $\begin{array}{l}\text { clorpirifós formulado } \\
\text { sem surfactante }\end{array}$ & 144 & $\begin{array}{l}1,3 \mathrm{~b} \\
(93,3)\end{array}$ & $\begin{array}{l}10,5 \mathrm{a} \\
(-28,6)\end{array}$ & $11,3 \mathrm{bc}$ & $9,3 \mathrm{a}$ & $43,3 \mathrm{a}$ \\
\hline $\mathrm{T} 8$ & $\begin{array}{c}\text { clorpirifós + óleo } \\
\text { mineral }\end{array}$ & 144 & $\begin{array}{l}6,8 \mathrm{~b} \\
(65,5)\end{array}$ & $\begin{array}{l}6,7 \mathrm{a} \\
(18,1)\end{array}$ & $38,3 \mathrm{ab}$ & $23,5 \mathrm{a}$ & $21,6 \mathrm{~b}$ \\
\hline T9 & Testemunha & - & $\begin{array}{c}19,8 \mathrm{a} \\
(0,0)\end{array}$ & $\begin{array}{l}8,2 \mathrm{a} \\
(0,0)\end{array}$ & $40,3 \mathrm{a}$ & $23,0 \mathrm{a}$ & $29,3 \mathrm{ab}$ \\
\hline & $\mathrm{CV}(\%)$ & & 132,36 & 74,25 & 91,78 & 77,81 & 41,26 \\
\hline & Desvio Padrão & & 6,58 & 6,39 & 16,02 & 11,96 & 12,08 \\
\hline
\end{tabular}

No parâmetro dano visual, o desempenho foi semelhante. Aos 2 DAA, os tratamentos não diferiram entre si, diferindo apenas em relação à testemunha. Aos 6 DAA, não houve diferenças estatísticas entre nenhum tratamento. Aos 10 DAA, praticamente todos os tratamentos já atingiram o nível de dano econômico, porém aqueles dissolvidos em óleo ainda mostravam alguma diferença em relação à testemunha e ao padrão, excetuando-se o tratamento (T7). Uma possível explicação para a menor proteção à cultura do tratamento padrão (tratamento T4) aos 10 DAA, seria em relação 
aos inimigos naturais. No momento em que o produto estaria perdendo o seu efeito residual, seria o momento de ação dos mesmos. Porém, como sofreram um efeito de choque maior em função da dose do padrão, o restabelecimento da população se dará de modo mais lento. A mistura com óleo mineral (tratamento T8) se mostrou aquém do esperado, e abre espaço para questionamentos e novos estudos. A análise para os dados transformados (Tabela 24) não mostra alterações significativas em relação a análise feita com os dados originais. Apenas para a avaliação de contagem aos 2 DAA, o tratamento T5 mostra não ser estatisticamente diferente nem em relação aos demais tratamentos e nem à testemunha.

Tabela 24. Eficiência dos tratamentos no controle da lagarta do cartucho em milho, Nova Fátima/PR, safra de 1997 (Ensaio III). Dados transformados.

\begin{tabular}{|c|c|c|c|c|c|c|c|}
\hline \multirow{2}{*}{\multicolumn{3}{|c|}{ Tratamento }} & \multicolumn{5}{|c|}{ Avaliações } \\
\hline & & & \multicolumn{2}{|c|}{ Contagem $^{1}$} & \multicolumn{3}{|c|}{ Dano visual ${ }^{2}$} \\
\hline 1 & Produto & g.ha ${ }^{-1}$ i.a. & $2 \mathrm{DAA}^{3}$ & 6DAA & 2DAA & 6DAA & 10DAA \\
\hline \multirow[t]{2}{*}{$\mathrm{T} 1$} & clorpirifós + & 144 & $1,62 b^{4}$ & $3,16 \mathrm{a}$ & $20,70 \mathrm{ab}$ & $20,19 a$ & $38,54 \mathrm{ab}$ \\
\hline & óleo de soja & $1: 0$ & & & & & \\
\hline \multirow[t]{2}{*}{$\mathrm{T} 2$} & clorpirifós + & 144 & $1,56 \mathrm{~b}$ & $2,44 \mathrm{a}$ & $12,29 b$ & $16,23 \mathrm{a}$ & $32,04 \mathrm{ab}$ \\
\hline & óleo de soja & $1: 1$ & & & & & \\
\hline \multirow[t]{2}{*}{$\mathrm{T} 3$} & clorpirifós + & 144 & $1,31 \mathrm{~b}$ & $2,39 \mathrm{a}$ & $15,87 \mathrm{~b}$ & $15,12 \mathrm{a}$ & $30,15 \mathrm{ab}$ \\
\hline & óleo de soja & $1: 2$ & & & & & \\
\hline \multirow[t]{2}{*}{$\mathrm{T} 4$} & clorpirifós + & 288 & $1,34 \mathrm{~b}$ & $2,68 \mathrm{a}$ & $8,92 \mathrm{~b}$ & $18,53 \mathrm{a}$ & $25,55 \mathrm{~b}$ \\
\hline & óleo de soja & 1:0 & & & & & \\
\hline \multirow[t]{2}{*}{ T5 } & clorpirifós + & 288 & $2,32 \mathrm{ab}$ & $3,72 \mathrm{a}$ & $26,05 \mathrm{ab}$ & $30,52 \mathrm{a}$ & $36,23 \mathrm{ab}$ \\
\hline & óleo de soja & $1: 1$ & & & & & \\
\hline \multirow[t]{2}{*}{ T6 } & clorpirifós + & 288 & $1,57 \mathrm{~b}$ & $2,99 \mathrm{a}$ & $20,47 \mathrm{ab}$ & $19,69 \mathrm{a}$ & $26,19 \mathrm{~b}$ \\
\hline & óleo de soja & $1: 2$ & & & & & \\
\hline \multirow[t]{2}{*}{$\mathrm{T} 7$} & clorpirifós formulado & 144 & $1,27 \mathrm{~b}$ & $3,14 \mathrm{a}$ & $17,69 \mathrm{ab}$ & $16,86 \mathrm{a}$ & $41,11 \mathrm{a}$ \\
\hline & sem surfactante & & & & & & \\
\hline $\mathrm{T} 8$ & $\begin{array}{l}\text { clorpirifós + } \\
\text { óleo mineral }\end{array}$ & 144 & $2,57 \mathrm{ab}$ & $2,67 \mathrm{a}$ & $36,85 \mathrm{a}$ & $27,32 \mathrm{a}$ & $26,23 \mathrm{~b}$ \\
\hline \multirow[t]{3}{*}{ T9 } & Testemunha & - & $4,04 \mathrm{a}$ & $2,70 \mathrm{a}$ & 37,39 a & $28,15 \mathrm{a}$ & $32,38 \mathrm{ab}$ \\
\hline & $\mathrm{CV}(\%)$ & & 51,19 & 32,21 & 54,73 & 43,64 & 24,99 \\
\hline & Desvio Padrão & & 1,001 & 0,927 & 11,933 & 9,341 & 8,009 \\
\hline \multicolumn{8}{|c|}{ Número médio de lagartas vivas em 15 plantas (dados transformados por $\sqrt{x+0,5}$ ). } \\
\hline \multicolumn{8}{|c|}{ Dados originais transformados por $\arcsin \sqrt{x+0,5}$} \\
\hline \multicolumn{8}{|c|}{${ }^{3}$ Dias após aplicação (DAA) } \\
\hline
\end{tabular}


A análise fatorial detalhada pode ser observada nas Tabela 26 a 28, e na Tabela 25 um resumo das interações significativas ao nível de significância de 10\%, nota-se a significância na interação entre dose e teor óleo.

Tabela 25. Significância da análise fatorial do teste de probabilidade $(\mathrm{F})$ para o controle de Lagarta do cartucho.

\begin{tabular}{cccccc}
\hline & \multicolumn{2}{c}{ Contagem de lagartas vivas } & \multicolumn{3}{c}{ Dano visual (\%calculado) } \\
Origem & 2 DAA & 6 DAA & 2 DAA & 6 DAA & 10 DAA \\
\hline Repetições & NS & NS & NS & NS & NS \\
Fator A: Dose & NS & NS & NS & NS & S \\
Fator B: Teor de óleo & NS & NS & NS & NS & S \\
A x B & NS & S & S & NS & S \\
\hline
\end{tabular}

S e NS : Significativo e Não Significativo ao nível de $10 \%$ de probabilidade, respectivamente.

Tabela 26. Análise Fatorial para contagem de lagartas aos 2 dias após aplicação.

\begin{tabular}{ccrrrrc}
\hline Origem & GL & \multicolumn{1}{c}{ SQ } & QM & F & Prob(F) & LSD $(0,10)$ \\
\hline Total & 35 & 541,029563 & & & & \\
Repetições & 5 & 46,853487 & 9,3707 & 0,603 & 0,6982 & 4,69 \\
Fator A: Dose & 1 & 19,488062 & 19,4881 & 1,254 & 0,2734 & 2,71 \\
Fator B: Óleo & 2 & 42,810919 & 21,4055 & 1,377 & 0,2707 & 3,32 \\
AB & 2 & 43,352220 & 21,6761 & 1,395 & 0,2665 & 4,69 \\
Erro & 25 & 388,524874 & 15,5410 & & & \\
\hline
\end{tabular}

Tabela 27. Análise Fatorial para contagem de lagartas aos 6 dias após aplicação.

\begin{tabular}{ccrrrrr}
\hline Origem & GL & \multicolumn{1}{c}{ SQ } & QM & F & Prob(F) & LSD $(0,10)$ \\
\hline Total & 35 & 1270,844076 & & & & \\
Repetições & 5 & 196,630394 & 39,3261 & 1,335 & 0,2822 & 6,46 \\
Fator A: Dose & 1 & 76,948062 & 76,9481 & 2,612 & 0,1186 & 3,73 \\
Fator B: Óleo & 2 & 55,292779 & 27,646389 & 0,938 & 0,4046 & 4,57 \\
AB & 2 & 205,358648 & 102,6793 & 3,485 & 0,0462 & 6,46 \\
Erro & 25 & 736,614193 & 29,4646 & & & \\
\hline
\end{tabular}

Tabela 28. Análise fatorial para percentagem calculada de dano visual aos 2 dias após aplicação.

\begin{tabular}{ccrrrcc}
\hline Origem & GL & \multicolumn{1}{c}{ SQ } & QM & F & Prob(F) & LSD $(0,10)$ \\
\hline Total & 35 & 4094,249866 & & & & \\
Repetições & 5 & 129,829327 & 25,9659 & 0,284 & 0,9173 & 11,37 \\
Fator A: Dose & 1 & 189,745132 & 189,7451 & 2,077 & 0,1620 & 6,56 \\
Fator B: Óleo & 2 & 228,906320 & 114,4532 & 1,253 & 0,3031 & 8,04 \\
AB & 2 & 1261,651031 & 630,8255 & 6,904 & 0,0041 & 11,37 \\
Erro & 25 & 2284,118056 & 91,3647 & & & \\
\hline
\end{tabular}


Tabela 29. Análise Fatorial para percentagem calculada de dano visual aos 6 dias após aplicação.

\begin{tabular}{ccrrrcc}
\hline Origem & GL & \multicolumn{1}{c}{ SQ } & QM & F & Prob(F) & LSD $(0,10)$ \\
\hline Total & 35 & 6236,748749 & & & & \\
Repetições & 5 & 457,508141 & 91,5016 & 0,550 & 0,7370 & 15,34 \\
Fator A: Dose & 1 & 418,847147 & 418,8471 & 2,517 & 0,1252 & 8,86 \\
Fator B: Óleo & 2 & 412,333370 & 206,1667 & 1,239 & 0,3069 & 10,85 \\
AB & 2 & 787,255725 & 393,6279 & 2,365 & 0,1146 & 15,34 \\
Erro & 25 & 4160,814367 & 166,4326 & & & \\
\hline
\end{tabular}

Tabela 30. Análise Fatorial para percentagem calculada de dano visual aos 10 dias após aplicação.

\begin{tabular}{ccrlccc}
\hline Origem & GL & \multicolumn{1}{c}{ SQ } & QM & F & Prob(F) & LSD $(0,10)$ \\
\hline Total & 35 & 6158,543665 & & & & \\
Repetições & 5 & 946,577274 & 189,3155 & 1,544 & 0,2123 & 10,92 \\
Fator A: Dose & 1 & 459,601898 & 459,6019 & 3,749 & 0,0642 & 6,30 \\
Fator B: Óleo & 2 & 694,166612 & 347,0833 & 2,831 & 0,0779 & 7,72 \\
AB & 2 & 993,349037 & 496,6745 & 4,051 & 0,0229 & 10,92 \\
Erro & 25 & 3064,848844 & 122,5939 & & & \\
\hline
\end{tabular}

\subsection{Análise consolidada}

Os dados consolidados dos três ensaios também são mostrados na sua forma original (Tabela 31), e após a transformação (Tabela 32). Para a consolidação, foram agrupadas as avaliações de dois e três, e nove e dez dias após aplicação, por não representar um efeito significativo na análise final.

A análise consolidada apenas confirma as tendências observadas nas análises individuais. No parâmetro contagem aos 2 DAA todos os tratamentos atingiram níveis aceitáveis de controle não diferindo entre si, mas diferindo em relação à testemunha. Numericamente os melhores tratamentos são o padrão (T4) e a formulação CE dissolvida em óleo na maior concentração (T3). Aos 6 DAA, no entanto, embora nenhum tratamento seja estatisticamente diferente da testemunha, os tratamentos dissolvidos em óleo (T2) e (T3) ainda provêm um controle próximo a 80\%, enquanto que o padrão (T4) já perdeu a sua efetividade. Este resultado parece indicar que a presença do óleo sem o emulsificante efetivamente favorece a absorção pelas folhas do produto contribuindo para um maior efeito residual. 
Tabela 31. Eficiência dos tratamentos no controle da lagarta do cartucho em milho. Dados originais consolidados dos três ensaios.

\begin{tabular}{|c|c|c|c|c|c|c|}
\hline \multirow{2}{*}{\multicolumn{3}{|c|}{ Tratamento }} & \multicolumn{4}{|c|}{ Avaliações } \\
\hline & & & \multicolumn{2}{|c|}{$\begin{array}{l}\text { Contagem } \\
\left(\% \text { controle }^{2}\right)\end{array}$} & \multicolumn{2}{|c|}{$\begin{array}{l}\text { Dano visual } \\
\text { (\% calculada) }\end{array}$} \\
\hline 1 & Produto & g.ha ${ }^{-1}$ i.a. & $2 \mathrm{DAA}^{3}$ & 6DAA & 6DAA & 10DAA \\
\hline $\mathrm{T} 1$ & $\begin{array}{l}\text { clorpirifós + } \\
\text { óleo de soja }\end{array}$ & $\begin{array}{l}144 \\
1: 0\end{array}$ & $\begin{array}{l}3,2 b^{4} \\
(86,0)\end{array}$ & $\begin{array}{r}7,6 \mathrm{a} \\
(62,7)\end{array}$ & $7,2 \mathrm{~b}$ & $20,8 \mathrm{a}$ \\
\hline $\mathrm{T} 2$ & $\begin{array}{l}\text { clorpirifós + } \\
\text { óleo de soja }\end{array}$ & $\begin{array}{r}144 \\
1: 1\end{array}$ & $\begin{array}{l}3,0 \mathrm{~b} \\
(86,9)\end{array}$ & $\begin{array}{r}4,4 \mathrm{a} \\
(78,3)\end{array}$ & $6,6 \mathrm{~b}$ & $14,6 \mathrm{a}$ \\
\hline $\mathrm{T} 3$ & $\begin{array}{l}\text { clorpirifós + } \\
\text { óleo de soja }\end{array}$ & $\begin{array}{r}144 \\
1: 2\end{array}$ & $\begin{array}{l}1,3 \mathrm{~b} \\
(94,1)\end{array}$ & $\begin{array}{r}4,6 \mathrm{a} \\
(77,6)\end{array}$ & $6,2 \mathrm{~b}$ & $13,9 \mathrm{a}$ \\
\hline $\mathrm{T} 4$ & $\begin{array}{l}\text { clorpirifós + } \\
\text { óleo de soja }\end{array}$ & $\begin{array}{r}288 \\
1: 0\end{array}$ & $\begin{array}{l}1,4 \mathrm{~b} \\
(93,7)\end{array}$ & $\begin{array}{c}9,6 \mathrm{a} \\
(53,0)\end{array}$ & $11,3 \mathrm{~b}$ & $22,5 \mathrm{a}$ \\
\hline T5 & $\begin{array}{l}\text { clorpirifós formulado } \\
\text { sem surfactante }\end{array}$ & 144 & $\begin{array}{l}6,1 \mathrm{~b} \\
(73,1)\end{array}$ & $\begin{array}{l}12,3 \mathrm{a} \\
(40,1)\end{array}$ & $10,6 \mathrm{~b}$ & $22,4 \mathrm{a}$ \\
\hline T6 & Testemunha & - & $\begin{array}{l}22,5 \mathrm{a} \\
(0,0)\end{array}$ & $\begin{array}{c}20,5 \mathrm{a} \\
(0,0)\end{array}$ & $33,6 \mathrm{a}$ & $40,6 \mathrm{a}$ \\
\hline & CV (\%) & & 84,68 & 69,46 & 54,15 & 72,65 \\
\hline & Desvio Padrão & & 5,29 & 6,84 & 6,80 & 16,32 \\
\hline
\end{tabular}

Número médio de lagartas vivas em 15 plantas.

${ }^{2}$ Entre parênteses: percentagem de controle calculada segundo Abbott.

${ }^{3}$ Dia após aplicação (DAA)

${ }^{4}$ Médias seguidas pela mesma letra na coluna não diferem estatisticamente entre si pelo teste de Tukey ao nível de significância de $10 \%$.

Outro fato que chama a atenção é que a formulação pronta sem emulsificante (T5) mostrou um resultado aquém do esperado e citado em literatura. Isto levanta a questão em relação ao tipo de óleo, pois como já mencionado, as formulações comerciais em sua absoluta maioria utilizam óleos minerais (cadeia de hidrocarbonetos longa) como solventes. Este dado confirma também o obtido no ensaio III (T8), onde a dissolução da formulação CE em óleo mineral não apresentou um bom desempenho.

A consistência dos dados para o parâmetro contagem aos 2 DAA é mostrada na Figura 19. Os números sobre cada tratamento mostram o número de ensaios sumarizados. Nos tratamentos comuns a todos os experimentos, tem-se um total de catorze pontos de dados sumarizados. 
Tabela 32. Eficiência dos tratamentos no controle da lagarta do cartucho em milho. Dados transformados, consolidados dos três ensaios.

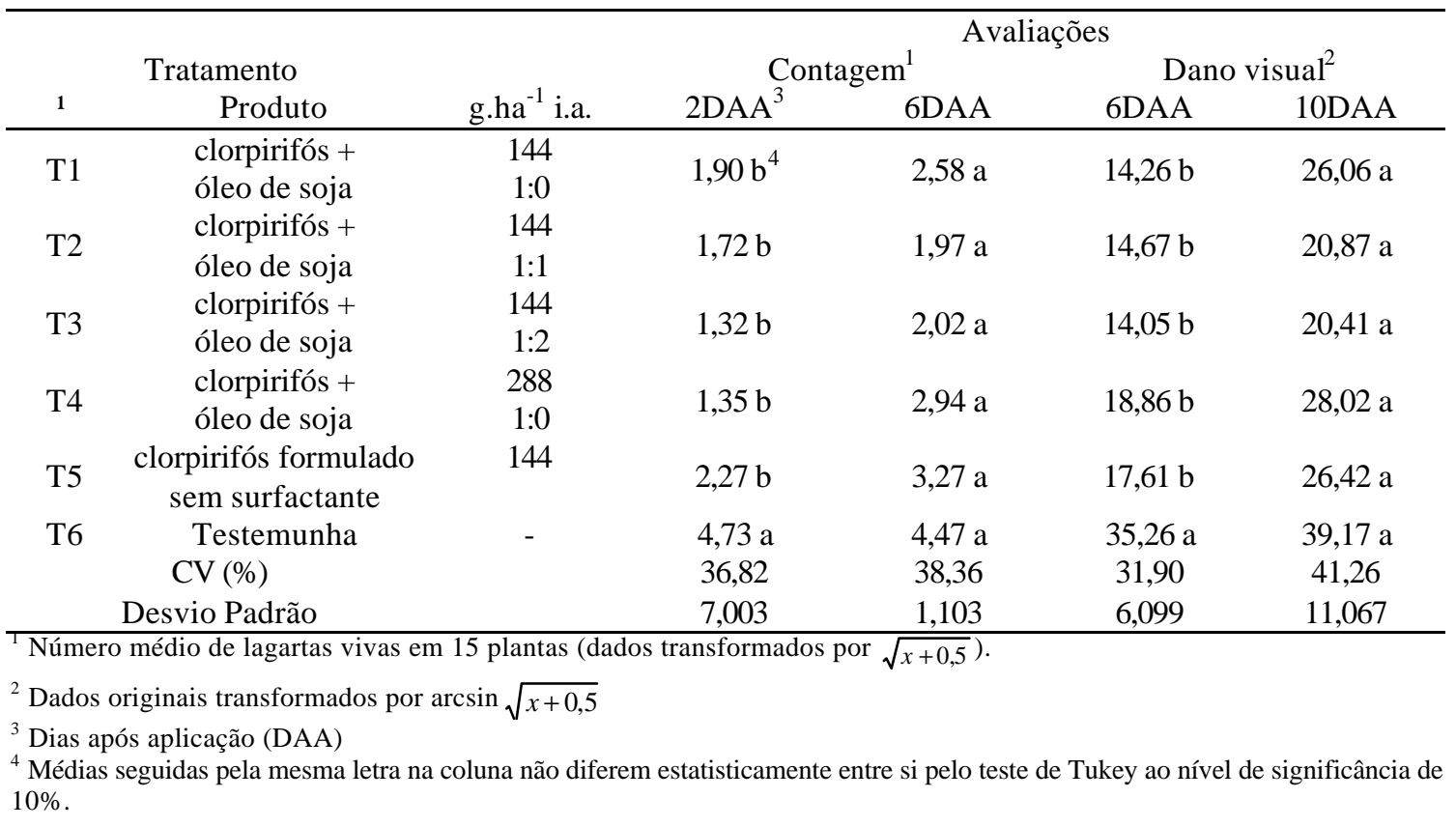

A avaliação consolidada do percentual de dano visual aos 6 e 10 DAA, mantém o perfil observado para contagem (é lógico pois é reflexo do mesmo), com nenhum tratamento diferindo entre si aos 6 DAA, mas diferindo em relação à testemunha. Todos os tratamentos proveram proteção à cultura abaixo do nível de dano econômico considerado de $20 \%$, que, de modo geral, situou-se abaixo da metade do nível observado na testemunha.

Em função da forte pressão da praga nos três ensaios, aos 10 DAA todos os tratamentos já não apresentavam proteções adequadas, sendo o momento para uma reaplicação. Novamente os tratamentos T2 e T3, dissolvidos em óleo, mostraram uma leve superioridade. Embora de maneira mais sutil que nas análises individuais, na análise consolidada também se observa uma tendência à dose resposta para o teor de óleo tanto aos 6 como aos 10 DAA.

A análise de consistência dos dados para este parâmetro é mostrada na Figura 20para a avaliação aos 6 DAA, e na Figura 21avaliação aos 10 DAA. Novamente, o número sobre o tratamento indica o número de ensaios sumarizados. 

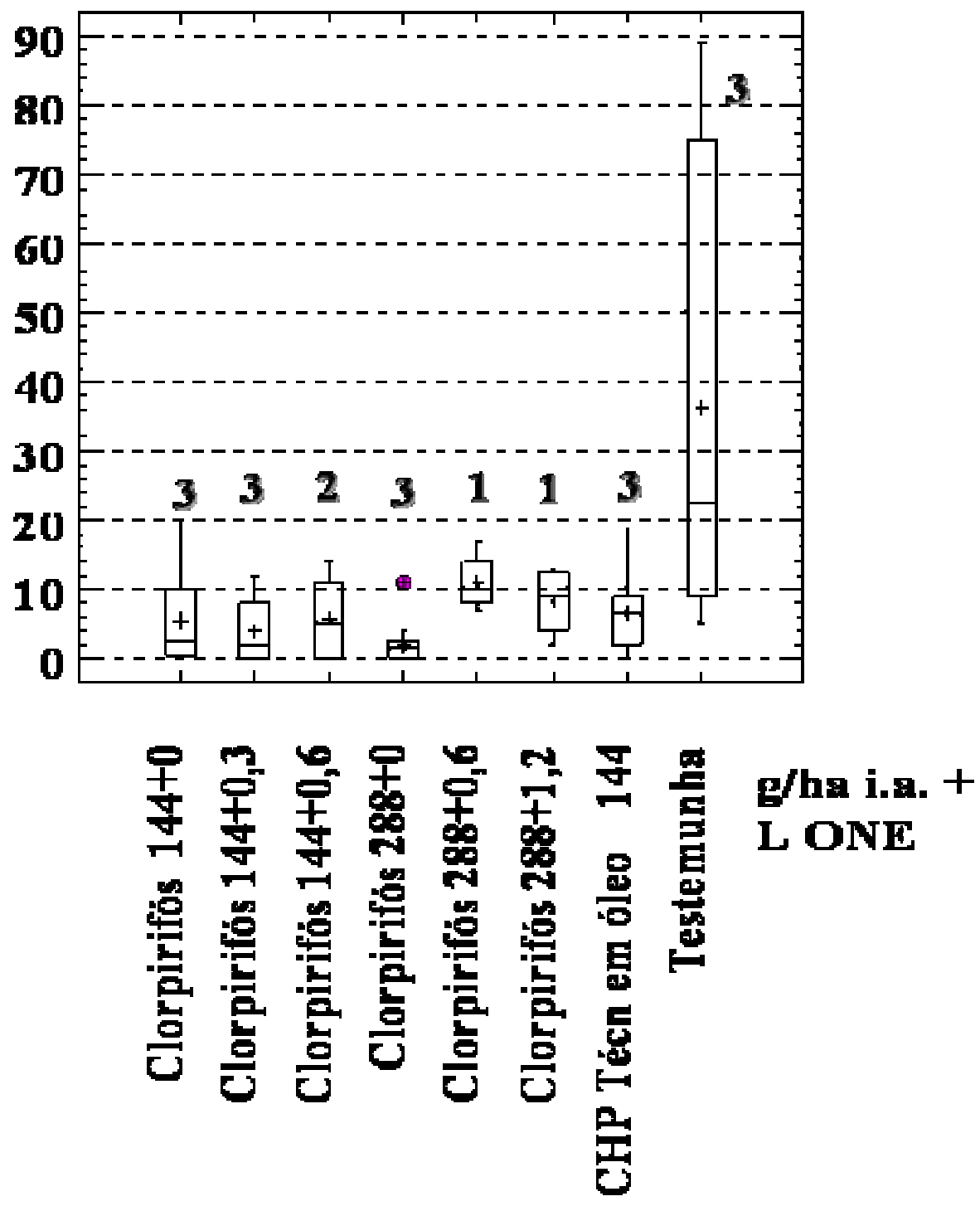

Figura 19 - Análise consolidada dos três ensaios quanto à contagem de lagartas vivas aos 2 dias após aplicação. 


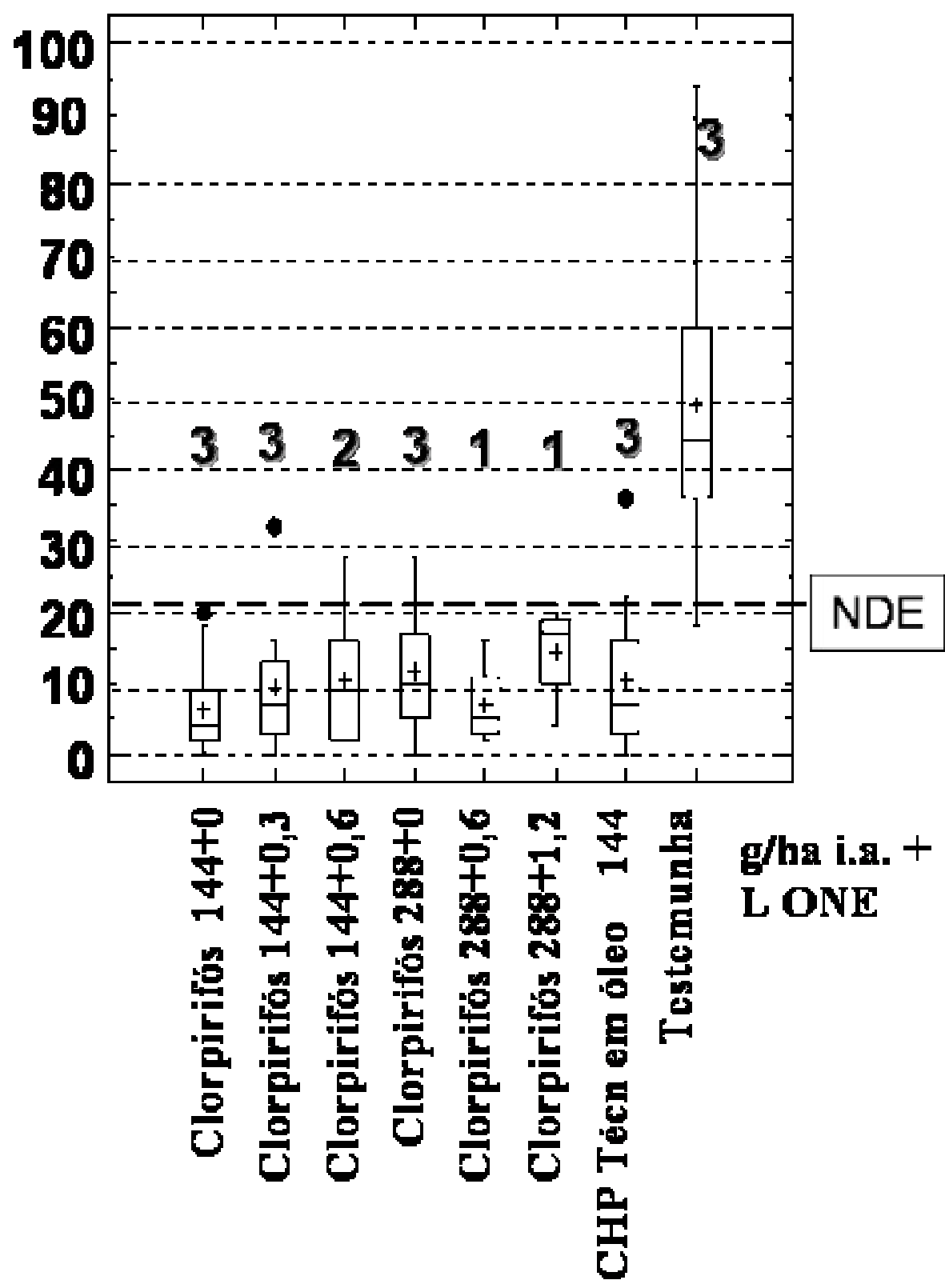

Figura 20 - Análise consolidada dos três ensaios quanto à percentagem de dano visual aos 6 dias após aplicação. (NDE: Nível de Dano Econômico).

As três figuras mostram que a menor dose com óleo apresentou um controle equivalente ao tratamento padrão (Formulação CE a 288 g. ha ${ }^{-1}$ i.a., sem óleo). Porém a Figura 21 (10 DAA) mostra uma menor consistência dos dados o que era esperado pela dose reduzida aplicada. 


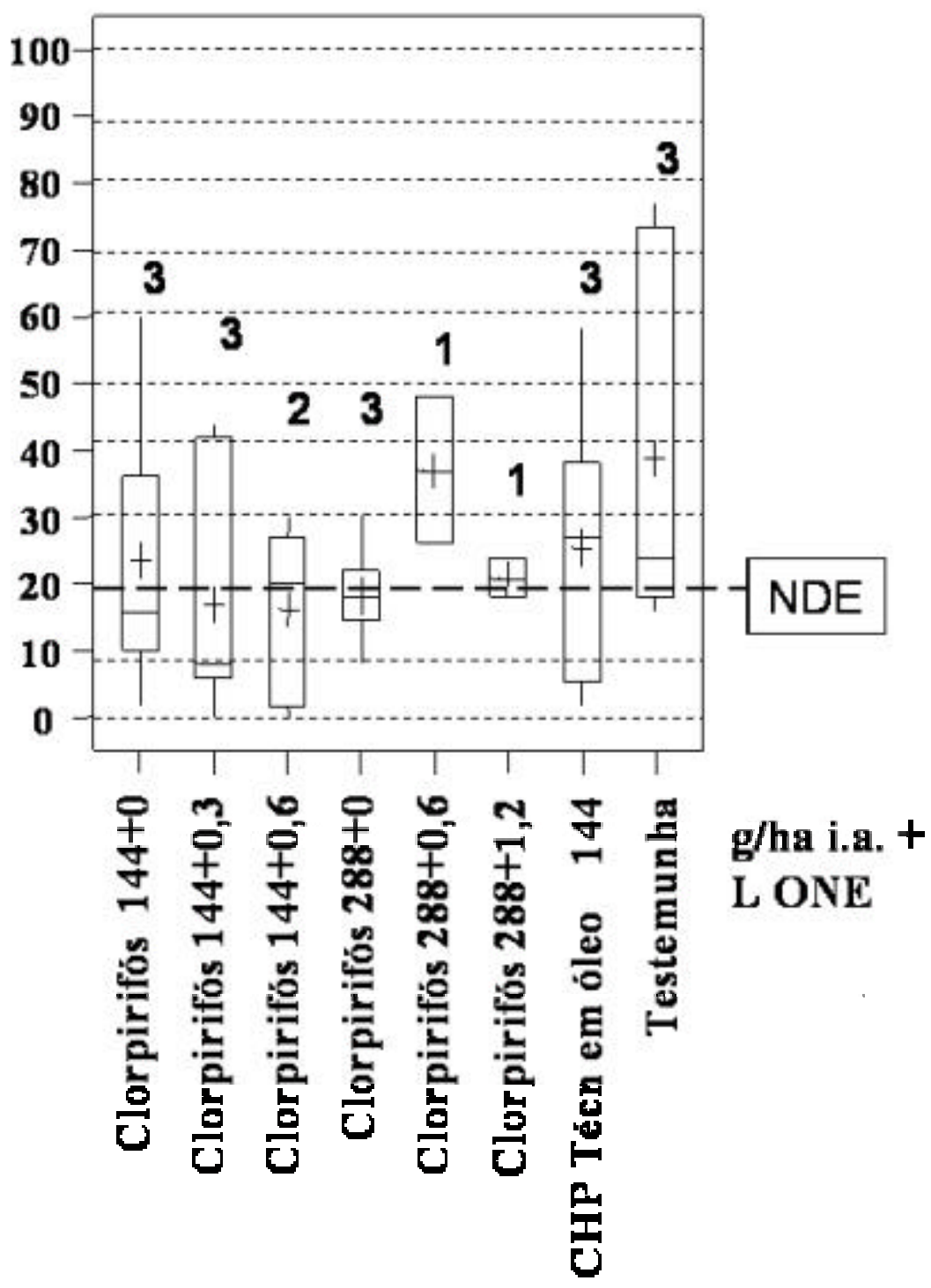

Figura 21 - Análise consolidada dos três ensaios quanto à percentagem de dano visual aos 10 dias após aplicação. (NDE: Nível de Dano Econômico).

A menor dose (144 g.ha ${ }^{-1}$ i.a.) sem óleo sempre foi menos consistente que a dose cheia (288 g.ha ${ }^{-1}$ i.a.) na mesma condição. Os resultados, embora não concludentes, 
assinalam para uma possível redução de dose mediante a dissolução da formulação CE em óleo sem emulsificante e a injeção direta dessa mistura.

Um ensaio utilizando teor de óleo como dose resposta, subsidiaria o melhor entendimento sobre a relação entre teor de óleo e quantidade de ingrediente ativo no alvo folha.

\subsection{Considerações finais}

O melhor entendimento dos princípios que regem a formação de emulsões em tubulações com regime de escoamento turbulento, associado ao entendimento dos processos de absorção de produtos pelas plantas, parece ser a chave para o entendimento da quimigação enquanto tecnologia de aplicação eficiente e de baixo custo.

Determinar qual a proporção produto e óleo mais adequada, para os diferentes tipos de óleo, é outro ponto que merece um maior estudo. 


\section{CONCLUSÕES}

De acordo com os resultados obtidos, pode-se concluir que: (i) a dissolução da formulação concentrado emulsionável de clorpirifós em óleos sem surfactantes mostrouse eficaz e consistente para o controle de lagarta do cartucho em milho, (ii) há a necessidade do desenvolvimento de formulações específicas para quimigação, com o ingrediente ativo dissolvido em óleo sem surfactante (ou emulsificante). A adição de óleo a formulações já registradas é uma alternativa tecnológica para o produtor, (iii) há a possibilidade da redução da dose aplicada, ou do número de aplicações pela dissolução em óleo da formulação CE, e (iv) a metodologia utilizada para a instalação dos ensaios mostrou-se adequada. 


\section{REFERÊNCIAS BIBLIOGRÁFICAS}

ABBOTT, W.S. A method of computing the effectiveness of an insecticide. Journal of Economic Entomology, v.18, p.265-267, 1925.

AMERICAN SOCIETY OF AGRICULTURAL ENGINEERS (ASAE) Safety devices for chemigation. St. Joseph/MI, p. 890-892, 2000. (ASAE Standards EP 409)

ASSOCIAÇÃO BRASILEIRA DE NORMAS TÉCNICAS (ABNT) Equipamentos de irrigação mecanizada - Pivô central e lateral móvel providos de emissores fixos ou rotativos - Determinação da uniformidade de distribuição de água. S.n.t.(Norma NBR 14244).

BANZATTO, D.A.; KRONKA, S.N. Experimentação agrícola. Jaboticabal: FUNEP, 1989. 247p.

BASANTA, M.V. Modelo para estimativa do volume máximo de calda visando aplicação foliar de produtos químicos na cultura de milho (Zea mays, L.) Piracicaba/SP, 1999. 65p. Dissertação(Mestrado) - Escola Superior de Agricultura "Luiz de Queiroz", Universidade de São Paulo.

BECHER, D.Z. Applications and Agriculture. BECHER, P. (Ed.). Encyclopedia of emulsion technology, New York: Marcel Dekker, 1985, v.2, cap.4, p.239-320.

BERNARDO, S. Manual de irrigação.2. ed. Viçosa: UFV, Imprensa Universitária, 1982. 462p.

BLEIHOLDER, H.; KIRFEL, H.; LANGELUEDDEKE, P.; STAUSS, R. Codificação unificada dos estádios fenológicos de culturas e ervas daninhas. Pesquisa Agropecuária Brasileira, v.26, n.9, p.1423-1429, 1991.

BODE, L.E.; GEBHART, M.E.; DAY, C.L. Spray deposits pattern and droplet sizes obtained from nozzles used for low volume applications. Transaction of the ASAE, v.11, n.6, p.754-756, 1968. 
BRENNEMAN, T.B.; SUMNER, D.R. Application of ethyltrianol via chemigation and ground sprays for peanut disease Control. Phytopathology, v.78, n.12, p.1561$1562,1988$.

BRENNEMAN, T.B.; SUMNER, D.R.; HARRISON, G.W. Deposition and retention of chlorotalonil applied to peanut foliage: effect of application methods. Peanut Science, v.17, n.2, p. 14-16,1990.

BUSCHMAN, L.L.; LAMM, F.R.; SLODERBECK, P.E.; DICK, G.L. Chemigation in corn; effect of non-emulsified oils and sprinkler package on the efficacy of corn borers (Lepidoptera: Pyralidae) insecticides. Journal of Economic Entomology, v.78, n.6, p.1331-1336, 1985.

BYERS, M.E.; KAMBLE, S.T.; WITKOWSKY, J.F. Assessing insecticide drift during and after center pivot chemigation to corn using glass plates and gauze pads. Bulletin of environmental Contamination Toxicology, v.65, p.522-529, 2000.

CHALFANT, R.B.; YOUNG, J.R. Chemigation to manage insect pests of vegetables, peanuts and soybeans. In: NATIONAL SYMPOSIUM ON CHEMIGATION, 1., Tifton/GA, 1981. Proceedings. Tifton: University of Georgia, 1981, p.65-73.

CHALFANT, R.B.; YOUNG, J.R. Chemigation, or application of insecticides through overhead sprinkler irrigation systems, to manage insect pests infesting vegetable and agronomic crops. Journal of Economic Entomology, v.75, n.2, p.237-241, 1982.

CHALFANT, R.B.; HALL, M.; SEAL, D.R. Insecticidal control of soil insects of sweet potatoes in the Georgia coastal plain. Applied Agriculture Research, v.2, n.3, p.152-157, 1987.

CHALFANT, R.B.; BONDARI, K.; SUMNER, H.R.; HALL, M.R. Reduction of wireworm (Coleoptera: Elateridae) damage in Sweet Potato with insecticides applied by chemigation. Journal of Economic Entomology, v.86, n.1, p.123-130, 1993.

CHANDLER, L.D.; SUMNER, H.R. Effect of various chemigation methodologies on suppression of the fall armyworm (Lepidopterae: Noctuidae) in corn. Florida Entomologist, v.74, n.2, p.270-279, 1991. 
CHANDLER, L.D.; SUMNER, H.R. HERZOG, G.A. Management of bollworm in sprinkler irrigated coton: residual activity of four classes of insecticides applied via chemigation. In: BELTWIDE COTTON CONFERENCE, s.l., Proceedings, S.n.t., v.3, p.1614-1616, 1993.

CHRISTIANSEN, J.E. Irrigation by sprinkler. Berkeley: California Agricultural Station, 1942. 124 p. (Bulletin,670)

CHRISTOFIDIS, D. Irrigação, a fronteira hídrica e a produção de alimentos. Irrigação e Tecnologia Moderna - ITEM, n.54, p.46-55, 2002.

COCHRAN, D.L.; THREADGILL, E.D.; YOUNG, J.R. Effects of pressure and sprinkler orifice diameter on oil-formulated insecticide used in chemigation. St. Joseph/MI: ASAE., 1985. 14 p. (ASAE paper, 85-2577)

COCHRAN, D.L.; THREADGIL, E.D.; LAW, S.E. Physical properties of three oils and oil-insecticide formulations used in agriculture. Transaction of the ASAE, v.30, n.5, p.1338-1342, 1987.

COELHO, R.D. Caracterização do sistema pivô central (LEPA) operando em condição de microrelevo condicionado. Piracicaba, 1996. 181p. Tese(Doutorado) - Escola de Engenharia de São Carlos, Universidade de São Paulo.

COLLINS, S.B.; KNUDSEN, J.G. Drop size distributions produced by turbulent pipe flow of immiscible liquids. AICHE Journal, v.16, n.6, p.1072-1080, 1970.

COSTA, E.F.; VIEIRA, R.F.; VIANA, P.A. (Ed.). Quimigação - aplicação de produtos químicos e biológicos via irrigação. Brasília/DF: EMBRAPA- CNPMS, 1994. 315p.

CRUZ, O.C. Distribuição horizontal do inseticida clorpirifós aplicado via pivô central em cultura de milho (Zea mays L.) e sua retenção no dossel das plantas. Lavras/MG. Lavras, 1997. 54 p. Dissertação (Mestrado) Universidade Federal de Lavras.

CSINOS, A.S.; JOHNSON, A.W.; GOLDEN, A.M. Application of Ridomil and Nemacur conventionally and through irrigation water for vontrol of black shank and nematodes. In: NATIONAL SYMPOSIUM ON CHEMIGATION, 3., Tifton/GA, 1985. Proceedings, Tifton/GA: University of Georgia: 1985. 92-98p. 
CSINOS, A.S.; JOHNSON, A.W.; GOLDEN, A.M. Metalaxyl and fenamiphos applied through irrigation water to control Blank Shank / Root not complex in tobacco. Plant Disease, v.70, n.3, p.210-213, 1986.

CUNHA, J.P.A.; TEIXEIRA, M.M.; VIEIRA, R.F.; BARBOSA, L.C. A fungigação: uniformidade de distribuição do epoxiconazole em três lâminas de água no feijoeiro (Phaseolus vulgaris, L.). Engenharia na Agricultura, v.9, n.2, p.102-111, 2001.

CULBREATH, A.K.; BRENNEMAN, T.B.; CHANDLER, L.D.; et al. Chemigation and ground-spray applications of cyproconazole for control of late leaf spot of peanut. Plant Disease, v.77, n.5, p.505-507, 1993.

DOURADO NETO, D.; FANCELLI, A.L. Quimigação na cultura do feijão. In: FOLEGATTI, M.V. (Ed.). Fertirrigação. Guaíba: Agropecuária, 1999, p.393-432.

DOURADO NETO, D; FANCELli, A.L. Produção de Feijão. Guaíba: Agropecuária, 2000. 385 p.

DOWLER, C.C. Present herbicide application technology with sprinkler irrigation. Proceedings of Soil Crop Science Society of Florida, v.43, p.6-9, 1984.

DOWLER, C.C. Advantages of herbigation. International Water \& Irrigation Review, v 15, n.3, p.26-28, 1995.

DOWLER, C.C.; ROHDE, W.A.; FETZER, L.E.; et al. The effect of sprinkler irrigation on herbicides efficacy, distribution, and penetration in some Coastal Plain soils. Georgia: University of Georgia, College of Agriculture, 1982. 27p. (Research Bulletin, 281).

FANCELli, A.L.; DOURADO NETO, D. Produção de milho.Guaíba: Agropecuária, 2000. p.283-297.: Quimigação

FISCHBACH, P.E. Applying chemical through irrigation systems, safety and environmental considerations. In: NATIONAL SYMPOSIUM ON CHEMIGATION, 2., Tifton/GA, 1982. Proceedings, Tifton/GA: University of Georgia, 1982. p. 80-87.

FRANC, G.D.; NNODU, E.C.; HARRISON, M.D.; et al. Evaluation of sprinkler application of fungicides for controle of potato early blight in Colorado. American Potato Journal, v.60, p.631-643, 1983. 
GROSELLE, D.E.; STANSELL, J.R.; YOUNG, J.R. Effects of injection parameters on the droplet size of oil formulated insecticides during chemigation. Transaction of the ASAE, v.29, n.4, p. 1065-1069, 1986.

GUY, C.B.; TALBERT, R.E.; FERGUSON, J.A.: The performance of selective post emergence grass herbicides applied with different sprinkler irrigation water volumes. In: NATIONAL SYMPOSIUM ON CHEMIGATION, 3., Tifton/GA, 1985. Proceedings, Tifton/GA: University of Georgia, 1985. p.68-73.

HILLS, D.J.; WALLER, P.M. Lateral move chemigation of Lorsban- 4E on field corn. Applied Engineering in Agriculture, v.5, n.4, p.534-538, 1989.

HINZE, J.O. Fundamentals of hydrodinamic mechanism of splitting in dispersion processes. AIChE Journal, v.1, n.3, p.289-295, 1955.

IRRIGATION ASSOCIATION. Chemigation. S.n.t., 1997, 212 p.

JOHNSON, A.W. Application of nematicides through an overhead sprinkler irrigation system for control of nematodes on crops In: NATIONAL SYMPOSIUM ON CHEMIGATION, 1., Tifton/GA, 1981. Proceedings, Tifton/GA: University of Georgia, 1981. p.89-95.

JOHNSON, A.W. Nematicides and irrigation technology -past present, and future In: NATIONAL SYMPOSIUM ON CHEMIGATION, 3., Tifton/GA, 1981. Proceedings, Tifton/GA: University of Georgia, 1985. p.153-157.

JOHNSON, A.W.; YOUNG, J.R.; THREADGILL, E.D.; DOWLER, C.C.; SUMNER, D.R. Chemigation for crop production management. Plant Disease, v.70, n.11, p.998-1004, 1986.

JUNQUEIRA NETO, A. Aplicação de herbicida, inseticida e fungicida via pivô central na cultura do feijão. Informe Agropecuário, v.17, n.178, p.35-38, 1994.

KOHL, R.A.; DEBOER, D.W. Drop Size Distributions for a low pressure spray type agricultural sprinkler. Transaction of the ASAE, v.27, n.6, p. 1836-1840, 1984.

KOHL, R.A.; KOHL, K.D. ; DEBOER, D.W. Chemigation drift and volatilization potential. Applied Engineering in Agriculture, v 27, n.6, p.174-177, 1987.

KOO, Y.M. Development of a wide flow range nozzle for agricultural chemical application. Kansas, 1990.173p. Thesis. (Ph.D.) - Kansas State University. 
KOO, Y.M.; SUMNER, H.R.; CHANDLER, L.D. Formation of immiscible oil droplets during chemigation I. In line dispersion. Transaction of the ASAE, v.35, n.4, p.1121-1125, 1992a.

KOO, Y.M.; SUMNER, H.R.; CHANDLER, L.D. Formation of immiscible oil droplets during chemigation II. Nozzle dispersion and emulsification. Transaction of the ASAE, v.35, n.4, p.1127-1133, 1992 b.

KOO, Y.M.; SUMNER, H.R.; CHANDLER, L.D. Insecticide-oil droplet size effect on fall armyworm larvae control via chemigation. Transaction of the ASAE, v.36, n.4, p.1033-1038, 1993.

McMASTER, G.M.; DOUGLAS, D.R. Fungicide application through sprinkler irrigation systems. Transaction of the ASAE,v.19, p.1041-1044, 1976.

MAROUELLI, W.A. Improving chemigation efficacy by controlling droplet size distribution of oil-based pesticides. Tucson, 1996. 245p.Thesis (Ph.D.). University of Arizona.

MAROUELLI, W.A.; WALLER, P.M. New chemigation droplet generator for foliar pesticide application. St Joseph: ASAE, 1997a, 17p. (ASAE Paper, 97-2103)

MAROUELLI, W.A.; WALLER, P.M. Field evaluation of new foliar chemigation system. St Joseph: ASAE, 1997b, 16p. (ASAE Paper, 97-2104).

MAROUELLI, W.A.; WALLER, P.M. Oil drop generator for foliar chemigation: theory and laboratory evaluation. Transaction of the ASAE, v.42, n.5, p.12891301, 1999a.

MAROUELLI, W.A.; WALLER, P.M. Oil drop generator for foliar chemigation: field evaluation. Transaction of the ASAE, v.42, n.6, p.1599-1607, 1999 b.

MAYO, Z.B. Influences of rainfall and sprinkler irrigation on the residual activity of insecticides applied to corn to control of adult western corn rootworm (Coleoptera: Chrysomelidae). Journal of Economic Entomology, v.77, n.1, p.190-193, 1984.

MIRANDA, E.E.(Coord.) Coleção Brasil visto do espaço. - Paraná.(Compact Disc) Brasília/DF: EMBRAPA Monitoramento por Satélite, 2001. 
NAZARENO, N.R.X.; BRISOLLA, A.D.; ZANDONA, J.C. Uso de agroquímicos na cultura da batata em Curitiba e Guarapuava. Informe da Pesquisa, IAPAR,, v.18, n. 114, p.56, jun 1995.

OGG JUNIOR., A.G.; DOWLER, C.C.; MARTIN, A.R.; LANGE, A.H.; HEIKES, P.E. Application of herbicides through irrigation systems. S.1.: USDA, 1983, 8p (USDA, Item AD -FO2280).

PEREIRA, A.S. Desenvolvimento de um protótipo aplicador de produtos químicos para um sistema de irrigação pivô central. Piracicaba, 2001.64p. Tese(Doutorado) Escola Superior de Agricultura “Luiz de Queiroz”, Universidade de São Paulo.

PETERS, L.L.; LOWRY, S.R. Western corn rootworm (Cóleoptera: Chrysomelidae) larval control with chlorpyrifos applied at planting time versus a post-planting chemigation application to corn grown under two different tillage systems. Journal of the Kansas Entomological Society. v.64, n.4, p.451-454, 1991.

PINTO, N.F.J.A. Fungigação e nematigação. In: COSTA, E.F.; VIEIRA, R.F.; VIANA, P.A.(Ed.). Quimigação - aplicação de produtos químicos e biológicos via irrigação. Brasília: EMBRAPA, SPI, 1994, cap.9, p.229-248.

RAUN, E.S. Five years of insectigation on the Great Plains. In: NATIONAL SYMPOSIUM ON CHEMIGATION, 1., Tifton/GA, 1981. Proceedings, Tifton/GA: University of Georgia, 1981. p.52-55.

RAUN, E.S. Insectigation through grower's variable equipment In: NATIONAL ENTOMOLOGICAL SOCIETY MEETING, San Antonio, TX, 1984. Proceedings, Texas. s.ed., 1984. p.30-32.

REESE, L.E. Chemigation transport - A computer model for transport of a non-soluble particle or droplet within a discharging agricultural irrigation pipeline. East Lansing, MI, 1986. 178p. Thesis (Ph.D.) - Michigan State University.

REESE, L.E.; LOUDON, T.L. Modeling the transport of a non-soluble pesticide in a center pivot. St Joseph: ASAE, 1986. 27p. (ASAE Paper, 86-2586).

SANTO, G.S. Nemagation on irish potatoes and grapes In: NATIONAL SYMPOSIUM ON CHEMIGATION, 2., Tifton/GA, 1982. Proceedings, Tifton/GA: University of Georgia, 1982. p.64-68. 
SANTO, G.S.; QUALLS, M. Control of Meloidogyne spp. On Russet Burbank potato by applying metham sodium through center pivot irrigation systems. Journal of Nematology, v.16, n.2, p.159-161, 1984.

SCHMIDT, W. Ensaio de dose-resposta de clorpirifós no controle de larva alfinete (Diabrotica speciosa) em milho aplicado por insetigação. In: CONGRESSO NACIONAL DE IRRIGAÇÃO E DRENAGEM, 11., Campinas/SP, 1996. Anais, Campinas: ABID, 1996. p.504-514.

SCHMIDT, W. Quimigação: características, vantagens e desvantagens. In: SEMINÁRIO DE QUIMIGAÇÃO, Barreiras/BA, Jun 1997. Anais, Barreiras: Dow Elanco, 1997. p. 46-54.

SCHMIDT, W. Herbigação. In: CONGRESSO BRASILEIRO DA CIÊNCIA DA PLANTAS DANINHAS, 22., Foz do Iguaçu/PR, 2000. Palestras, Londrina: SBCPD, 2000. p.117-136.

SCHMIDT, W.; CARNEIRO, E.L.A. Avaliação do uso da insetigação no controle de larva alfinete Diabrotica speciosa (Cóleoptera: Chrysomelidae) em milho comparado a outros métodos de aplicação. In: CONGRESSO BRASILEIRO DE ENTOMOLOGIA, 16., Salvador, 1997. Anais. Salvador: Sociedade Entomológica do Brasil/ EMBRAPA-CNPMF, /Resumo/ p.156.

SCHMIDT, W.; DOURADO NETO, D. Tecnologia de aplicação de defensivos e fertilizantes via irrigação. In: FANCELLI, A.L.;DOURADO NETO, D.(Ed.).Feijão irrigado - tecnologia e produtividade. Piracicaba: ESALQ, Departamento de Produção vegetal, 2003 cap. 4, p.49-62.

SILVA, C.L.; RAMOS, M.M.; FERREIRA, P.A.; et al. Medição e simulação da interceptação foliar de água na cultura do milho. Pesquisa Agropecuária Brasileira, v.29, n.11, p.1735-1741, 1994.

SILVEIRA, R.C.M.; HILLS, D.J.; YATES, W.E. Insecticide oil distribution patterns from a pesticide application. Transaction of the ASAE, v.30, n.2, p.438-441, 1987.

SLEICHER, C.A. Maximum stable drop diameter in turbulent flow. AICHE Journal, v.8, n.4, p.471-477, 1962. 
SPRAY DRIFT TASK FORCE A summary of chemigation application studies// Missouri: Agricultural Research Services, 1997.1v.

STONE, K.C.; STANSELL, J.R.; YOUNG, J.R. Insecticide distribution through an irrigated corn canopy. Transaction of the ASAE, v.37, n.1, p.135-138, 1994.

SUMNER, H.R.; COCHRAN, D.L. Collecting oil-formulated pesticide droplets from chemigation sprinklers. St Joseph: ASAE, 1988. 13p. (ASAE Paper, 882622).

SUMNER, H.R.; BOUSE, L.F.; YOUNG, J.R. Oil-formulated pesticide droplet size distribution in chemigation. St Joseph: ASAE, 1991a, 12p. (ASAE Paper, 911056).

SUMNER, H.R.; CHALFANT, R.B.; COCHRAN, D. Influence of chemigation parameters on fall armyworm control in field corn. Florida Entomologist, v.74, n.2, p.280-287, 1991 b.

SUMNER, H.R., BOUSE, L.F.; YOUNG, J.R. Size distribution of oil-formulated pesticide droplets in chemigation. Transaction of the ASAE, v.35, n.5, p.1527$1530,1992$.

SUMNER, H.R.; CHANDLER, L.D.; HERZOG, G.A.; DOWLER, C.C. Defoliation of cotton leaves by chemigation methods. In: BELTWIDE COTTON CONFERENCE, s.1., 1993. Proceedings, Beltwide: s.ed., 1993.v.3, p.1610-1613.

THREADGIL, E.D. Chemigation via sprinkler irrigation: Current status and Future Development. Applied Engineering in Agriculture, v.1, n.1, p.16-23, 1985.

VIANA, P.A Insetigação. In: COSTA, E.F.; VIEIRA, R.F.; VIANA, P.A. (Ed.) Quimigação - aplicação de produtos químicos e biológicos via irrigação. Brasília: EMBRAPA, SPI, 1994, cap.10, p.249-268.

VIANA, P.A.; COSTA, E.F. Controle da lagarta elasmo, Elasmopalpus lignosellus, com inseticidas químicos via irrigação por aspersão, na cultura do milho. Relatório Técnico Anual EMBRAPA/CNPMS, 1988-1991, 1992a, /resumo/ p.45. 
VIANA, P.A.; COSTA, E.F. Eficiência de inseticidas misturados em óleo vegetal aplicados via irrigação por aspersão para o controle da lagarta do cartucho, Spodoptera frugiperda, em milho. Relatório Técnico Anual EMBRAPA/CNPMS, 1992-1993, 1994, p.139. /resumo/

VIEIRA, R.F. Introdução a quimigação In: COSTA, E.F.; VIEIRA, R.F.; VIANA, P.A.(Ed.). Quimigação - aplicação de produtos químicos e biológicos via irrigação. Brasília: EMBRAPA, SPI, 1994, cap.1, p.13-40.

VIEIRA, R.F.; SUMNER, D.R. Application of fungicides to foliage through overhead sprinkler irrigation - A review. Pesticide Science, v.55, n.4, p.412-422, 1999.

VILELA, L.A.A. Metodologia para dimensionamento de um sistema de pulverização acoplável a pivô central. Piracicaba, 2002.127p. Tese(Doutorado) - Escola Superior de Agricultura "Luiz de Queiroz", Universidade de São Paulo.

VILLA NOVA, N.A.; DOURADO NETO, D.; TOMAZELA, C.; FANCELLI, A.L. Estimativa de perda por deriva em pivô central. In: FANCELLI, A.L.; DOURADO NETO, D. Tecnologia da produção do feijão irrigado. 2 ed., Piracicaba: Publique, 1997. 182p.

WALLER, P.M. Reducing off-target Contamination by improving chemigation uniformity. Davis, CA, 1992. 190p. Thesis (Ph.D.) University of California.

WALLER, P.M.; HILLS, D.J. Chemigation pipeline transport model for nonsoluble pesticide - I Theory. Transaction of the ASAE, v.38, n.6, p.1699-1709, 1995.

WALLER, P.M.; HILLS, D.J.; GILES, D.K. Chemigation pipeline transport model for nonsoluble pesticide - II. Numerical and field validation. Transaction of the ASAE, v.38, n.6, p.1711-1718, 1995a.

WALLER, P.M.; HILLS, D.J.; STEINKE, W.E. Chemigation application efficiency of oil-based pesticide. Transaction of the ASAE, v.38, n.2, p.531-538, 1995 b.

WALSTRA, P. Formation of emulsions. In: BECHER, P. (Ed.). Encyclopedia of emulsion technology. Basic Theory, New York: Marcel Dekker, 1983. cap.2. p. 58125.

WARE, G.W. (Ed.) Reviews of environmental contamination and toxicology. Tucson, AZ: Springer-Verlag, New York, 1993. 154p. 
WAUCHOPE, R.D.; YOUNG, J.R.; CHALFANT, R.B.; et al. Deposition, mobility and persistence of sprinkler irrigation applied chlorpyrifos on corn foliage and in soil. Pesticide Science, v.32, p.235-243, 1991.

YATES, W.E. Spray pattern analysis and evaluation of deposits from agricultural aircraft. Transaction of the ASAE, v.5, n.1, p.49-53. 1962.

YOUNG, J.R. Suppression of fall armyworm population by incorporation of insecticides into irrigation water. Florida entomologist, v.63, n.4, p. 447-450, 1980.

YOUNG, J.R. Chemigation: insecticides applied in irrigation water for control of the corn earworm and fall armyworm in sweet and field corn. In: NATIONAL SYMPOSIUM ON CHEMIGATION, 1., Tifton/GA, 1981. Proceedings, Tifton/GA: University of Georgia, 1981. p.56-64.

YOUNG, J.R. Chemigation: application of insecticides in vegetable oils for control of foliar insects in corn. In: AGCHEM USES OF SOYBEAN OIL WORKSHOP, 1984. Tifton/GA, 1984. Proceedings, Tifton/GA: University of Georgia, 1984. p.590-612.

YOUNG, J.R. Fall Armyworm (Lepidoptera: Noctuidae) control through chemigation; an update. Florida Entomologist, v.69, p.593-598, 1986.

YOUNG, J.R.; CHALFANT, R.B. Insectigation: the application od inseticides in irrigation water. In: NATIONAL SYMPOSIUM ON CHEMIGATION, 3., Tifton/GA, 1985. Proceedings, Tifton/GA: University of Georgia, 1985. p.99-108.

YOUNG, J.R.; CHALFANT, R.B.; HERZOG, G.A. Role of formulations in the application of insecticides through irrigation systems. In: NATIONAL ENTOMOLOGICAL SOCIETY MEETING, San Antonio, TX, 1984. Proceedings, Texas. s.ed., 1984, p.2-12.

YOUNG, J.R.; DOWLER, C.C.; CHANDLER, L.D. et al: A review of pesticide formulations for chemigation. In: HALL, F.R.; BERGER, P.D.; COLLINS, H.M.(Ed.).1' Pesticide formulations an Application systems Philadelphia: American Society testing materials (ASTM), 1995, v.14, p.71-82. (ASTM, STP 1234). 


\section{BIBLIOGRAFIA RECOMENDADA}

ALVES, S.B.; ZUCCHI, R.A.; VENDRAMIM, J.D. Pragas do milho, arroz, trigo e sorgo. Curso de entomologia aplicada à agricultura. Piracicaba: FEALQ, 1992. p.273-310.

BECHER, P. Effect of preparation parameters on the initial size distribution function in oil-water emulsions. Journal of Colloid and Interface Science, v.24, p.91-96, 1967.

BRADY, U.E.; TIPPINS, R.; PERRY, J. et al. Chlorpyrifos exposure of workers entering sweet corn after chemigation. Bulletin of Enviromental Contamination Toxicology, v.46, p.343-350, 1991.

BRENNEMAN, T.B.; SUMNER, D.R. Effects of chemigated and conventionally sprayed tebuconazole and tractor traffic on peanut. Plant Disease, v.73, n.10, p.843846, 1989.

CHRISTOFIDIS, D. Os recursos hídricos e a prática de quimigação no Brasil e no mundo. Irrigação e Tecnologia Moderna - ITEM, n. 49, p.8-13, 2001.

COUNCIL FOR AGRICULTURAL SCIENCE AND TECHNOLOGY. Effective use of water in irrigated agriculture. Ames, IO: Council For Agricultural Science And Technology, 1988, 64p. (Task Force Report, 113)

DOWELANCO Lorsban* 4E Insecticide. Specimen label. Indianápolis.IN, 1992.14p. (Label, 11258-004).

EASTON, G.D.; NAGLE, M.E. Lack of economic benefits by fungicides applied through center pivot irrigation systems for control of Alternaria solani in potato. Plant disease, v.69, n.2, p.152-153, Feb1985. 
HAMM, P.B.; CLOUGH, G.H. Comparison of application methods on deposition and redistribution of chlorothalonil in a potato canopy and potential for control of late blight. Plant Disease, v.83, n.5, p.441-444, 1999.

HAY, D.R.; EISENHOUER, D.E. Anti-pollution equipment for chemigation. St Joseph: ASAE., 1986.14p (ASAE paper, 86-2589).

OLITTA, A.F.L. Os métodos de irrigação. São Paulo/SP: Livraria Nobel, 1983. 267 p.

PAL, R. Pipeline flow of unstable and surfactant-stabilized emulsions. AIChE Journal, v,39, n.11, p.1754-1764, 1993.

PILCHER, S.; PEAIRS, F. Extension's experience with insectigation in Colorado, Equipment, oil additive, and control of European corn borer an wessern bean cutworm in field corn. In: NATIONAL ENTOMOLOGICAL SOCIETY MEETING, San Antonio, TX, 1984. Proceedings, Texas, s.ed., 1984. p.24-29.

SCHMIDT, W. Impacto ambiental da quimigação. In: SEMINÁRIO DE QUIMIGAÇÃO, Barreiras/BA, Jun 1997. Anais, Barreiras: Dow Elanco, 1997. p.55-67.

VIANA, P.A.; COSTA, E.F. Controle da lagarta do cartucho, Spodoptera frugiperda, com inseticidas via irrigação por aspersão, na cultura do milho. Relatório Técnico Anual EMBRAPA/CNPMS, 1988-1991, 1992b. p.45. /resumo/

VIEIRA, R.F.; PAULA JÚNIOR, T.J.; PERES, A.P.; MACHADO, J.C. Fungicidas aplicados via água de irrigação no controle do mofo branco no feijoeiro e incidência do patógeno na semente. Fitopatologia Brasileira, v.26, n.4, p.770-773, 2001.

WARNER, J.W.; NIELSON, K.; REGAN, J.B. Potential groundwater impacts from chemigation. Down to earth, v.45, n.3, p.5-8, 1989.

WEISSLING, T.J.; PEAIRS, F.B.; COLLINS, F. Comparison of chemigated and aerially applied chlorpyrifos and fenvalerate for control of European corn borer (Lepidoptera: Pyralidae) larvae. Journal of Economic Entomology v.85, n.2, p.539-543, Apr.1992. 